\title{
Silvana Tognini
}

\section{Tendência da mortalidade materna na região do Grande ABC Paulista de 1997 a 2011}

Tese apresentada à Faculdade de Medicina da Universidade de São Paulo para a obtenção do título de Doutor em Ciências

Programa de Pós-Graduação em Ciências Médicas

Área de concentração: Processos Inflamatórios e Alérgicos

Orientadora: Profa. Dra. Maria Lúcia Bueno Garcia

São Paulo 


\section{Dados Internacionais de Catalogação na Publicação (CIP)}

Preparada pela Biblioteca da

Faculdade de Medicina da Universidade de São Paulo

Creprodução autorizada pelo autor

Tognini, Silvana

Tendência da mortalidade materna na região do grande $\mathrm{ABC}$ paulista de 1997 a 2011 / Silvana Tognini. -- São Paulo, 2014.

Tese(doutorado)--Faculdade de Medicina da Universidade de São Paulo. Programa de Ciências Médicas. Área de concentração: Processos Inflamatórios e Alérgicos.

Orientadora: Maria Lúcia Bueno Garcia.

Descritores: 1.Mortalidade materna 2.Políticas públicas 3.Mulheres 4.Saúde da mulher/estatística \& dados numéricos 5 .Complicações na gravidez/mortalidade 6.Mortalidade 7.Sistema único de saúde 8.Estudos epidemiológicos 9.Período pós-parto 10.Objetivos de desenvolvimento do milênio 11.Brasil/epidemiologia 


\section{Silvana Tognini}

Tese elaborada no Departamento de Clínica Médica da Faculdade de Medicina da Universidade de São Paulo, junto ao Programa de Pós-Graduação em Ciências Médicas da Faculdade de Medicina da USP (recomendado pelo Conselho Técnico Científico CAPES- Protocolo de Pesquisa nº 289/11.

Área de Concentração: Processos Inflamatórios e Alérgicos Orientadora: Profa. Dra. Maria Lúcia Bueno Garcia

\section{São Paulo}


“Comece fazendo o que é necessário, depois o que é possível, e de repente voce estará fazendo o impossível."

São Francisco de Assis

"Feliz daquele que transfere o que sabe $e$ aprende o que ensina"

Cora Coralina 


\section{DEDICATÓRIA}

Aos meus filhos Leonardo e Vítor, por compreenderem o processo de construção de mais uma etapa da minha vida.

Aos meus pais Helena e Paulo (In Memoriam), por não medirem esforços ao me instruírem ao longo de toda a minha formação e existência.

À Professora e amiga Simone B. Groppo, pela dedicação e competência nos ensinamentos.

Aos meus amigos, em especial Maria Aparecida e Sônia, por me apoiarem e compreenderem a minha ausência nos muitos momentos de estudo.

Ao Doutor Edson S. Freitas, pelo incentivo e colaboração para o enriquecimento do estudo. 


\section{AGRADECIMENTOS ESPECIAIS}

À Deus, com a sua presença infinita, que me amparou e me iluminou em mais uma etapa da minha vida.

À Professora Doutora Maria Lúcia Bueno Garcia, por me acolher com o seu profissionalismo exemplar para a construção do estudo, pelo apoio, dedicação, competência, ética, amizade, brilhantismo, estímulo e mais do que isso, entusiasmo contagiante, sem medir esforços ao longo do processo ensino-aprendizagem.

À Professora Doutora Lourdes Conceição Martins, pela presença competente, afetuosa e amiga de grande valor. Pelo incentivo, pela alegria de cada etapa concluída. Pela presença de luz e sabedoria nas suas orientações e nas diversas fases deste estudo.

Aos Mestres da Banca Examinadora de Exame de Qualificação de Doutorado: Dr. Alfésio Luis Ferreira Braga, Dra. Dirce Maria Trevisan Zanetta, Dra. Isabela Judith Martins Benseñor, pelos valorosos ensinamentos e contribuições para o estudo. 


\section{AGRADECIMENTOS}

Esse estudo é o resultado de uma longa jornada e trajetória de trabalho e expresso aqui o meu reconhecimento e a minha sincera e eterna gratidão aos envolvidos.

Aos professores do curso de Pós-Graduação da Faculdade de Medicina da Universidade de São Paulo, pelos ensinamentos.

Às Funcionárias Angélica, Rose, Silvana, Kátia da Secretaria da Pós-Graduação em Ciências Médicas da Faculdade de Medicina da Universidade de São Paulo, por proporcionar total atenção nos processos requeridos, além da excelente competência e acolhimento.

Aos funcionários da Faculdade de Medicina da Universidade de São Paulo.

Ao Ministério da Educação e Cultura - Fundação Coordenação Aperfeiçoamento de Pessoal de Nível Superior (CAPES), por proporcionar subsidio para a elaboração do estudo e conclusão deste trabalho.

Às mulheres que compuseram o estudo e que por motivos relacionados ao ciclo gravídico puerperal, perderam suas vidas. (In Memoriam). 
Esta tese está de acordo com as seguintes normas, em vigor no momento desta publicação:

Referências: adaptado de International Committee of Medical Journals Editors (Vancouver).

Universidade de São Paulo. Faculdade de Medicina. Divisão de Biblioteca e Documentação. Guia de apresentação de dissertações, teses e monografias. Elaborado por Anneliese Carneiro da Cunha, Maria Julia de A. L. Freddi, Maria F. Crestana, Marinalva de Souza Aragão, Suely Campos Cardoso, Valéria Vilhena. 3a ed. São Paulo: Divisão de Biblioteca e Documentação; 2011.

Abreviaturas dos títulos dos periódicos de acordo com List of Journals Indexed in Index Medicus 


\section{SUMÁRIO}

LISTA DE ABREVIATURAS E SIGLAS

LISTA DE TABELAS

LISTA DE FIGURAS

RESUMO

\section{ABSTRACT}

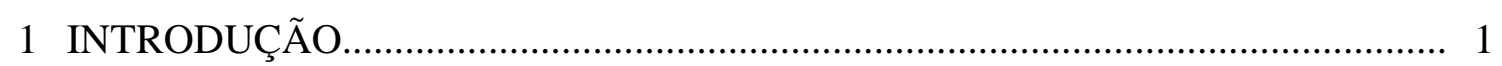

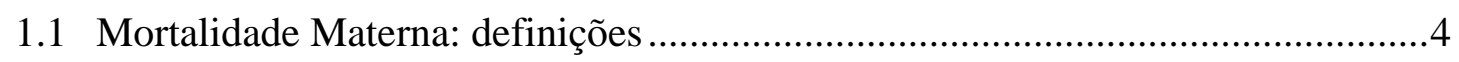

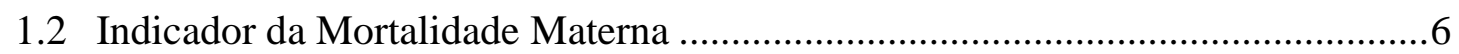

1.3 Medidas internacionais e nacionais para redução da Mortalidade Materna ...........8

1.4 Sistemas de informações da Mortalidade Materna .................................................

1.5 Vigilância da Mortalidade Materna no Brasil....................................................11

1.6 Medidas públicas para a redução da Mortalidade Materna no Estado de São Paulo ..12

1.7 Mortalidade Materna na região do Grande ABC Paulista ....................................12

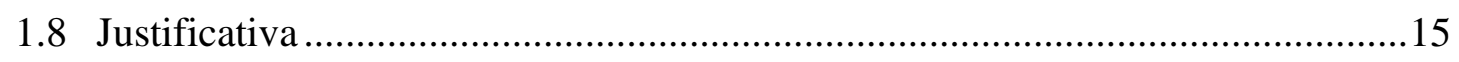

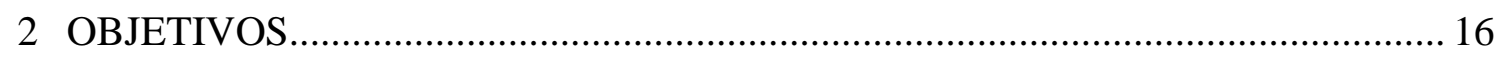

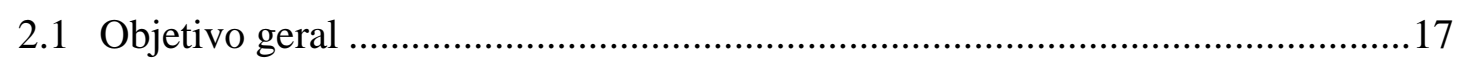

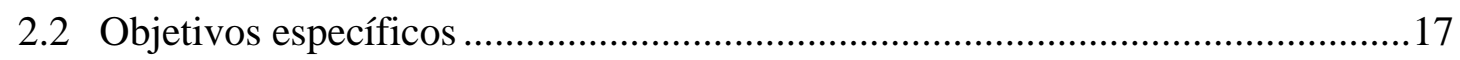

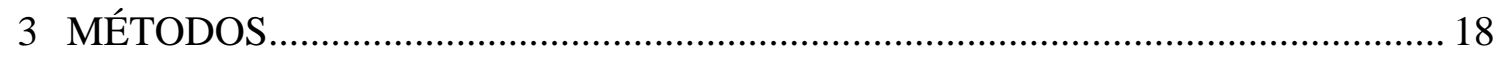

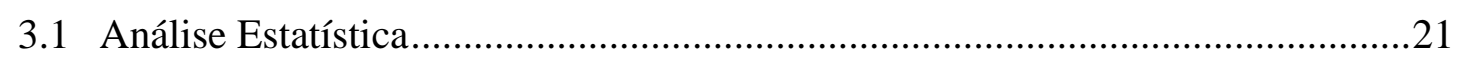

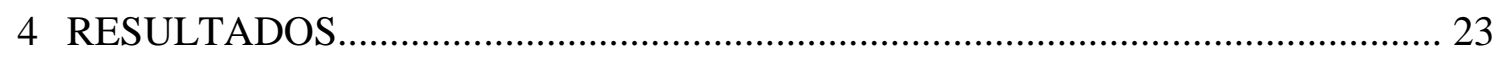

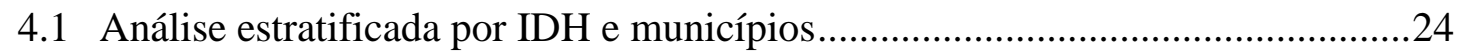

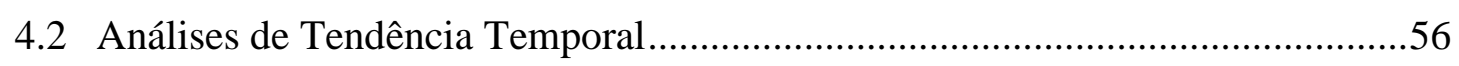

4.3 Análise de Tendência Temporal Pela Regressão Linear ....................................69

5 DISCUSSÃO

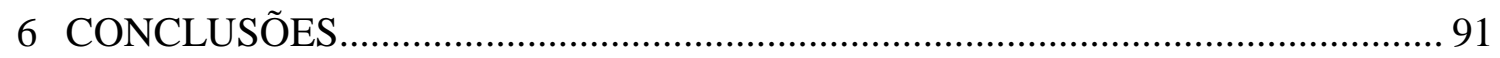

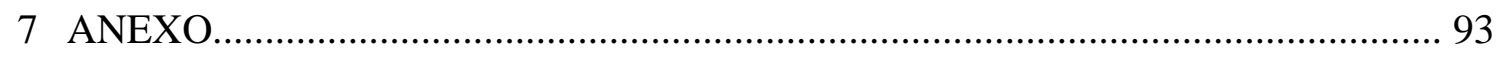

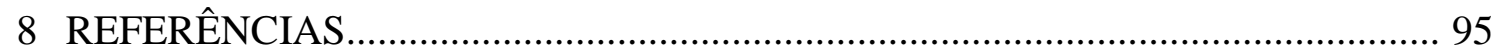

APÊNDICES 


\section{LISTA DE ABREVIATURAS E SIGLAS}

CEMM Comitê de Estudos da Mortalidade materna

CID-10 Classificação Estatística Internacional de Doenças e Problemas Relacionados à Saúde - Décima Revisão OMS/OPAS

DATASUS Departamento de Informática do Sistema Único de Saúde

DIR II Direção Regional de Saúde II

DO Declaração de Óbito

FEBRASGO Federação Brasileira de Ginecologia e Obstetrícia

IBGE Instituto Brasileiro de Geografia e Estatística

IMM Índice da Mortalidade materna

IMMD Índice da Mortalidade Materna Direta

IMMI Índice da Mortalidade Materna DiretaIndireta

IPRS Índice Paulista de Responsabilidade Social

MM Mortalidade materna

MMD Mortalidade Materna Direta

MMI Mortalidade maternaIndireta

MS Ministério da Saúde do Brasil

NV Nascido vivos

ODM Objetivo do desenvolvimento do milênio

OMS Organização Mundial da Saúde

ONU Organização das Nações Unidas

OPAS Organização Pan-Americana da Saúde

PHPN Programa de Humanização no Pré-Natal e Nascimento

PNUD Programa das Nações Unidas para o Desenvolvimento 
RMM Razão da Mortalidade materna

SEADE Sistema Estadual de Análise de Dados

SES SP Secretaria de Estado da Saúde de São Paulo

SIM Sistema de Informação em Mortalidade

SINASC Sistema de Informação em Nascidos Vivos

SUS Sistema Único de Saúde

VE Vigilância Epidemiológica 


\section{LISTA DE TABELAS}

Tabela 1. População feminina e nascidos vivos na região do Grande $A B C$

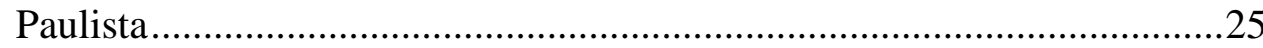

Tabela 2. IMMD e número absoluto por população, municípios e período de 1997 a

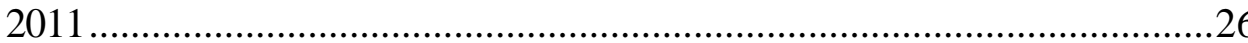

Tabela 3. Índice da Mortalidade Materna Direta e Indireta estratificado por IDH ...27

Tabela 4. Mortalidade Materna Direta (MMD) e Mortalidade Materna Indireta (MMI) por municípios: números absolutos e índices da mortalidade

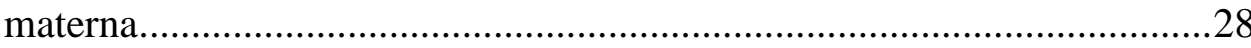

Tabela 5. Índices da Mortalidade Materna Direta e Indireta, por municípios ...........30

Tabela 6. Índice Mortalidade Materna Direta por etnia e grupo de estudo ................31

Tabela 7. Índice da Mortalidade Materna por município e etnia...............................33

Tabela 8. Índice Mortalidade Materna Direta por faixa etária e grupo de estudo .....34

Tabela 9. Índice da Mortalidade Materna por faixa etária e municípios ....................36

Tabela 10. Índice Mortalidade Materna Direta por estado civil e IDH ......................37

Tabela 11. Índice da Mortalidade Materna Direta por municípios e estado civil........39

Tabela 12. Índice Mortalidade Materna Direta por escolaridade (anos de estudo)

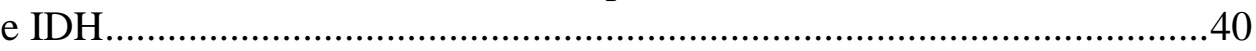

Tabela 13. Índice da Mortalidade Materna por municípios e escolaridade (anos

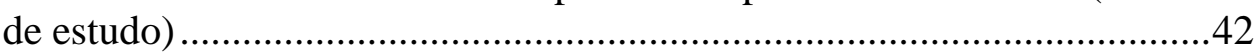

Tabela 14A. Índice Mortalidade Materna Direta por causas (CID 10) e grupo de estudo

Tabela 14B. Índice Mortalidade Materna Direta por causas (CID 10) e grupo de estudo (continuação)

Tabela 15A. Índice da Mortalidade Materna Direta por causas (CID 10) e municípios

Tabela 15B Índice da Mortalidade Materna por causas (CID 10) e municípios ...........46

Tabela 16. Índice da Mortalidade Materna Direta (IMMD) total e por IDH estratificados por período de ocorrência do óbito.........................................47

Tabela 17. IMMD por municípios e período da gravidez ou puerpério ......................49

Tabela 18. IMMD por local de ocorrência do óbito ...............................................50

Tabela 19. Índice da Mortalidade Materna Direta (IMMD) por municípios estratificada por local de ocorrência do óbito ........................................52

Tabela 20. Índice Mortalidade Materna Direta por investigação e grupo de estudo ...53

Tabela 21. Índice da Mortalidade Materna por investigação e municípios 55 


\section{LISTA DE FIGURAS}

Figura 1. Índice da Mortalidade Materna Direta, Indireta total e Grupos de IDH..............27

Figura 2. Índice da Mortalidade Materna Direta por IDH e municípios.

Figura 3. Índices da Mortalidade Materna Direta por IDH (2A) e por municípios (2B) estratificados por etnia.

Figura 4. Índice da Mortalidade Materna Direta por IDH (A) e municípios (B) em relação a Faixa Etária.

Figura 5. Índices da Mortalidade Materna Direta (IMMD) por IDH e municípios estratificados em relação ao estado civil

Figura 6. Índice da Mortalidade Materna Direta (IMMD) por IDH (A) e município (B) estratificados por escolaridade

Figura 7. IMMD causas (CID 10), por grupo IDH (A), por municípios (B) e pelas causas principais por municípios $(\mathrm{C})$

Figura 8. Índices da Mortalidade Materna Direta (IMMD) por grupo IDH (A) e municípios (B) estratificados por período de ocorrência do óbito.

Figura 9. Índice da Mortalidade Materna Direta (IMMD) por IDH (A) e por municípios (B) estratificados por local de ocorrência do óbito.....

Figura 10. Índice da Mortalidade Materna Direta por grupo IDH (A), municípios (B), estratificados por investigação de fichas de notificação do óbito materno

Figura 11. Índices da Mortalidade Materna Direta e Indireta por ano de estudo .................56

Figura 12. Série temporal e medidas públicas para controle da MM.

Figura 13. Série Temporal dos Índices da Mortalidade Materna Direta (IMMD) por municípios .

Figura 14. Série temporal por municípios do estudo

Figura 15. Série temporal dos Índices da Mortalidade Materna Direta (IMMD) por IDH: grupo 1 e 2

Figura 16. IMMD por etnia, série temporal 
Figura 17. Série temporal IMMD estratificado por estado civil .62

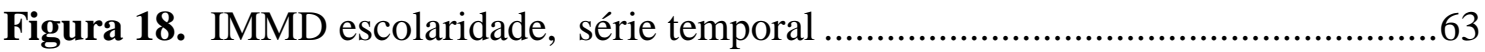

Figura 19. IMMD causas (CID 10), série temporal. .................................................64

Figura 20. Série Temporal causas principais dos óbitos por IDH...............................64

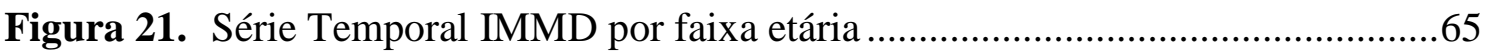

Figura 22. Série temporal IMMD por período de ocorrência do óbito ..........................66

Figura 23. Série temporal dos IMMD por local de ocorrência do óbito ......................67

Figura 24. Série temporal dos IMMD por ficha de investigação do óbito....................68

Figura 25. Tendência para a Mortalidade Materna Direta no tempo ...........................69

Figura 26. Regressão Linear dos IMMD por municípios pelo tempo...........................70

Figura 27. Regressão Linear IMMD São Caetano do Sul pelo tempo...........................71

Figura 28. Regressão Linear dos IMMD por IDH 1 (A) e 2 (B) e tempo de estudo ....72

Figura 29. Série Temporal Milênio municípios total e Grupos IDH ............................73

Figura 30. Série Temporal Milênio por município .....................................................74

Figura 31. Tendência Temporal do Índice da Mortalidade Materna Direta por municípios Totais e São Caetano do Sul Tempo Total (15 anos) e Pós ano 2000

Figura 32. Tendência Temporal dos IMMI pelo período do estudo .............................76

Figura 33. Tendência Temporal dos IMMI após o ano 2000 …....................................78 


\section{RESUMO}

Tognini S. Tendência da mortalidade materna na região do Grande ABC Paulista de 1997 a 2011 [tese]. São Paulo: Universidade de São Paulo, Faculdade de Medicina; 2014. 103p.

Introdução:A mortalidade materna é um dos melhores indicadores do desenvolvimento socioeconômico de um país. O Brasil implementou políticas públicas para redução da mortalidade materna até 2015. A região do Grande ABC Paulista no Brasil apresenta grande heterogeneidade socioeconômica entre seus municípios, podendo refletir a desigualdade social do país, porém apresentando dimensões que permitem maior controle de dados da mortalidade. Objetivo: Avaliar a tendência da mortalidade materna na região do Grande ABC Paulista no período de 1997 a 2011. Metodologia: Estudo ecológico de série temporal, cujos dados foram obtidas no banco de dados do Departamento de Informática do Sistema Único de Saúde do Brasil (DATASUS) do Ministério da Saúde do Brasil (MS). Os dados foram transformados em Índices da Mortalidade Materna Direta (IMMD), estratificados por municípios, índices de desenvolvimento humano (IDH), causas de óbito materno segundo Classificação internacional de doenças (CID-10), local e período de ocorrência do óbito, dados sóciodemográficos e submetidos a comparações (teste U de Mann-whitney, teste de Kruskal-Wallis e teste de Dunn) e associações pela regressão linear, com significância de 5\%. Resultados: Os IMMD predominaram em mulheres solteiras, entre 20-34 anos de idade, brancas, escolaridade entre 4-7 anos, intra-hospitalar, no puerpério imediato, por hemorragias/tromboses/embolias e eclâmpsias. Não houve diferença nos IMMD em relação ao grupo IDH. Rio Grande da Serra atingiu IMMD alto (OMS) na maioria das covariáveis analisadas. Apenas São Caetano do Sul apresentou IMMD baixo (OMS), alto IMMI (p=0,03), queda nos IMMD no período de 1997 a 2011 (beta= -0,67/ano, $\mathrm{p}=0,03$ ) e tendência neste milênio ( 2000 a 2011 , beta=-0,55/ano, $\mathrm{p}=0,07$ ) com estimativa de queda de $65,1 \%$ até 2015 . A soma dos óbitos não investigados, não se aplica e de fichas sem investigação para qualquer variável analisada ultrapassa $50 \%$. Conclusão: Os índices da Mortalidade Materna Direta na região do Grande ABC Paulista apresentaram níveis altos e queda discreta no tempo. Apenas o município de São Caetano do Sul apresentou queda expressiva de IMMD nos 15 anos de estudo e tendência a queda neste milênio com estimativa de atingir 65,1\% até 2015 .

Descritores: Mortalidade materna; Políticas públicas; Mulheres; Saúde da mulher/estatística \& dados numéricos; Complicações na gravidez/mortalidade; Mortalidade; Sistema Único de Saúde; Estudos epidemiológicos; Saúde da mulher/estatística \& dados numéricos; Período pós-parto; Objetivos de desenvolvimento do milênio; Brasil/epidemiologia. 


\begin{abstract}
Tognini S. Trends in maternal mortality in the Greater São Paulo ABC region 1997 to 2011 [thesis]. São Paulo: "Universidade de São Paulo, Faculdade de Medicina"; 2014. 103p.
\end{abstract}

Introduction: Maternal mortality is one of the best indicators of socioeconomic development of a country. Brazil has implemented public policies to reduce maternal mortality by 2015 . The Grande ABC Paulista region in Brazil shows great socioeconomic heterogeneity among its municipalities, which can reflect the country social inequality, however presenting dimensions that allow greater control of mortality data. Objective: To evaluate the trend of maternal mortality in the Grande ABC Paulista region in the period of 1997-2011. Methodology: Ecological time series, where data was obtained from the database of the Information Technology Department of the Public Health Care System (DATASUS) of the Health Ministry of Brazil (MS). The data was transformed into direct maternal mortality indices (DMMI), stratified by municipalities, Human Development Indices (HDI), causes of maternal death according to the International Classification of Diseases (ICD-10), period and local of maternal death, socio-demographic parameters. Data were submitted to comparison tests (Mann-Whitney U test, Kruskal-Wallis test, followed by Dunn's multiple comparisons test) and association tests (linear regression) when applied and a significance of 5\%. Results: The DMMI predominated in single women, aged 20-34 years old, white, 4 to 7 school age, in-hospital, postpartum, by bleeding / thrombosis / embolism and eclampsia. There was no difference in DMMI when comparing by HDI group. The Municipality of Rio Grande da Serra reached high DMMI values in the most of the analyzed covariates. São Caetano do Sul presented the lowest DMMI values and was the only municipality which presented decrement in the DMMI during the 15 years of the studied period (beta $=-0.67 /$ year, $\mathrm{p}=0.03$ ) and a trend in this millennium (2000-2011, beta- $0.55 /$ year, $\mathrm{p}=0.07$ ) with an estimated fall of $65.61 \%$ by 2015 . The sum of not investigated, not applied and files without investigation for any analyzed variable exceeded 50\%. Conclusion: The DMMI in the Grande ABC Paulista showed high levels and downward trend in time. São Caetano do Sul was the sole municipality where the DMMR dropped in 15 years of study and presented a tendency to decrease in this millennium with an estimated fall of $65.1 \%$ by 2015 .

Descriptors: Maternal mortality; Public policies; Women; Women's health/statistics \& numerical data; Pregnancy complications/mortality; Mortality; Unified Health System; Epidemiologic studies; Postpartum period; Millennium development goals; Brazil/epidemiology. 


\section{INTRODUÇÃO}


A mortalidade materna pode ser considerada uma violação de direitos humanos, onde os direitos à vida e à saúde de qualidade devem ser premissa singular à mulher ${ }^{1}$.

Mais de 350 mil mulheres morrem a cada ano nos países em desenvolvimento por complicações gravídicas sendo que a grande maioria destas mortes ocorrem na faixa etária da idade fértil da mulher ${ }^{2,3,4}$. No Brasil considera-se faixa etária da idade fértil da mulher de dez a quarenta e nove anos e em outros países de quinze a quarenta e nove anos de idade ${ }^{3}$.

Todos os anos no mundo, mais de um milhão de crianças ficam órfãs ${ }^{5}$. Estas crianças que perdem suas mães precocemente têm até 10 vezes mais chances de morrerem prematuramente ${ }^{5}$.

[...] o homem apresenta crenças e comportamentos aprendidos e assimilados ao longo de sua vida a partir de interações com os membros da família, em especial,com os pais. Oliveira ${ }^{6}$

A maternidade pode ser vista como uma construção social de aspectos históricos, de valores comunitários e culturais, onde o nascimento ocorre na plenitude da sociedade em que a mulher está inserida ${ }^{7}$, cuja responsabilidade é integral do Estado que deve garantir direitos, onde ações em saúde estão intimamente relacionadas à estes direitos e demandam responsabilidades governamentais ${ }^{1,8}$.

Os altos índices da mortalidade materna espelham precárias condições socioeconômicas das mulheres, que culminam com outros fatores, como dificuldade de acesso da população aos serviços de saúde ${ }^{2,9}$. 
Além da Mortalidade materna ser considerada como "um relevante indicador para a avaliação do desenvolvimento humano de uma população" ${ }^{\text {"10 }}$, reflete a má assistência e a insatisfatória operacionalização das políticas públicas voltadas à saúde da mulher ${ }^{11,12}$.

A construção de medidas públicas que promovam a prevenção e atenção integral aos direitos reprodutivos das mulheres, com perspectiva de ações para a melhoria da qualidade de vida e saúde, são relevantes para a redução da morbimortalidade materna ${ }^{1,2}$.

Após duas décadas de iniciativas mundiais para a redução da mortalidade materna ${ }^{13,14}$, de intervenções, além do acompanhamento de resultados das medidas públicas implantadas com objetivo de proporcionar melhoria da qualidade dos serviços de saúde como também, atingir metas para a redução da mortalidade materna evitável ${ }^{15}$, principalmente nos países em desenvolvimento como o Brasil, ainda nos deparamos com altos índices destas mortes, tornando as taxas da mortalidade materna inaceitavelmente elevadas ${ }^{16}$, aparentemente sem perspectivas para redução imediata.

No Brasil, a cada 100.000 crianças que nascem vivas, 69 mães ao ano perdem as suas vidas por motivos relacionados ao ciclo gravídico puerperal ${ }^{4,17}$.

Segundo o Ministério da Saúde do Brasil, 92\% dos casos da mortalidade materna são evitáveis ${ }^{16,18,19}$.

O Brasil, país de grande extensão tende a ser complexo e difícil de administrar. Com quase duzentos milhões de habitantes, há diferenças regionais marcantes. Regiões mais ricas, como o Sul e o Sudeste (onde a expectativa de vida é comparável àquela de países ricos), e regiões mais pobres, como o Norte, o Nordeste e a fronteira do CentroOeste (que se expandem com rapidez) e vem passando por diversas transformações econômicas, sociais e ambientais ${ }^{20}$. 
A partir da década de 30, o Brasil compôs um sistema nacional de políticas sociais, mas somente após 1934, o estado assumiu responsabilidades com a educação e a saúde apesar do alcance ainda ser limitado ${ }^{5,21}$.

Com a Constituição Federal de 1988, os brasileiros tem direito à atenção à saúde gratuita, prestada por um sistema nacional de saúde com características únicas na América Latina, financiado por impostos e contribuições sociais específicas ${ }^{22}$. Apresenta ainda, na sua administração, um sistema público de saúde complexo e descentralizado, no qual grande parte dos serviços prestados são em razão de contratos com instituições privadas, onde acarreta inevitavelmente conflitos e contradições ${ }^{21}$.

Portanto, a relação entre a mortalidade materna, medidas e políticas públicas e fatores socioeconômicos, como renda, produto interno bruto, educacão e cultura, demonstram constituir contexto denso ${ }^{22}$.Além disso, para Kwawukume ${ }^{23}$ os desafios para a redução da mortalidade materna são conhecidos e as estratégias para esta redução possuem inexpressividade econômica.

Intervenções apropriadas em cada região dependem da atenção dos gestores, dos profissionais de saúde, do conhecimento e sensibilização da sociedade e da aplicação de medidas públicas para a prevenção das mortes maternas, tendo em vista a vulnerabilidade pelas quais muitas mulheres se encontram neste país ${ }^{24}$.

\subsection{Mortalidade materna: definições}

A determinação diagnóstica das causas da mortalidade materna, deve seguir rígidos critérios de identificação e avaliação, onde a ausência destes critérios claros pode dificultar esta classificação devido à sua complexidade ${ }^{25}$. 
A mortalidade materna é "a morte de uma mulher durante a gestação ou dentro de um período de 42 dias após o término da gestação, independente da duração ou da localização da gravidez, devida a qualquer causa relacionada ao ciclo gravídico puerperal, agravada pela gravidez ou por medidas em relação a ela, porém não devida a causas acidentais ou incidentais" ${ }^{11,26}$.

As causas da mortalidade materna estão classificadas como "todas as categorias incluídas no Capítulo XV (CID 10) ${ }^{26}$ - Gravidez, Parto e Puerpério". Estão excluídas as mortes por causas maternas ocorridas entre 43 dias e um ano após o parto, as chamadas mortes maternas tardias ou mortes no puerpério tardio e as sequelas de causa materna, ocorridas mais de um ano após a gravidez, mas cuja causa básica foi causa materna ${ }^{11,27}$.

De acordo com a causa do óbito, a morte materna pode ser classificada como direta ou indireta. As mortes maternas diretas resultam de complicações obstétricas relacionadas à gravidez, parto e puerpério, devidas às intervenções, omissões, tratamento incorreto ou de uma sequência de eventos resultantes de qualquer uma destas situações, como: hemorragia, infecção puerperal, hipertensão, tromboembolismo, acidente anestésico ${ }^{19,26,27}$.

As mortes maternas indiretas decorrem de doenças pré-existentes ou que se desenvolvem durante a gestação (intercorrências) e que não se devem a causas obstétricas diretas, mas que foram agravadas pelos efeitos fisiológicos da gestação como: cardiopatias, colagenoses e outras doenças crônicas ${ }^{19,26,27}$.

As principais causas da Mortalidade Materna Direta (MMD) configuram-se em complicações no ciclo gravídico puerperal devido à uma série de intercorrências ou mesmo falhas na assistência em saúde, que resultam muitas vezes em hemorragia, infecção puerperal, hipertensão, tromboembolismo ${ }^{19,28}$. 
Para Cecatti ${ }^{10}$ nos países desenvolvidos o cenário da mortalidade materna mostra que as causas obstétricas indiretas ${ }^{5,11}$ são predominantes quando comparadas às causas obstétricas diretas $^{5,11}$, demonstrando melhor qualidade na assistência à saúde.

Universalmente as doenças cardíacas são consideradas a maior causa da Mortalidade Materna Indireta (MMI) no ciclo gravídico puerperal ${ }^{29}$.

No Brasil, a incidência de doenças cardíacas na gravidez em centros de referência atinge até $4,2 \%$, ou seja, oito vezes maior quando comparada a estatísticas internacionais ${ }^{29}$.

\subsection{Indicador da mortalidade materna}

Para Laurenti ${ }^{15}$ a mortalidade materna pode ser considerada um excelente indicador de saúde, não só da mulher, mas da população geral, cujo objetivo é avaliar, fornecer subsídios para o estabelecimento de medidas públicas visando a melhoria da qualidade da saúde da população assistida em seus diversos territórios.

As informações em saúde são instrumentos essenciais à tomada de decisões para o monitoramento, avaliação e desenvolvimento de ações no âmbito reprodutivo e sexual das mulheres.

A Organização Mundial da Saúde (OMS) estabeleceu parâmetros para avaliar os índices da mortalidade materna, classificado em: baixa até 20, média de 20 a 49, alta de 50 a 149 , muito alta maior que 150 para cada cem mil nascidos vivos ${ }^{30}$.

No Brasil, o Ministério da Saúde (MS), com o objetivo de alcançar o Pacto do Milênio $^{5}$ (até 35 óbitos maternos/100.000 NV), compôs classificação intermediária à OMS, relacionada ao "baixo risco para mortalidade materna", assim disposto: 
1. Aceitável < 20; 2. Recomendado MS/Baixo de 21 a 35; 3. Baixo de 36 a 99;

4. Moderado de 110 a 299; 5. Alto de 300 a 549; 6. Muito alto de 550 a 999;

7. Extremamente alto $\geq 1000$ mortes de mulheres para cada 100.000 nascidos vivos ${ }^{31}$.

Calcula-se o índice da mortalidade materna pela mensuração do número de mães que morrem para cada cem mil nascidos vivos ${ }^{11,19,26}$.

A mortalidade materna também é um importante indicador da realidade social de um país porque as condições das mortes das mulheres mostram em que âmbito ocorre o desenvolvimento humano da população ${ }^{9,32}$.

O Índice de Desenvolvimento Humano $(\text { IDH })^{33}$ ou também denominado de índice de bem estar de um país, foi desenvolvido por Mahbub Haq e Amartya Sen na década de 90 para o Programa das Nações Unidas para o Desenvolvimento (PNUD) ${ }^{4}$, avalia o grau de desenvolvimento humano do país através da classificação de dados econômicos (renda per capita) $)^{34}$ e condições sociais (educação através da escolaridade/taxa de alfabetização e longevidade que mede indiretamente condições de saúde/salubridade e mortes precoces) $)^{4,33,35}$. É classificado em 3 níveis: países desenvolvidos com IDH muito alto, entre $(0,8-1,0499)$, países em desenvolvimento com IDH alto, entre (0,7-0,7999) e países subdesenvolvidos com IDH baixo (menor que 0,7). Segundo a ONU, o Brasil de 1980 a 2012 atingiu aumento de IDH 0,52 para 0,73, sendo considerado nível alto de IDH e classificado como país em desenvolvimento, ocupando o $85^{\circ}$ lugar no ranking mundial ${ }^{4,35}$.

O Estado de São Paulo através da Fundação Sistema Estadual de Análise de Dados $(\text { SEADE) })^{36}$ e a Assembléia Legislativa do Estado de São Paulo (ALESP), pressupondo que a renda per capita $^{34}$ é insuficiente para indicar as condições de vida e saúde da população e sua mensuração, incorpora para avaliação e classificação dos 
seus municípios, além do IDH que analisa a renda per capita, a longevidade e escolaridade, o Índice Paulista de Responsabilidade Social (IPRS) ${ }^{36}$. O IPRS também inclui condições de vida e meio ambiente, gerando um indicador mais abrangente para avaliar a real estrutura dos seus municípios. O IPRS classifica os municípios em cinco grupos: Grupo 1: reúne municípios com elevado nível de riqueza e bons indicadores sociais; Grupo 2: engloba localidades com bons níveis de riqueza, que não se refletem nos indicadores sociais, os quais se situam aquém dos registrados pelos municípios pertencentes ao Grupo 1; Grupo 3: municípios com nível de riqueza baixo, mas com bons indicadores nas dimensões escolaridade e longevidade; Grupo 4: esse grupo apresenta baixa riqueza e níveis intermediários de longevidade ou escolaridade; Grupo 5: composto por municípios tradicionalmente pobres, com baixos níveis de riqueza, longevidade e escolaridade ${ }^{36}$.

\subsection{Medidas internacionais e nacionais para redução da mortalidade materna}

A Organização das Nações Unidas (ONU) instituiu os Objetivos do Desenvolvimento do Milênio (ODM $)^{5}$. As metas propostas são de queda de três quartos na mortalidade materna, com contagem regressiva para 2015. É um grande desafio para a saúde mundial o Progresso do Milênio, em especial a meta 5 (ODM5), que trata da redução da mortalidade materna ${ }^{5,37,39}$. O Brasil é um dos países signatários, comprometidos a atingir as metas dos Objetivos do Milênio (ODM), na redução da morbimortalidade materna até o ano de $2015^{5,38,39}$. 
Estudos estimaram através de cálculos matemáticos que o Brasil apresenta progresso, porém insuficiente para atingir a meta cinco de desenvolvimento do milênio (ODM), pois os modelos matemáticos apontam para reduções anuais em torno de $4 \%$, abaixo dos 5,4\% requeridos para a redução da mortalidade materna proposta, até o ano de $2015^{5,39,40}$.

O Ministério da Saúde do Brasil (MS), instituiu algumas medidas para a melhoria da qualidade de saúde da população e figuram dentre elas o Programa de Humanização no Pré-natal e Nascimento em 2000, a Notificação Compulsória da Mortalidade Materna em 2003, o Pacto Nacional pela Redução da Mortalidade Materna e Neonatal em 2004, o Pacto pela Saúde e Pela Vida em 2006, a Vigilância Epidemiológica da Mortalidade Materna em 2008, a regulamentação do Indicador de Monitoramento do Pacto pela Vida em 2009 e a Rede Cegonha em 2011 18,20,41.

No Brasil, as medidas públicas para a atenção à saúde da mulher, devem manter suas necessidades numa perspectiva que contemple a promoção da saúde, a prevenção de doenças, o controle das doenças e agravos e a garantia do direito à saúde.

Assim, ações para redução da mortalidade materna, podem desencadear melhorias no acesso ao controle da natalidade, nas condições sociais e de saúde ${ }^{42}$.

\subsection{Sistemas de informações da mortalidade materna}

As informações são essenciais para a obtenção do perfil da mortalidade materna em regiões e compõem instrumento de relevância para credibilidade e articulação das medidas públicas para o desenvolvimento das ações reprodutivas da vida sexual das mulheres ${ }^{20}$. 
A OMS estabelece o registro civil de todas as mortes e suas causas como um método adequado para mensurar a mortalidade materna. Entretanto, mesmo para os países com sistema nacional de registro, é mantida a recomendação da vigilância dos óbitos maternos para a correta classificação de suas causas e correção, com objetivo de evitar a subnotificação da mortalidade materna ${ }^{43}$.

A subinformação no sistema de informações sobre mortalidade do Ministério da Saúde do Brasil (SIM/MS) e o preenchimento inadequado das causas das mortes nas declarações de óbitos (DO) podem ocorrer por razão específica, já que a causa básica da morte até pode estar declarada pelo médico, mas não há a informação se esta morte estava ou não relacionada à gravidez, ao parto e ao puerpério. Assim, proporcionalmente, as causas maternas são as menos informadas ${ }^{11}$.

Portanto, a mensuração da mortalidade materna pode não ser real, devido à subnotificação dos casos e preenchimento inadequado na declaração de óbito, principalmente em países em desenvolvimento como o Brasil.

Está demonstrado que a distribuição espacial da mortalidade materna é desigual $^{9}$.

Sirken $^{44}$ afirma que "as causas das mortes declaradas nos atestados de óbitos representam a fonte individual mais importante para se estabelecer parâmetros epidemiológicos sobre doenças, no âmbito nacional e loco-regional para o conjunto da população estudada.

Desde 1990, estudos realizados pelo Ministério da Saúde do Brasil permitem estimar Índices da Mortalidade Materna (IMM), sendo que as dificuldades para mensurar estas mortes tem sido amplamente documentados ${ }^{21}$. 


\subsection{Vigilância da mortalidade materna no Brasil}

No Brasil, a Portaria GM/MS nº 653 de 28 de maio de 2003, estabelece que o óbito materno passe a ser evento de notificação compulsória para a investigação dos fatores determinantes e as possíveis causas dos óbitos, assim como para a adoção de medidas que possam evitar novas mortes maternas ${ }^{20,41}$.

A vigilância epidemiológica (VE) da mortalidade materna foi regulamentada pela Portaria GM/MS nº 1.119 de 5 de junho de 2008, que estabelece fluxos e prazos para agilizar a disponibilidade de informações pelo Sistema de Informação sobre

Mortalidade (SIM) ${ }^{20,41}$ e define no artigo $2^{\circ}$ que os óbitos maternos e os óbitos de mulheres em idade fértil, independentemente da causa declarada, são considerados eventos de investigação obrigatória, com o objetivo de levantar fatores determinantes, suas possíveis causas, assim como subsidiar a adoção de medidas que possam evitar a sua reincidência. "A notificação do óbito se faz pelo preenchimento e encaminhamento da Declaração de Óbito gerada na fonte notificadora para as Secretarias Municipais de Saúde" 20,41 .

A implantação e ampliação dos Comitês da Mortalidade Materna em municípios e estados, beneficiam o aprofundamento do estudo sobre a ocorrência dos óbitos maternos e a melhoria da informação e da assistência em saúde ${ }^{45}$.

Portanto, investigações dos óbitos em mulheres em idade fértil e a inclusão dos dados no Sistema de Informação sobre mortalidade do Ministério da Saúde do Brasil (SIM/MS), contribuem para a obtenção de dados cada vez mais confiáveis, favorecendo análise epidemiológica mais adequada, além da implementação de ações e medidas públicas, que contribuem para a evitabilidade das mortes maternas ${ }^{19}$. 


\subsection{Medidas públicas para a redução da mortalidade materna no Estado de São Paulo}

O Estado de São Paulo vem adotando medidas públicas nacionais com o objetivo de promover assistência integral obstétrica, mediante ações que visem aprimorar a atenção à saúde das mulheres grávidas, como o acesso das mulheres aos serviços de saúde em sua área de abrangência.

Em 2011 foi promulgada a Lei Estadual $n^{\circ} 14.544$, de 14 de setembro ${ }^{46}$, que autoriza o Poder Executivo a instituir o Programa "Rede de Proteção à Mãe Paulista", sendo que o principal objetivo é promover a melhoria da qualidade da assistência obstétrica e neonatal, mediante ações que visem a assistência à saúde da gestante e do recém nascido ${ }^{46}$. Esta iniciativa vem ao encontro da necessidade de evitabilidade das mortes maternas e infantis no Estado ${ }^{46}$.

\subsection{Mortalidade materna na região do Grande ABC Paulista}

A Região do Grande ABC Paulista, Região Metropolitana do Estado de São Paulo - Brasil, composta de mais de 2 milhões de habitantes, contempla sete municípios: Santo André, São Bernardo do Campo, São Caetano do Sul, Diadema, Mauá, Ribeirão Pires e Rio Grande da Serra. Esta região se caracteriza por grande diversidade geográfica e socioeconômica, com municípios de muito alta renda per capita 33,34,35 como: Santo André, São Bernardo do Campo, São Caetano do Sul, contrapondo-se a municípios de alta renda per capita como: Diadema, Mauá, Ribeirão Pires, 
Rio Grande da Serra, com núcleos socioeconômicos deficitários, podendo traduzir um microcosmo brasileiro com perfis epidemiológicos mais confiáveis21,47,48. Esta região responde ainda pelo $4^{\circ}$ maior PIB (Produto Interno Bruto) do Brasil, equivalendo a 2,3\% da receita nacional de $\mathrm{R} \$ 3.143$ bilhões47. Das 7 cidades, 5 estão entre os 100 municípios brasileiros com maior participação na geração da riqueza brasileira sendo: São Bernardo do Campo responsável por 1\% (R \$29,8 bilhões), Santo André (R $\$ 13,4$ bilhões), São Caetano do Sul (R $\$ 10$ bilhões), Diadema ( $\$$ \$9 bilhões) e Mauá (R \$5,6 bilhões). Os municípios de Ribeirão Pires e Rio Grande da Serra não figuram entre os 100 maiores produtores do Brasil47, confirmando a heterogeneidade na região e apresentando independência política financeira do município de São Paulo.

O município de São Caetano do Sul, um dos maiores IDH do Brasil e na região, possui área de $15,33 \mathrm{Km}^{2}$, população total de 149.236 habitantes e densidade demográfica de 9.734.90 hab $/ \mathrm{km}^{2}$. A taxa de analfabetismo corresponde a 6,77. No entanto, contrapõe-se com o município de Rio Grande da Serra que apresenta um dos menores IDH na região do Grande ABC Paulista, que possui área de $36,24 \mathrm{Km}^{2}$, população total de 43.974 habitantes e densidade demográfica de $1.210,07 \mathrm{hab} / \mathrm{km}^{2}$. A sua taxa de analfabetismo corresponde a $14,02 \%{ }^{47,49}$.

De acordo com o Índice Paulista de Responsabilidade Social de 2008 (IPRS) ${ }^{36}$, os municípios na região do Grande ABC Paulista estão classificados por grupos assim distribuídos: Grupo 1. municípios de Ribeirão Pires, Santo André e São Caetano do Sul; Grupo 2. municípios de Diadema, Mauá e São Bernardo do Campo; Grupo 5. município de Rio Grande da Serra ${ }^{36}$. O município de São Caetano do Sul encontra-se entre os municípios do Estado de São Paulo em $1^{\circ}$ lugar no ranking do indicador de escolaridade, seguido do $14^{\circ}$ lugar em riqueza e do $69^{\circ}$ lugar em longevidade, 
figurando-se entre os melhores municípios em qualidade de vida e saúde da população na região estudada; contrapondo-se ao município Rio Grande da Serra que ocupou o $62^{\circ}$ lugar no ranking de indicador de escolaridade, seguido $148^{\circ}$ lugar em riqueza e $418^{\circ}$ lugar em longevidade, figurando-se como município que merece maior atenção para a melhoria da qualidade de vida e saúde da população na região estudada ${ }^{36}$.

Segundo o IBGE ${ }^{47}$, o número de Unidades de Saúde (US) do Sistema Único de Saúde (SUS) que compõem os municípios na região do Grande ABC Paulista são respectivamente em ordem decrescente de: 70 (US) em São Bernardo do Campo, 60 (US) em Santo André, 38 (US) em São Caetano do Sul, 31 (US) em Diadema, 30 (US) em Mauá, 11 (US) em Ribeirão Pires, 08 (US) em Rio Grande da Serra, totalizam-se 248 (US) na região, sendo que destas, 08 são maternidades, 136 são Unidades Básicas de Saúde (UBS), com 294 Equipes de Saúde da Família do Programa da Saúde da Família, sendo a maior concentração no município de Diadema e a menor concentração no município de Rio Grande da Serra. A região conta com 16 Unidades de Pronto Atendimento (UPA), sendo a maior concentração (09 UPA) no município de São Bernardo do Campo e ausência de UPA nos municípios de Rio Grande da Serra e São Caetano do Sul. Possui 48 ambulatórios de especialidades médicas de gestão municipal e 04 ambulatórios de especialidades médicas de gestão estadual; sendo a maior concentração no município de São Caetano do Sul, com 13 ambulatórios de especialidades médicas de gestão municipal e a menor concentração no município de Rio Grande da Serra com 02 ambulatórios de especialidades médicas de gestão municipal e ausência de ambulatórios de especialidade de gestão estadual ${ }^{47,50}$.

Os dados sobre a mortalidade materna na região do Grande $\mathrm{ABC}$ Paulista de 1997 a 2006, eram obtidos e disponibilizados pelo Sistema Estadual de Análise de 
Dados (SEADE) e os dados secundários obtidos pelo Comitê de Estudos da Mortalidade materna (CEMM) na região do Grande $\mathrm{ABC}$ Paulista, vinculado à Direção Regional de Saúde II de Santo André (extinta em 2006), da Secretaria de Estado da Saúde de São Paulo (SES-SP) $)^{36,47,48}$

\subsection{Justificativa}

Este estudo propôs analisar o perfil e a tendência temporal da mortalidade materna na região do Grande ABC Paulista de 1997 a 2011.

A diversidade geográfica e socioeconômica na região do Grande $\mathrm{ABC}$, permite estudos de municípios com perfis diferenciados no que diz respeito às áreas geográficas, ambientais e socioeconômicas como áreas rurais, áreas de preservação de mananciais, áreas industriais e áreas urbanas assim como, áreas de alta renda per capita contrapondo-se a áreas carentes, podendo espelhar um microcosmo do Brasil.

As pesquisas sobre mortalidade materna são relevantes e contribuem para a construção de medidas públicas que promovam a prevenção e atenção integral e humanizada às mães. Também podem contribuir para a redução da morbimortalidade materna e assegurar o respeito aos direitos humanos, sexuais e reprodutivos destas mulheres.

O estudo de série temporal de mais de uma década permite estimativas das taxas da mortalidade materna, com o objetivo de projetar o IMMD na região do Grande ABC Paulista, neste milênio até 2015, conforme propostas de pactos nacionais e internacionais para redução da mortalidade materna. 


\section{OBJETIVOS}




\subsection{Objetivo geral}

Verificar a tendência temporal do índice da mortalidade materna na região do Grande ABC Paulista no período de 1997 a 2015.

\subsection{Objetivos específicos}

Na região do Grande ABC Paulista no período de 1997 a 2011:

a. Analisar o perfil sociodemográfico das mães que morreram de causas evitáveis no ciclo gravídico puerperal

b. Estratificar o Índice da Mortalidade Materna por:

b.1: Municípios

b.2: IDH

b.3: Causas

b.4: Período e Local de Ocorrência do Óbito

b.5: Subnotificação, inadequação e investigação da mortalidade materna

b.6: Série temporal 
3 MÉTODOS 
O projeto foi aprovado pela Comissão de Ética para Análise de projetos de pesquisa - CAPPESQ, sob número 289/11, da Diretoria Clínica do Hospital das Clínicas e da Faculdade de Medicina da Universidade de São Paulo. Foram utilizados dados secundários de livre acesso não infringindo quaisquer legislações éticas vigentes no Brasil.

É um estudo ecológico, observacional, de série temporal sobre mortalidade materna na região do Grande ABC Paulista no período de 1997 a 2011.

Os municípios analisados foram estratificados quanto ao Índice de Desenvolvimento Humano - IDH, em 2 grupos: grupo1 IDH > 0,8 (Santo André 0,815, São Bernardo do Campo 0,850 e São Caetano do Sul 0,862) e grupo 2 com IDH entre 0,7-0,8 (Diadema 0,757, Mauá 0,766, Ribeirão Pires 0,784, Rio Grande da Serra 0,749$)^{4,47}$.

As informações sobre os óbitos maternos foram obtidas junto ao Sistema de Informação da Mortalidade (SIM), abastecida pelos municípios na região do Grande ABC Paulista, do Sistema de Informação de Nascidos Vivos (SINASC) e do Banco de Dados do Sistema Único de Saúde -Ministério da Saúde do Brasil, óbitos maternos por residência entre 1997 a $2011^{49}$.

O Índice da Mortalidade Materna (IMM) foi calculado a partir dos dados referentes a cada ano estudado para todos os municípios na região do Grande $\mathrm{ABC}$ Paulista, obedecendo-se ao índice de cálculo para mortalidade materna ${ }^{19,20}$. 
O cálculo para o IMM corresponde à relação entre o número de óbitos maternos (MM) (diretos ou indiretos), por um determinado período, pelo número de nascidos vivos (NV) do mesmo período, multiplicado por $100.000^{19,20}(\mathrm{NV})$, como consta na equação a seguir:

$$
\mathrm{IMM}=\frac{\mathrm{MM} \text { (período) }}{\mathrm{NV} \text { (período) }} \times 100.000
$$

Os índices da Mortalidade Materna Direta (IMMD) foram estratificados por ano, IDH, para o período de estudo de 1997 a 2011. Também foram obtidas as informações e IMMD da população feminina em idade fértil, óbitos de mulheres idade fértil, nascidos vivos, etnia (raça/cor), faixa etária, estado civil, escolaridade (anos de estudo), causas (CID 10), período de ocorrência do óbito materno, local do óbito materno e por investigação através das fichas da Vigilância Epidemiológica (VE) do óbito materno ${ }^{26,41}$.

Utilizou-se a Classificação Estatística Internacional de Doenças e Problemas Relacionados à Saúde - CID 10 - Décima Revisão - Organização Mundial da Saúde $(\mathrm{OMS})^{4}$ para definição do tipo da mortalidade materna, além de agrupar as causas dos óbitos maternos para referência no estudo. Mortalidade Materna Direta (MMD) corresponde aos seguintes códigos: O00-O08, O11-O23, O24.4,O26-O92, A34, D39.2, E23.0, F53 e M83.0. Mortalidade Materna Indireta (MMI) corresponde aos seguintes códigos: O10, O24 (exceto O24.4), O25,O98-O99 e B20-B24. As mortes obstétricas não especificadas correspondem ao CID O95. As causas foram agregadas em 11 grupos segundo CID 10: Hemorragias/tromboses/embolias de origem obstétricas relacionadas com a gravidez/parto/puerpério: O72, O67, O62, O45, O46, O01, O44, O75, O87, O88; Outras doenças prévias que não complicaram no parto/puerpério: O99, O11; Eclâmpsias: O15, O14, O13, O10, O16; Infecções prévias na gestação (HIV e outras 
infecções crônicas) B20, O98, B24; Complicações no puerpério não classificadas em outra seção: O90; Infecção puerperal: O85, O86, O73, O23; Abortamento: O06; Trauma obstétrico: O71; Diabete Melito na gravidez: O24; Outros Produtos anormais: O02; Assistência Prestada a Mãe: O36 ${ }^{19,26,41}$.

É importante destacar que embora sejam raras, podem ocorrer mortes por causas externas em mulheres (Capítulo XX: V01-Y98 - CID10), podendo comprometer o desenvolvimento normal do ciclo gravídico-puerperal, interrompendo-o. Deve ser considerada como Mortalidade Materna Indireta, desde que não haja dúvida em relação a esse comprometimento ${ }^{19,26,41}$.

\subsection{Análise Estatística}

Foi realizada a análise descritiva de todas as variáveis do estudo. As variáveis qualitativas foram apresentadas em termos de seus valores absolutos. As variáveis quantitativas foram apresentadas em termos de seus valores de tendência central e de dispersão ${ }^{51}$.

A normalidade e homogeneidade das variâncias foram avaliadas pelos testes de Kolgomorov-Smirnov e Levene, respectivamente. Como as variáveis contínuas não apresentaram distribuição normal, foi utilizado o teste não paramétrico $U$ de Mann-Whitney para a comparação entre os dois grupos de IDH. Para as comparações entre municípios e anos de estudo, foi utilizado o teste de Kruskal-Wallis, seguido pelo teste de comparações múltiplas de Dunn ${ }^{51}$. 
A tendência da Mortalidade Materna Direta foi avaliada utilizando-se o modelo de regressão linear. A variável Índice da Mortalidade Materna não apresentou aderência a curva normal, portanto para ser usada no modelo de regressão linear a mesma foi transformada pela raiz quadrada e com isso o Índice da Mortalidade Materna apresentou distribuição normal ${ }^{51}$.

O nível de significância foi considerado em $5 \%$ e o pacote estatístico utilizado foi o Statistical Package of Social Science versão 17.0 for Windows. 
4 RESULTADOS 
Foram computados um total de 12.614.460 mulheres (população feminina) em idade fértil e 595.569 nascidos vivos na região do Grande $\mathrm{ABC}$ Paulista no período de 1997 a 2011. Ocorreram 13.316 óbitos de mulheres em idade fértil, sendo 143 Mortalidade Materna Direta (MMD) e 63 Mortalidade Materna Indireta (MMI) e 01 Mortalidade Materna Não Especificada (MMNE), por residência ${ }^{49}$.

A seguir serão apresentados os valores médios \pm desvio-padrão e a variação (valores mínimo e máximo) e nível de significância para as variáveis no período de estudo, para cada município na região e estratificados pelo $\operatorname{IDH}^{33,34,35}$ (Grupo 1 Muito Alto: Santo André, São Bernardo do Campo, São Caetano do Sul; Grupo 2 Alto: Diadema, Mauá, Ribeirão Pires, Rio Grande da Serra e Grupo total que corresponde aos 07 municípios na região).

\subsection{Análise estratificada por IDH e municípios}

A tabela 1 apresenta a análise descritiva da população feminina idade fértil, nascidos vivos (NV), óbitos de mulheres em idade fértil, Mortalidade Materna Direta, IDH (grupo 1- muito alto, grupo 2 - alto) no período de 1997 a 2011. Os valores são expressos por média do número absoluto no período analisado (15 anos). Observa-se que há diferenças entre os dois grupos de estudo $(\mathrm{p}<0,01)$ sendo o grupo $1 \mathrm{com}$ maior população com relação à população feminina em idade fértil, nascidos vivos e óbitos maternos em idade fértil. 
Tabela 1. População feminina e nascidos vivos na região do Grande ABC Paulista

\begin{tabular}{|c|c|c|c|c|c|}
\hline & $\begin{array}{c}\text { População Feminina } \\
\text { Idade Fértil }\end{array}$ & NV & $\begin{array}{l}\text { Óbitos } \\
\text { Mulheres } \\
\text { Idade Fértil }\end{array}$ & $\begin{array}{c}\text { M M } \\
\text { Direta }\end{array}$ & M M Indireta \\
\hline \multicolumn{6}{|l|}{ Grupo Total } \\
\hline Média $\pm d p$ & $120017,1 \pm 88440,3$ & $5672,0 \pm 4126,2$ & $126,8 \pm 88,9$ & $1,3 \pm 1,4$ & $0 \pm 1,0$ \\
\hline Mínimo-Máximo & $12244,0-281632,0$ & $573,0-13574,0$ & $12,0-278,0$ & $0-6,0$ & $0-5$ \\
\hline \multicolumn{6}{|l|}{ Grupo 1} \\
\hline Média $\pm d p$ & $174608,1 \pm 95403,5$ & $7734,5 \pm 4474,7$ & $174,7 \pm 93,2$ & $1,7 \pm 1,8$ & $0 \pm 1,2$ \\
\hline Mínimo-Máximo & $40293,0-281632,0$ & $1606,0-13574,0$ & $33,0-278,0$ & $0-6,0$ & $0-5$ \\
\hline \multicolumn{6}{|l|}{ Grupo 2} \\
\hline Média $\pm d p$ & $79073,9 \pm 55018,4$ & $4125,2 \pm 3066,1$ & $90,9 \pm 66,2$ & $1,0 \pm 1,0$ & $0 \pm 0,7$ \\
\hline Mínimo-Máximo & $12244,0-143727,0$ & $573,0-8891,0$ & $12,0-187,0$ & $0-4,0$ & $0-3$ \\
\hline $\begin{array}{l}\text { Nível de } \\
\text { significância }^{\&}\end{array}$ & $<0,01$ & $<0,01$ & $<0,01$ & 0,17 & $<0,02$ \\
\hline
\end{tabular}

Mortalidade materna (MM).Valores expressos como média $\pm d p$ (desvio padrão), valores mínimo e máximo; M M Direta: Mortalidade Materna Direta (MMD), Média expressa do número absoluto de cada população pelo período analisado (N/15); NV: Nascidos Vivos; \&:Teste U de Mann-Whitney, Grupo 1-IDH Muito Alto; Grupo 2=IDH Alto. IDH Muito alto: 0,8-1,0499 Grupo 1*- Municípios de Santo André, São Bernardo do Campo, São Caetano do Sul. IDH Alto: 0,7-0,799 Grupo 2**- Municípios de Diadema, Mauá, Ribeirão Pires, Rio Grande da Serra ${ }^{47}$.

A tabela 2 apresenta a análise descritiva para as variáveis Índice da Mortalidade Materna Direta (IMMD) por municípios na região do Grande ABC Paulista, e população feminina em idade fértil, nascidos vivos, óbitos de mulheres em idade fértil e Mortalidade Materna Direta (MMD) por município de estudo. Os valores são expressos por números absolutos da população analisada e média da Mortalidade Materna Direta no período estudado (15 anos). Observa-se que há diferenças entre os municípios para as variáveis população feminima em idade fértil, nascidos vivos e óbitos de mulheres em idade fértil ( $<<0,01)$. Para a população feminima em idade fértil, os municípios de Diadema e Mauá são iguais, porém ambos diferem dos demais municípios na região $(\mathrm{p}<0,01)$. Para a variável nascidos vivos e óbitos maternos observa-se o mesmo padrão, exceto que o Município de Ribeirão Pires não difere do município de São Caetano do Sul. 
Tabela 2. IMMD e número absoluto por população, municípios e período de 1997 a 2011

\begin{tabular}{|c|c|c|c|c|c|}
\hline \multicolumn{6}{|c|}{ Dados demográficos } \\
\hline Municipios & $\begin{array}{c}\text { População } \\
\text { Feminina } \\
\text { Idade Fértil }\end{array}$ & NV & $\begin{array}{c}\text { Óbitos } \\
\text { Mulheres } \\
\text { Idade Fértil }\end{array}$ & $\begin{array}{c}\text { M M } \\
\text { Direta }\end{array}$ & $\begin{array}{c}\text { M M } \\
\text { Indireta }\end{array}$ \\
\hline \multicolumn{6}{|l|}{ Diadema } \\
\hline Média $\pm d p$ & $130496,5 \pm 8226,2$ & $7373,6 \pm 907,8$ & $164,7 \pm 14,7$ & $1,4 \pm 0,9$ & $0,6 \pm 1,0$ \\
\hline Mínimo-Máximo & $115710,0-140234,0$ & $6256,0-8891,0$ & $140,0-187,0$ & $0-3,0$ & $0-3,0$ \\
\hline \multicolumn{6}{|l|}{ Mauá } \\
\hline Média $\pm d p$ & $134754,5 \pm 7551,8$ & $6769,1 \pm 918,2$ & $144,4 \pm 18,5$ & $1,8 \pm 1,3$ & $0,6 \pm 0,7$ \\
\hline Mínimo-Máximo & $122302,0-143727,0$ & $5744,0-8498,0$ & $121,0-177,0$ & $0-4,0$ & $0-2,0$ \\
\hline \multicolumn{6}{|l|}{ Ribeirão Pires } \\
\hline Média $\pm d p$ & $37617,3 \pm 1736,1$ & $1672,1 \pm 181,5$ & $38,6 \pm 7,1$ & $0,6 \pm 0,6$ & $0,2 \pm 0,4$ \\
\hline Mínimo-Máximo & $35036,0-40947,0$ & $1409,0-1935,0$ & $29,0-52,0$ & $0-2,0$ & $0-1,0$ \\
\hline \multicolumn{6}{|c|}{ Rio Grande da Serra } \\
\hline Média $\pm d p$ & $13427,5 \pm 800,0$ & $686,1 \pm 74,0$ & $15,7 \pm 2,6$ & $0,4 \pm 0,7$ & $0 \pm 0$ \\
\hline Mínimo-Máximo & $12244,0-14881,0$ & $573,0-829,0$ & $12,0-22,0$ & $0-2,0$ & $0-0$ \\
\hline \multicolumn{6}{|l|}{ Santo André } \\
\hline Média $\pm d p$ & $217929,6 \pm 4655,8$ & $9710,0 \pm 1150,4$ & $234,6 \pm 17,7$ & $2,4 \pm 1,9$ & $0,9 \pm 1,1$ \\
\hline Mínimo-Máximo & $211229,0-225909,0$ & $8619,0-12286,0$ & $208,0-262,0$ & $0-6,0$ & $0-3,0$ \\
\hline \multicolumn{6}{|c|}{ São Bernardo do Campo } \\
\hline Média $\pm d p$ & $261669,1 \pm 13827,4$ & $11781,8 \pm 999,6$ & $243,0 \pm 21,6$ & $2,4 \pm 1,8$ & $1,4 \pm 1,3$ \\
\hline Mínimo-Máximo & $239316,0-281632,0$ & $10890,0-13574,0$ & $205,0-278,0$ & $0-5,0$ & $0-4,0$ \\
\hline \multicolumn{6}{|c|}{ São Caetano do Sul } \\
\hline Média $\pm d p$ & $44225,5 \pm 1366,5$ & $1711,6 \pm 90,9$ & $46,5 \pm 9,9$ & $0,3 \pm 0,4$ & $0,4 \pm 1,3$ \\
\hline Mínimo-Máximo & $40293,0-45550,0$ & $1606,0-1907,0$ & $33,0-70,0$ & $0-1,0$ & $0-5,0$ \\
\hline $\begin{array}{l}\text { Nível de } \\
\text { significância }^{\&}\end{array}$ & $<0,01$ & $<0,01$ & $<0,01$ & $\mathbf{0 , 1 7}$ & $<0,01$ \\
\hline
\end{tabular}

\&:Teste kruskal-Wallis, M M Direta: Mortalidade Materna Direta, M M Indireta: Mortalidade Materna Indireta. Média expressa do número absoluto de cada população pelo período analisado (N/15); NV: Nascidos Vivos; municípios de Santo André, São Bernardo do Campo, São Caetano do Sul, Diadema, Mauá, Ribeirão Pires, Rio Grande da Serra ${ }^{47}$.

A tabela 3 apresenta a análise descritiva para as variáveis Índice da Mortalidade Materna Direta e Indireta total por residência e estratificado por IDH. Observa-se que não há diferenças entre os dois grupos de estudo. 
Tabela 3. Índice da Mortalidade Materna Direta e Indireta estratificado por IDH

\begin{tabular}{|c|c|c|}
\hline & \multicolumn{2}{|c|}{ Índice da Mortalidade Materna } \\
\hline & Direta & Indireta \\
\hline \multicolumn{3}{|l|}{ Grupo Todo } \\
\hline Média $\pm d p$ & $30,4 \pm 44,9$ & $10,3 \pm 30,1$ \\
\hline Mínimo-Máximo & $0-257,7$ & $0-282,8$ \\
\hline \multicolumn{3}{|l|}{ Grupo 1} \\
\hline Média \pm dp & $21,1 \pm 20,6$ & $14,4 \pm 42,6$ \\
\hline Mínimo-Máximo & $0-62,2$ & $0-282,8$ \\
\hline \multicolumn{3}{|l|}{ Grupo 2} \\
\hline Média $\pm d p$ & $37,3 \pm 55,9$ & $7,2 \pm 15,0$ \\
\hline Mínimo-Máximo & $0-257,7$ & $0-59,9$ \\
\hline Nível de Significância $^{\&}$ & 0,49 & $\mathbf{0 , 1 2}$ \\
\hline
\end{tabular}

\&:Teste U de Mann-Whitney, Grupo 1-IDH Muito Alto; Grupo 2=IDH Alto; dp: desvio padrão

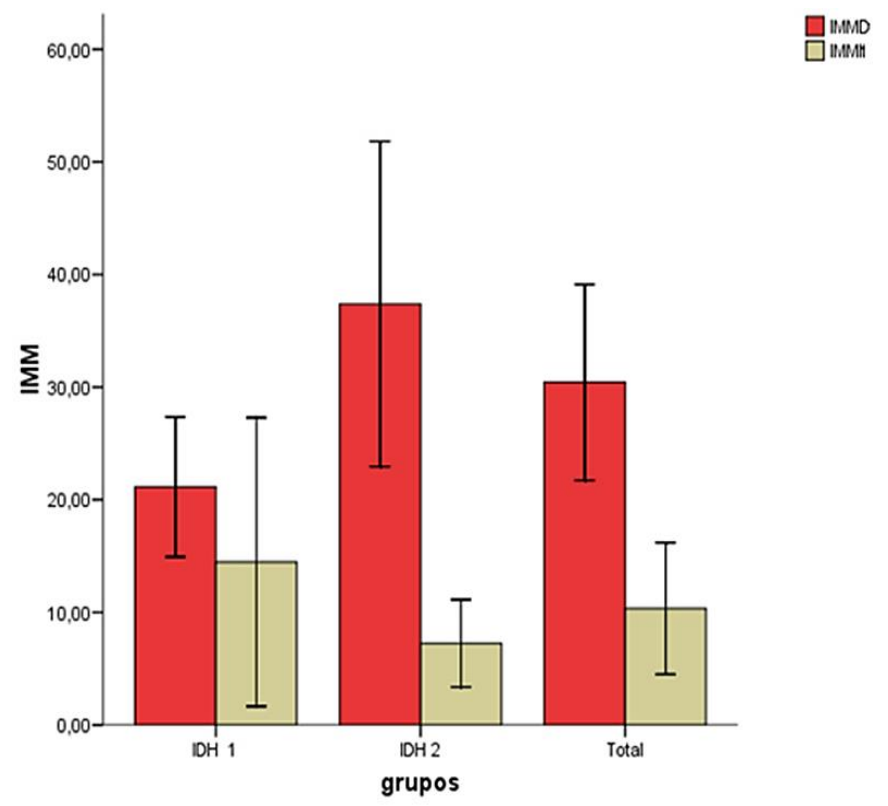

Valores expressos por média e Intervalo de Confiança (IC)95\%; IMM: Índice da Mortalidade Materna; IMMD: Índice da Mortalidade Materna Direta; IMMI: Índice da Mortalidade Materna Indireta; IDH: Índice de Desenvolvimento Humano: IDH 1: IDH muito alto (municípios Santo André, São Bernardo do Campo e São Caetano do Sul); IDH 2: IDH alto (municípios Diadema, Mauá, Ribeirão Pires e Rio Grande da Serra).

Figura 1. Índice da Mortalidade Materna Direta, Indireta total e Grupos de IDH 
A tabela 4 apresenta o número absoluto e Índice da Mortalidade Materna Direta (IMMD) e Indireta (IMMI) por residência, por municípios na região do Grande ABC Paulista e período de estudo de 1997 a 2011. A tabela demonstra altos IMMD nos municípios de Rio Grande da Serra e Ribeirão Pires, ambos pertencentes ao grupo 2 quando estratificados por IDH (Tabela 4, Figura 2). Por outro lado os índices da Mortalidade Materna Indireta são mais expressivos em São Caetano do Sul pertencente ao grupo 1 do IDH.

Tabela 4. Mortalidade Materna Direta (MMD) e Mortalidade Materna Indireta (MMI) por municípios: números absolutos e índices da mortalidade materna

\begin{tabular}{lcccc}
\hline \hline & \multicolumn{2}{c}{ IMMD } & \multicolumn{2}{c}{ IMMI } \\
\cline { 2 - 5 } Municípios & $\mathbf{n}^{\mathbf{0}}$ absoluto & índice & $\mathbf{n}^{\mathbf{0}}$ absoluto & índice \\
\hline Diadema** & 21 & 18,7 & 10 & 9,2 \\
Mauá** & 27 & 26,0 & 9 & 8,4 \\
Ribeirão Pires** & 10 & 40,5 & 3 & 11,3 \\
Rio Grande da Serra** & 7 & 64,1 & 0 & 0 \\
Santo André* & $\mathbf{3 6}$ & $\mathbf{2 4 , 0}$ & $\mathbf{1 4}$ & $\mathbf{8 , 8}$ \\
São Bernardo do Campo* & $\mathbf{3 7}$ & $\mathbf{2 0 , 6}$ & $\mathbf{2 1}$ & $\mathbf{1 2 , 1}$ \\
São Caetano do Sul* & $\mathbf{5}$ & $\mathbf{1 8 , 7}$ & $\mathbf{6}$ & $\mathbf{2 2 , 3}$ \\
\hline Total 15 anos & $\mathbf{1 4 3}$ & $\mathbf{2 4 , 0}$ & $\mathbf{6 3}$ & $\mathbf{1 0 , 5}$ \\
\hline \hline
\end{tabular}

Índice da Mortalidade Materna Direta (IMMD) e Índice da Mortalidade Materna Indireta (IMMI) ${ }^{49}$. IDH Muito alto: 0,8-1,0499 Grupo 1*- municípios de Santo André, São Bernardo do Campo, São Caetano do Sul. IDH Alto: 0,7-0,799 Grupo $2^{* *}$ - municípios de Diadema, Mauá, Ribeirão Pires, Rio Grande da Serra ${ }^{47}$. 
A figura 2 e a tabela 5 apresentam a análise descritiva e comparativa para as variáveis Índice da Mortalidade Materna Direta e Indireta por municípios na região do Grande ABC Paulista. Observa-se que Rio Grande da Serra apresenta menores índices da Mortalidade Materna Indireta (IMMI) quando comparado com o município de São Caetano do Sul $(\mathrm{p}=0,02)$. No quesito Índice da Mortalidade Materna Direta (IMMD) não houve diferenças entre os grupos.

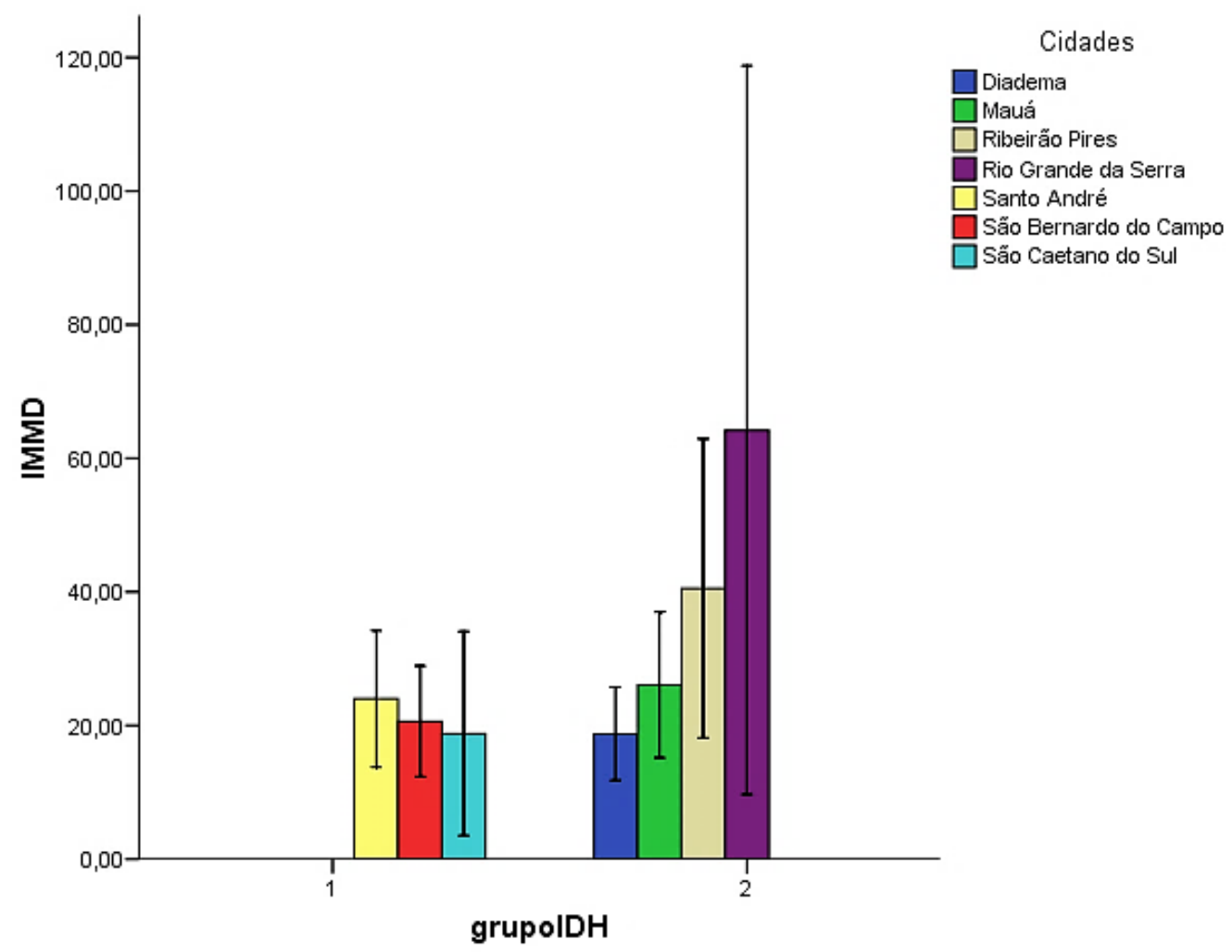

Valores expressos por média e IC95\%; IMMD: Índice da Mortalidade Materna Direta; IDH: Índice de Desenvolvimento Humano: IDH 1: IDH muito alto (municípios Santo André, São Bernardo do Campo e São Caetano do Sul); IDH 2: IDH alto (municípios Diadema, Mauá, Ribeirão Pires e Rio Grande da Serra).

Figura 2. Índice da Mortalidade Materna Direta por IDH e municípios 
Tabela 5. Índices da Mortalidade Materna Direta e Indireta, por municípios

\begin{tabular}{|c|c|c|}
\hline \multirow[b]{2}{*}{ Municípios } & \multicolumn{2}{|c|}{ Índice Mortalidade Materna } \\
\hline & Direta & Indireta \\
\hline \multicolumn{3}{|l|}{ Diadema } \\
\hline Média \pm dp & $18,7 \pm 12,6$ & $9,2 \pm 14,8$ \\
\hline Mínimo-Máximo & $0-34,2$ & $0-43,6$ \\
\hline \multicolumn{3}{|l|}{ Mauá } \\
\hline Média \pm dp & $26,0 \pm 19,7$ & $8,4 \pm 9,7$ \\
\hline Mínimo-Máximo & $0-51,0$ & $0-24,6$ \\
\hline \multicolumn{3}{|l|}{ Ribeirão Pires } \\
\hline Média \pm dp & $40,5 \pm 40,4$ & $11,3 \pm 23,5$ \\
\hline Mínimo-Máximo & $0-141,9$ & $0-59,9$ \\
\hline \multicolumn{3}{|l|}{ Rio Grande da Serra } \\
\hline Média $\pm d p$ & $64,1 \pm 98,5$ & $0 \pm 0$ \\
\hline Mínimo-Máximo & $0-257,7$ & $0-0$ \\
\hline \multicolumn{3}{|l|}{ Santo André } \\
\hline Média $\pm d p$ & $24,0 \pm 18,4$ & $8,8 \pm 10,5$ \\
\hline Mínimo-Máximo & $0-54,8$ & $0-25,9$ \\
\hline \multicolumn{3}{|l|}{ São Bernardo do Campo } \\
\hline Média $\pm d p$ & $20,6 \pm 14,9$ & $12,1 \pm 11,5$ \\
\hline Mínimo-Máximo & $0-44,6$ & $0-35,7$ \\
\hline \multicolumn{3}{|l|}{ São Caetano do Sul } \\
\hline Média $\pm d p$ & $18,7 \pm 27,5$ & $22,3 \pm 73,3$ \\
\hline Mínimo-Máximo & $0-62,2$ & $0-282,8$ \\
\hline Nível de significância ${ }^{\&}$ & $\mathbf{0 , 5 7}$ & 0,02 \\
\hline
\end{tabular}

\&:Teste kruskal-Wallis 
A tabela 6 apresenta a análise descritiva para as variáveis Índice da Mortalidade Materna Direta por etnia e grupo de estudo. Observa-se que há diferenças entre os dois grupos de estudo onde no Grupo 1 observa-se maior índice na etnia negra $(\mathrm{p}=0,03)$.

Tabela 6. Índice Mortalidade Materna Direta por etnia e grupo de estudo

\begin{tabular}{|c|c|c|c|c|}
\hline & \multicolumn{4}{|c|}{ Índice por Etnia } \\
\hline & Branca & Negra & Parda & Ignorada \\
\hline \multicolumn{5}{|l|}{ Grupo todo } \\
\hline Média $\pm d p$ & $30,5 \pm 51,8$ & $3,3 \pm 16,1$ & $8,8 \pm 27,0$ & $2,9 \pm 13,9$ \\
\hline Mínimo-Máximo & $0-282,8$ & $0-151,1$ & $0-164,7$ & $0-128,8$ \\
\hline \multicolumn{5}{|l|}{ Grupo 1} \\
\hline Média $\pm d p$ & $24,7 \pm 45,1$ & $3,4 \pm 9,9$ & $3,4 \pm 7,6$ & $1,5 \pm 5,6$ \\
\hline Mínimo-Máximo & $0-282,8$ & $0-62,2$ & $0-35,7$ & $0-34,5$ \\
\hline \multicolumn{5}{|l|}{ Grupo 2} \\
\hline Média $\pm d p$ & $34,7 \pm 56,4$ & $3,2 \pm 19,6$ & $12,8 \pm 34,8$ & $3,9 \pm 17,8$ \\
\hline Mínimo-Máximo & $0-248,4$ & $0-151,0$ & $0-164,7$ & $0-128,8$ \\
\hline Nível de significância $^{\text {\& }}$ & 0,79 & 0,03 & 0,47 & 0,96 \\
\hline
\end{tabular}

Valores expressos como média \pm desvio padrão (mínimo-máximo); Média expressa do número absoluto de cada população pelo período analisado (N/15); ${ }^{\star}$ :Teste U de Mann-Whitney, Grupo 1=IDH Muito Alto; Grupo 2=IDH Alto 
A figura 3 apresenta o painel dos índices da Mortalidade Materna Direta total, por IDH e por municípios. Observamos que a etnia predominante é a branca em todos os grupos com valores próximos da etnia total. Existe diferença entre a etnia negra entre grupos IDH $(\mathrm{p}=0,03)$. Porém, obtivemos apenas tendência quando se compararam os municípios ( $\mathrm{p}=0,06$; Tabela 7$)$.
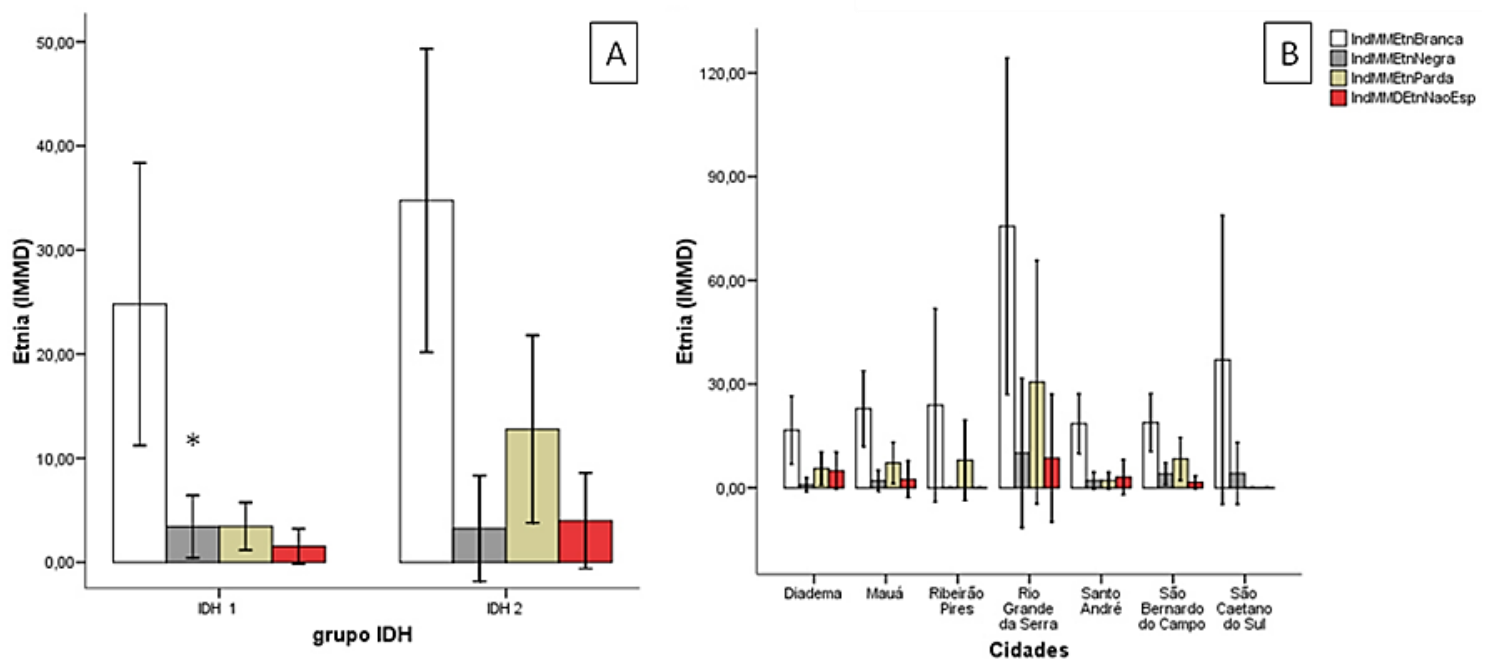

Valores expressos por média e IC95\%; IMMD: Índice da Mortalidade Materna Direta; IDH: Índice de Desenvolvimento Humano: IDH 1: IDH muito alto (municípios Santo André, São Bernardo do Campo e São Caetano do Sul); IDH 2: IDH alto (municípios Diadema, Mauá, Ribeirão Pires e Rio Grande da Serra). *p=0,03.

Figura 3. Índices da Mortalidade Materna Direta por IDH (2A) e por municípios (2B) estratificados por etnia

A tabela 7 apresenta o IMMD estratificado por município e etnia. Observamos que não há diferenças entre os municípios neste quesito. Porém, a etnia negra, que foi significativa na estratificação por IDH, entre municípios apresenta apenas tendência $(\mathrm{p}=0,06)$ onde Rio Grande da Serra apresenta os maiores índices de MMD quando comparado com Diadema, Mauá, Ribeirão Pires, Santo André, São Bernardo do Campo e São Caetano do Sul. 
Tabela 7. Índice da Mortalidade Materna por município e etnia

\begin{tabular}{|c|c|c|c|c|}
\hline \multirow[b]{2}{*}{ Municípios } & \multicolumn{4}{|c|}{ Etnia } \\
\hline & Branca & Negra & Parda & Ignorada \\
\hline \multicolumn{5}{|l|}{ Diadema } \\
\hline Média $\pm d p$ & $16,6 \pm 17,7$ & $0,9 \pm 3,4$ & $5,5 \pm 8,6$ & $4,9 \pm 9,6$ \\
\hline Mínimo-Máximo & $0-58,2$ & $0-13,5$ & $0-26,3$ & $0-33,7$ \\
\hline \multicolumn{5}{|l|}{ Mauá } \\
\hline Média $\pm d p$ & $22,8 \pm 19,6$ & $2,0 \pm 5,3$ & $7,1 \pm 10,7$ & $2,4 \pm 9,5$ \\
\hline Mínimo-Máximo & $0-66,9$ & $0-15,3$ & $0-25,5$ & $0-36,9$ \\
\hline \multicolumn{5}{|l|}{ Ribeirão Pires } \\
\hline Média $\pm d p$ & $23,8 \pm 50,4$ & $0 \pm 0$ & $7,9 \pm 20,9$ & $0 \pm 0$ \\
\hline Mínimo-Máximo & $0-150,6$ & $0-0$ & $0-63,5$ & $0-0$ \\
\hline \multicolumn{5}{|l|}{ Rio Grande da Serra } \\
\hline Média $\pm d p$ & $75,6 \pm 87,9$ & $10,0 \pm 3$ & $30,5 \pm 63,4$ & $8,5 \pm 33,2$ \\
\hline Mínimo-Máximo & $0-248,4$ & $0-151,0$ & $0-164,7$ & $0-128,8$ \\
\hline \multicolumn{5}{|l|}{ Santo André } \\
\hline Média $\pm d p$ & $18,5 \pm 15,4$ & $2,0 \pm 4,3$ & $2,0 \pm 4,3$ & $3,0 \pm 9,1$ \\
\hline Mínimo-Máximo & $0-45,2$ & $0-11,0$ & $0-11,0$ & $0-34,5$ \\
\hline \multicolumn{5}{|l|}{ São Bernardo do Campo } \\
\hline Média $\pm d p$ & $18,8 \pm 15,1$ & $4,0 \pm 5,6$ & $8,3 \pm 11,1$ & $1,5 \pm 3,2$ \\
\hline Mínimo-Máximo & $0-54,5$ & $0-18,0$ & $0-35,7$ & $0-8,8$ \\
\hline \multicolumn{5}{|l|}{ São Caetano do Sul } \\
\hline Média $\pm d p$ & $36,9 \pm 75,4$ & $4,1 \pm 16,0$ & $0 \pm 0$ & $0 \pm 0$ \\
\hline Mínimo-Máximo & $0-282,8$ & $0-62,2$ & $0-0$ & $0-0$ \\
\hline Nível de significância ${ }^{\&}$ & $\mathbf{0 , 3 4}$ & 0,06 & $\mathbf{0 , 1 1}$ & 0,16 \\
\hline
\end{tabular}

${ }^{\&}$ :Teste kruskal-Wallis 
A tabela 8 apresenta a análise descritiva para as variáveis Índice da Mortalidade Materna Direta por faixa etária e grupos estratificados por IDH. Observa-se que há diferenças entre os dois grupos de estudo $(\mathrm{p}<0,01)$ apenas na faixa etária de 35 a 39 anos, onde o grupo 2 com IDH alto apresenta maior Índice da Mortalidade Materna Direta que o grupo 1 com IDH muito alto (tabela 8, figura 4). Quando estratificado por municípios, observa-se que há diferenças para a faixa etária de 20 a $24(\mathrm{p}<0,01)$ e 35 a 39 anos $(\mathrm{p}=0,05)$ onde o município de Rio Grande da Serra difere dos demais municípios (Figura 4, Tabela 9).

Tabela 8. Índice Mortalidade Materna Direta por faixa etária e grupo de estudo

\begin{tabular}{|c|c|c|c|c|c|c|c|c|c|}
\hline \multirow[b]{2}{*}{ Faixa Etária } & \multicolumn{9}{|c|}{ Índice por faixa etária (anos) } \\
\hline & $10-14$ & 15-19 & 20-24 & 25-29 & 30-34 & 35-39 & $40-44$ & 45-49 & $>\mathbf{5 0}$ \\
\hline \multicolumn{10}{|l|}{ Grupo Total } \\
\hline Média $\pm d p$ & $0,2 \pm 1,4$ & $3,3 \pm 17,0$ & $11,3 \pm 31,5$ & $8,3 \pm 20,1$ & $13,5 \pm 34,1$ & $6,0 \pm 17,5$ & $3,0 \pm 12,1$ & $0,7 \pm 5,7$ & $0,1 \pm 1,4$ \\
\hline Mínimo-Máximo & $0-11,7$ & $0-164,7$ & $0-164,7$ & $0-120,6$ & $0-169,2$ & $0-146,0$ & $0-113,1$ & $0-56,6$ & $0-14,8$ \\
\hline \multicolumn{10}{|l|}{ Grupo 1} \\
\hline Média \pm dp & $0,2 \pm 1,3$ & $1,7 \pm 4,2$ & $5,8 \pm 8,2$ & $8,1 \pm 19,7$ & $6,7 \pm 13,1$ & $7,6 \pm 13,1$ & $4,0 \pm 17,1$ & $1,4 \pm 8,5$ & $0 \pm 0$ \\
\hline Mínimo-Máximo & $0-9,1$ & $0-18,3$ & $0-27,1$ & $0-104,8$ & $0-57,4$ & $0-57,1$ & $0-113,1$ & $0-56,5$ & $0-0$ \\
\hline \multicolumn{10}{|l|}{ Grupo 2} \\
\hline Média \pm dp & $0,2 \pm 1,5$ & $4,5 \pm 22,3$ & $15,4 \pm 40,7$ & $8,4 \pm 20,6$ & $18,5 \pm 43,2$ & $4,8 \pm 20,3$ & $2,2 \pm 6,2$ & $0,2 \pm 1,8$ & $0,2 \pm 1,9$ \\
\hline Mínimo-Máximo & $0-11,7$ & $0-164,7$ & $0-164,7$ & $0-120,6$ & $0-169,2$ & $0-146,2$ & $0-33,4$ & $0-14,1$ & $0-14,8$ \\
\hline $\begin{array}{l}\text { Nível de } \\
\text { significância }\end{array}$ & $\mathbf{0 , 8 5}$ & $\mathbf{0 , 5 1}$ & $\mathbf{0 , 4 3}$ & 0,4 & 0,9 & $<0,01$ & $\mathbf{0 , 8 1}$ & 0,4 & $\mathbf{0 , 0}$ \\
\hline
\end{tabular}

\&:Teste U de Mann-Whitney, Grupo 1-IDH Muito Alto; Grupo 2=IDH Alto 

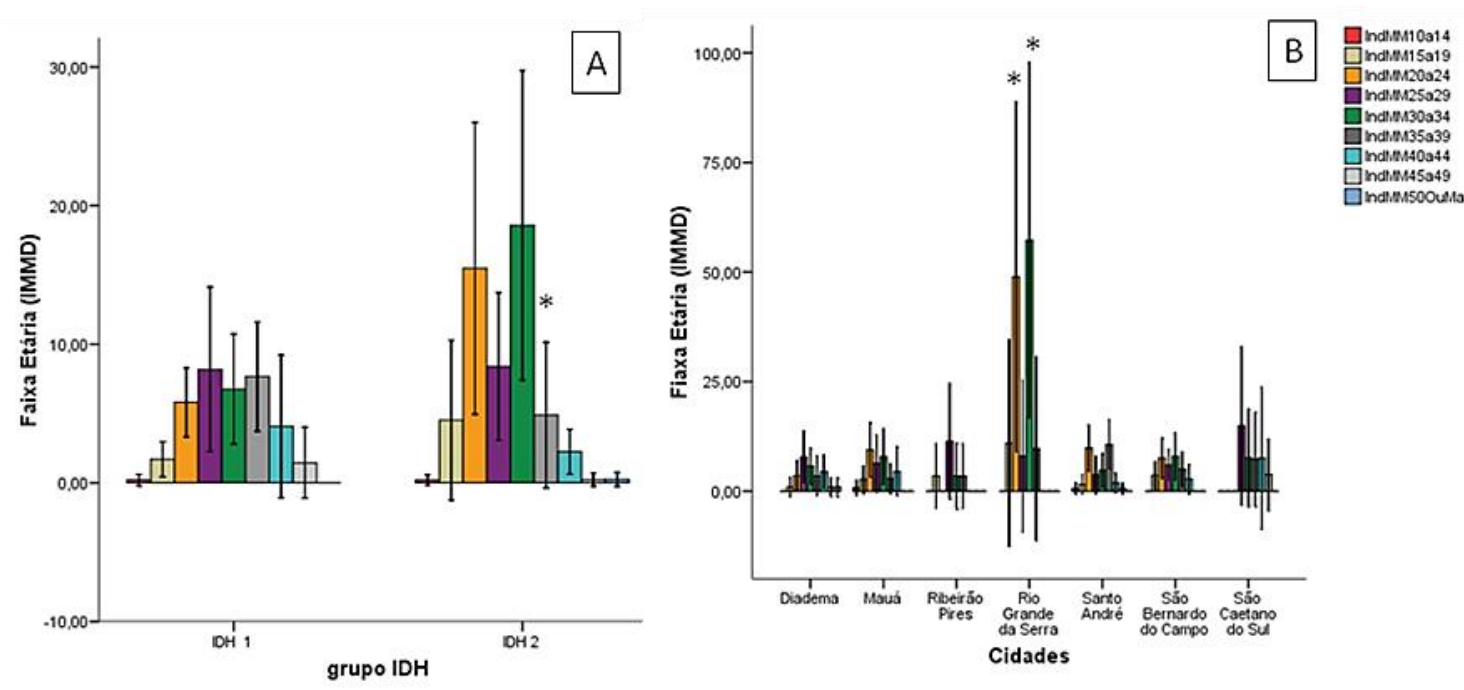

Valores expressos por média e IC95\%; IMMD: Índice da Mortalidade Materna Direta; IDH: Índice de Desenvolvimento Humano: IDH 1: IDH muito alto (municípios Santo André, São Bernardo do Campo e São Caetano do Sul); IDH 2: IDH alto (municípios Diadema, Mauá, Ribeirão Pires e Rio Grande da Serra). *p $\leq 0,05$.

Figura 4. Índice da Mortalidade Materna Direta por IDH (A) e municípios (B) em relação a Faixa Etária

A tabela 9 apresenta os IMMD por faixa etária por municípios. Observamos que há diferenças entre os municípios onde ocorrem mais óbitos em mães entre 20-24 anos $(p<0,01)$ e entre 35-39 anos $(p=0,05)$. O teste de Dunn apontou ser Rio Grande da Serra o município com maior IMMD entre 20-24 anos e Santo André e Rio Grande da Serra entre as idades 35 a 39 anos quando comparados às mães pertencentes aos outros municípios analisados. 
Tabela 9. Índice da Mortalidade Materna por faixa etária e municípios

\begin{tabular}{|c|c|c|c|c|c|c|c|c|c|}
\hline \multirow[b]{2}{*}{ Municípios } & \multicolumn{9}{|c|}{ Índice Mortalidade Materna por Faixa Etária } \\
\hline & 10 a 14 & 15 a 19 & 20 a 24 & 25 a 29 & 30 a 34 & 35 a 39 & 40 a 44 & 45 a 49 & $>\mathbf{5 0}$ \\
\hline \multicolumn{10}{|l|}{ Diadema } \\
\hline Média \pm dp & 0 & $1,0 \pm 3,9$ & $3,5 \pm 6,1$ & $7,8 \pm 10,6$ & $5,7 \pm 7,3$ & $3,5 \pm 8,2$ & $4,4 \pm 6,6$ & $0,9 \pm 3,6$ & $0,9 \pm 3,8$ \\
\hline (Min-Max) & $0-0$ & $0-15,0$ & $0-14,8$ & $0-29,1$ & $0-15,0$ & $0-29,1$ & $0-16,0$ & $0-14,1$ & $0-14,8$ \\
\hline \multicolumn{10}{|l|}{ Mauá } \\
\hline Média \pm dp & $0,8 \pm 3,0$ & $2,7 \pm 5,6$ & $9,5 \pm 11,3$ & $6,3 \pm 11,7$ & $7,9 \pm 11,4$ & $2,9 \pm 6,0$ & $4,5 \pm 10,0$ & $0 \pm 0$ & $0 \pm 0$ \\
\hline (Min-Max) & $0-11,8$ & $0-15,3$ & $0-30,5$ & $0-33,5$ & $0-35,3$ & $0-15,2$ & $0-33,5$ & $0-0$ & $0-0$ \\
\hline \multicolumn{10}{|l|}{ Ribeirão Pires } \\
\hline Média $\pm d p$ & $0 \pm 0$ & $3,4 \pm 13,3$ & $0 \pm 0$ & $11,4 \pm 23,7$ & $3,5 \pm 13,5$ & $3,4 \pm 13,3$ & $0 \pm 0$ & $0 \pm 0$ & $0 \pm 0$ \\
\hline (Min-Max) & $0-0$ & $0-51,7$ & $0-0$ & $0-63,5$ & $0-52,2$ & $0-51,7$ & $0-0$ & $0-0$ & $0-0$ \\
\hline \multicolumn{10}{|l|}{ Rio Grande Serra } \\
\hline Média $\pm d p$ & $0 \pm 0$ & $11,0 \pm 42,5$ & $48,9 \pm 72, C$ & $8,0 \pm 31,1$ & $57,2 \pm 73,2$ & $9,7 \pm 37,7$ & $0 \pm 0$ & $0 \pm 0$ & $0 \pm 0$ \\
\hline (Min-Max) & $0-0$ & $0-164,7$ & $0-164,7$ & $0-120,6$ & $0-169,2$ & $0-146,2$ & $0-0$ & $0-0$ & $0-0$ \\
\hline \multicolumn{10}{|l|}{ Santo André } \\
\hline Média $\pm d p$ & $0,6 \pm 2,3$ & $1,5 \pm 4,0$ & $9,8 \pm 9,4$ & $3,7 \pm 7,6$ & $4,8 \pm 6,8$ & $10,7 \pm 10,0$ & $1,9 \pm 4,0$ & $0,6 \pm 2,2$ & $0 \pm 0$ \\
\hline (Min-Max) & $0-9,2$ & $0-11,6$ & $0-27,2$ & $0-27,2$ & $0-22,0$ & $0-32,6$ & $0-11,4$ & $0-8,6$ & $0-0$ \\
\hline \multicolumn{10}{|l|}{ São Bernardo do Campo } \\
\hline Média $\pm d p$ & $0 \pm 0$ & $3,6 \pm 5,7$ & $7,6 \pm 8,2$ & $6,0 \pm 6,2$ & $7,9 \pm 9,6$ & $5,0 \pm 7,0$ & $2,8 \pm 6,0$ & $0 \pm 0$ & $0 \pm 0$ \\
\hline (Min-Max) & $0-0$ & $0-18,4$ & $0-26,8$ & $0-22,5$ & $0-36,4$ & $0-18,2$ & $0-17,9$ & $0-0$ & $0-0$ \\
\hline \multicolumn{10}{|l|}{ São Caetano do Sul } \\
\hline Média $\pm d p$ & $0 \pm 0$ & $0 \pm 0$ & $0 \pm 0$ & $14,9 \pm 32,4$ & $7,6 \pm 20,1$ & $7,3 \pm 19,3$ & $7,5 \pm 29,2$ & $3,8 \pm 14,6$ & $0 \pm 0$ \\
\hline (Min-Max) & $0-0$ & $0-0$ & $0-0$ & $0-104,8$ & $0-57,4$ & $0-57,2$ & $0-113,1$ & $0-56,6$ & $0-0$ \\
\hline Nível de significância ${ }^{\&}$ & 0,54 & $\mathbf{0 , 1 7}$ & $<0,01$ & 0,29 & 0,11 & $\mathbf{0 , 0 5}$ & $\mathbf{0 , 1 0}$ & 0,67 & $\mathbf{0 , 4 2}$ \\
\hline
\end{tabular}

\&:Teste kruskal-Wallis; $\mathrm{p}=$ nível de significância estatística $(\mathrm{p}<0,05)$. 
A tabela 10 apresenta a análise descritiva para as variáveis Índice da Mortalidade Materna Direta total e por grupo IDH por residência, em relação ao estado civil. Observa-se que não há diferenças entre os dois grupos de estudo. Observamos também a ausência de mortes maternas em mulheres separadas no grupo 2 estratificado por IDH.

Tabela 10. Índice Mortalidade Materna Direta por estado civil e IDH

\begin{tabular}{|c|c|c|c|c|c|}
\hline & \multicolumn{5}{|c|}{ Índice por Estado Civil } \\
\hline & Solteiro & Casado & Viúvo & Separado & Outro \\
\hline \multicolumn{6}{|l|}{ Grupo Todo } \\
\hline Média \pm dp & $24,2 \pm 43,5$ & $16,6 \pm 32,8$ & $2,8 \pm 18,0$ & $0,4 \pm 1,9$ & $2,4 \pm 13,6$ \\
\hline Mínimo-Máximo & $0-287,7$ & $0-164,7$ & $0-169,2$ & $0-11,3$ & $0-128,8$ \\
\hline \multicolumn{6}{|l|}{ Grupo 1} \\
\hline Média $\pm d p$ & $17,1 \pm 24,7$ & $15,0 \pm 22,8$ & $1,8 \pm 8,6$ & $1,0 \pm 2,9$ & $0,8 \pm 2,8$ \\
\hline Mínimo-Máximo & $0-113,1$ & $0-113,1$ & $0-56,5$ & $0-11,3$ & $0-10,9$ \\
\hline \multicolumn{6}{|l|}{ Grupo 2} \\
\hline Média $\pm d p$ & $29,6 \pm 53,0$ & $17,8 \pm 38,8$ & $3,6 \pm 22,7$ & $0 \pm 0$ & $3,6 \pm 17,9$ \\
\hline Mínimo-Máximo & $0-287,7$ & $0-164,7$ & $0-169,2$ & $0-0$ & $0-128,8$ \\
\hline Nível de Significância ${ }^{\&}$ & 0,66 & $\mathbf{0 , 3 1}$ & 0,25 & $\mathbf{0 , 0}$ & $\mathbf{0 , 9 7}$ \\
\hline
\end{tabular}

\&:Teste U de Mann-Whitney, Grupo 1-IDH Muito Alto; Grupo 2=IDH Alto 
A figura 5 apresenta os índices da Mortalidade Materna Direta por IDH (A) e município (B) em relação ao estado civil. Observamos que Rio Grande da Serra apresenta os maiores Índices da Mortalidade Materna Direta em mulheres solteiras ( $\mathrm{p}=0,03)$, casadas $(\mathrm{p}=0,02)$ e separadas $(\mathrm{p}=0,03)$ quando comparadas aos outros municípios.
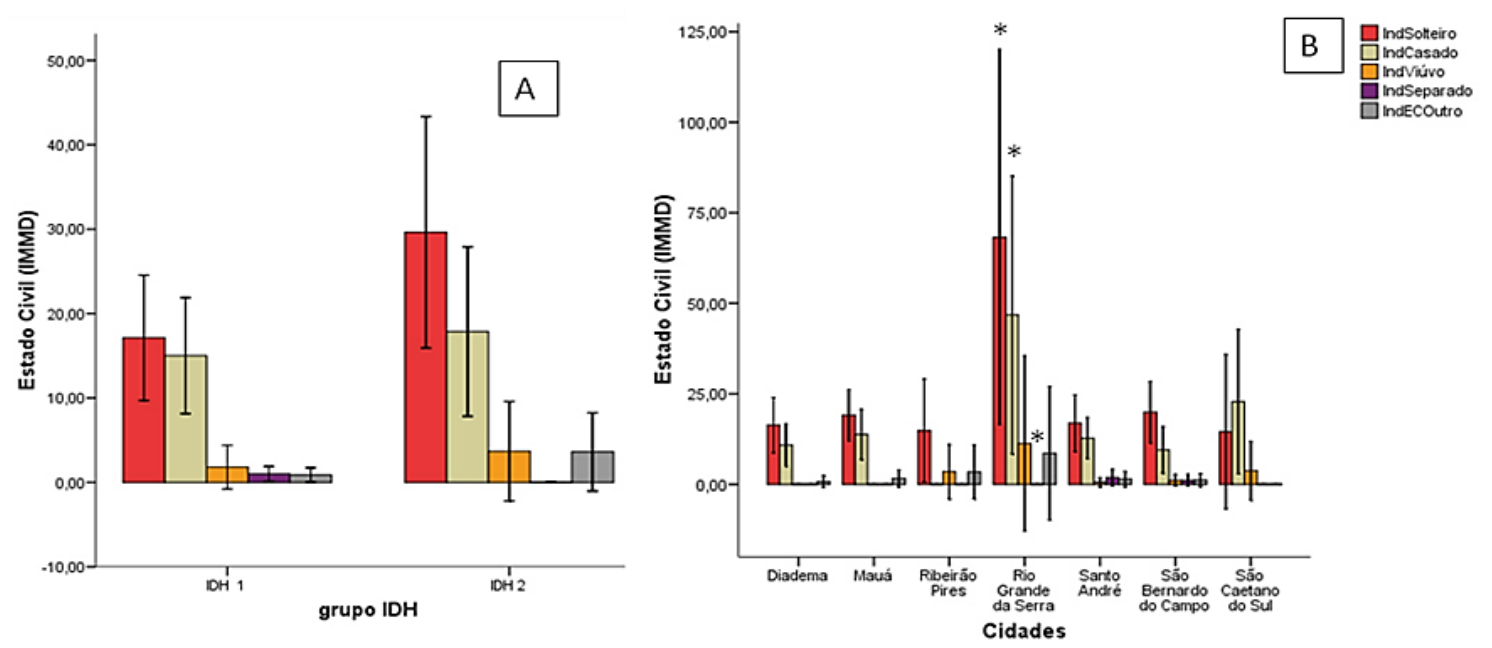

Valores expressos por média e IC95\%; IMMD: Índice da Mortalidade Materna Direta; IDH: Índice de Desenvolvimento Humano: IDH 1: IDH muito alto (municípios Santo André, São Bernardo do Campo e São Caetano do Sul); IDH 2: IDH alto (municípios Diadema, Mauá, Ribeirão Pires e Rio Grande da Serra). *p<0,03.

Figura 5. Índices da Mortalidade Materna Direta (IMMD) por IDH e municípios estratificados em relação ao estado civil

A tabela 11 apresenta a análise descritiva para as variáveis Índice da Mortalidade Materna Direta por municípios na região do Grande ABC Paulista e estado civil. Observa-se que há diferenças entre os municípios para o estado civil solteiro e casado onde o município de Rio Grande da Serra difere dos demais ( $p=0,03$ e $p=0,02$ respectivamente (teste de Kurskal Wallis e Pos Hoc teste de Dunn). Para o estado civil separado, o município de Santo André difere de Diadema, Mauá, Ribeirão Pires, Rio Grande da Serra e São Caetano do Sul $(\mathrm{p}=0,01)$. 
Tabela 11. Índice da Mortalidade Materna Direta por municípios e estado civil

\begin{tabular}{|c|c|c|c|c|c|}
\hline \multirow[b]{2}{*}{ Municípios } & \multicolumn{5}{|c|}{ Estado Civil } \\
\hline & Solteiro & Casado & Viúvo & Separado & Outro \\
\hline \multicolumn{6}{|l|}{ Diadema } \\
\hline Média \pm & $16,3 \pm 13,7$ & $10,8 \pm 10,3$ & $0 \pm 0$ & $0 \pm 0$ & $0,7 \pm 2,9$ \\
\hline Mínimo-Máximo & $0-43,6$ & $0-29,1$ & $0-0$ & $0-0$ & $0-11,3$ \\
\hline \multicolumn{6}{|l|}{ Mauá } \\
\hline Média $\pm d p$ & $19,0 \pm 12,8$ & $13,8 \pm 12,4$ & $0 \pm 0$ & $0 \pm 0$ & $1,6 \pm 4,3$ \\
\hline Mínimo-Máximo & $0-37,2$ & $0-33,4$ & $0-0$ & $0-0$ & $0-12,7$ \\
\hline \multicolumn{6}{|l|}{ Ribeirão Pires } \\
\hline Média $\pm d p$ & $14,8 \pm 25,6$ & $0 \pm 0$ & $3,4 \pm 13,4$ & $0 \pm 0$ & $3,4 \pm 13,3$ \\
\hline Mínimo-Máximo & $0-63,5$ & $0-0$ & $0-52,1$ & $0-0$ & $0-51,6$ \\
\hline \multicolumn{6}{|l|}{ Rio Grande da Serra } \\
\hline $\begin{array}{l}\text { Média } \pm d p \\
\text { Média } \pm d p\end{array}$ & $68,2 \pm 93,4$ & $46,7 \pm 69,2$ & $11,2 \pm 43,6$ & $0 \pm 0$ & $8,5 \pm 33,2$ \\
\hline Mínimo-Máximo & $0-287,7$ & $0-164,7$ & $0-169,2$ & $0-0$ & $0-128,8$ \\
\hline \multicolumn{6}{|l|}{ Santo André } \\
\hline Média $\pm d p$ & $16,9 \pm 14,0$ & $12,7 \pm 10,3$ & $0,58 \pm 2,2$ & $1,91 \pm 4,0$ & $1,45 \pm 3,8$ \\
\hline Mínimo- Máximo & $0-54,3$ & $0-32,6$ & $0-8,6$ & $0-11,4$ & $0-10,9$ \\
\hline \multicolumn{6}{|l|}{ São Bernardo do Campo } \\
\hline Média $\pm d p$ & $19,9 \pm 15,3$ & $9,5 \pm 11,5$ & $1,0 \pm 2,9$ & $1,1 \pm 2,9$ & $1,19 \pm 3,1$ \\
\hline Mínimo- Máximo & $0-62,5$ & $0-36,4$ & $0-8,8$ & $0-9,1$ & $0-9,1$ \\
\hline \multicolumn{6}{|l|}{ São Caetano do Sul } \\
\hline Média $\pm d p$ & $14,5 \pm 38,4$ & $22,8 \pm 36,0$ & $3,7 \pm 14,6$ & $0 \pm 0$ & $0 \pm 0$ \\
\hline Mínimo- Máximo & $0-113,1$ & $0-113,1$ & $0-56,6$ & $0-0$ & $0-0$ \\
\hline Nível de significância ${ }^{\&}$ & $\mathbf{0 , 0 3}$ & $\mathbf{0 , 0 2}$ & 0,76 & $\mathbf{0 , 0 3}$ & $\mathbf{0 , 8 5}$ \\
\hline
\end{tabular}

\&:Teste kruskal-Wallis 
A tabela 12 apresenta a análise descritiva para as variáveis Índice da Mortalidade Materna Direta (IMMD) total e por IDH em relação à escolaridade. Observa-se que não há diferenças entre os dois grupos de estudo.

Tabela 12. Índice Mortalidade Materna Direta por escolaridade (anos de estudo) e IDH

\begin{tabular}{|c|c|c|c|c|c|c|}
\hline & \multicolumn{5}{|c|}{ Índice de Escolaridade (anos de estudo) } & \multirow[b]{2}{*}{ Ignorado } \\
\hline & 1 a 3 & 4 a 7 & 8 a 11 & 12 a mais & Nenhuma & \\
\hline \multicolumn{7}{|l|}{ Grupo total } \\
\hline Média $\pm d p$ & $8,0 \pm 27,0$ & $14,7 \pm 40,4$ & $7,6 \pm 24,73$ & $4,2 \pm 17,4$ & $1,2 \pm 8,2$ & $8,7 \pm 25,1$ \\
\hline Mínimo-Máximo & $0-169,2$ & $0-287,7$ & $0-164,7$ & $0-124,2$ & $0-63,5$ & $0-169,7$ \\
\hline \multicolumn{7}{|l|}{ Grupo 1} \\
\hline Média $\pm d p$ & $4,0 \pm 9,7$ & $10,3 \pm 19,9$ & $5,0 \pm 8,7$ & $5,3 \pm 18,9$ & $0,1 \pm 1,1$ & $9,5 \pm 27,8$ \\
\hline Mínimo-Máximo & $0-57,4$ & $0-104,8$ & $0-35,7$ & $0-113,1$ & $0-7,5$ & $0-169,7$ \\
\hline \multicolumn{7}{|l|}{ Grupo 2} \\
\hline Média $\pm d p$ & $11,0 \pm 34,6$ & $18,0 \pm 50,5$ & $9,6 \pm 31,8$ & $3,3 \pm 16,4$ & $1,9 \pm 10,7$ & $8,2 \pm 23,1$ \\
\hline Mínimo-Máximo & $0-169,2$ & $0-287,7$ & $0-164,7$ & $0-124,2$ & $0-63,5$ & $0-128,9$ \\
\hline Nível de significância ${ }^{\&}$ & 0,91 & $\mathbf{0 , 3 7}$ & 0,29 & 0,29 & $\mathbf{0 , 7 2}$ & 0,54 \\
\hline
\end{tabular}

\footnotetext{
\&:Teste U de Mann-Whitney, Grupo 1-IDH Muito Alto; Grupo 2=IDH Alto
} 
A figura 6 apresenta os índices da Mortalidade Materna Direta (IMMD) por IDH (A) e municípios (B) em relação à escolaridade. Observamos que Santo André apresenta menores índices de mortes maternas de mulheres com escolaridade entre 8 a 11 anos que os outros municípios.
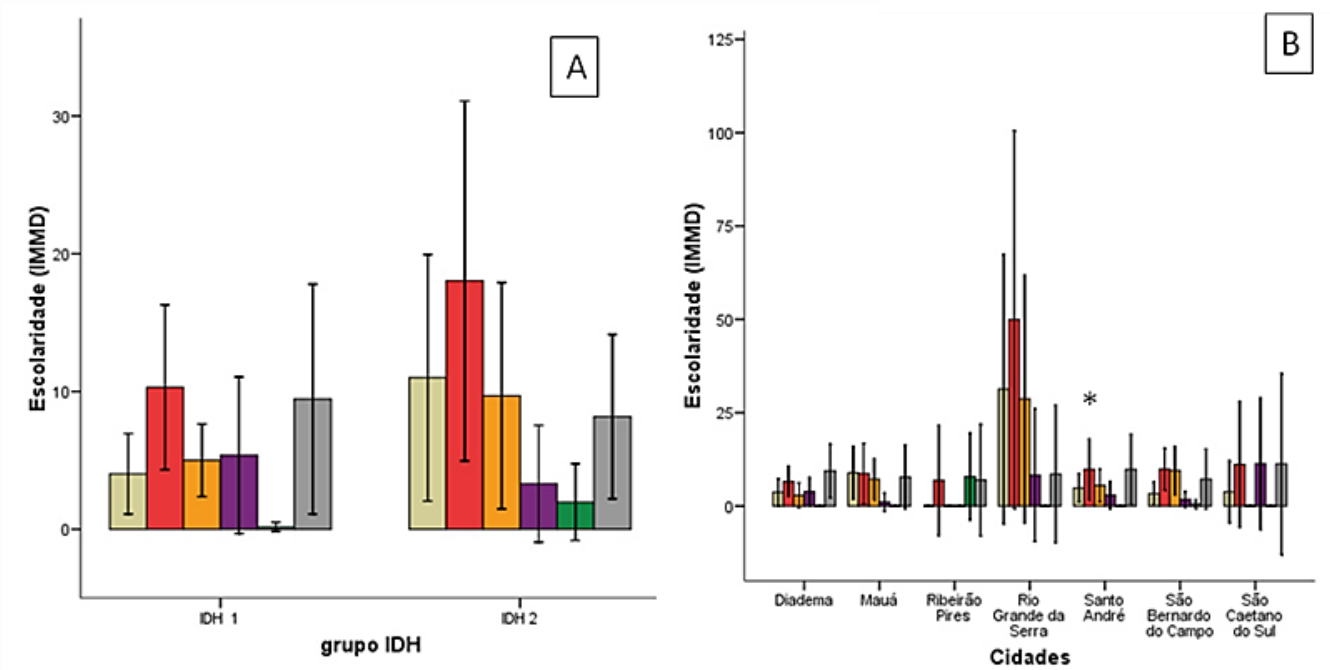

Valores expressos por média e IC95\%; IMMD: Índice da Mortalidade Materna Direta; IDH: Índice de Desenvolvimento Humano: IDH 1: IDH muito alto (municípios Santo André, São Bernardo do Campo e São Caetano do Sul); IDH 2: IDH alto (municípios Diadema, Mauá, Ribeirão Pires e Rio Grande da Serra); *p<0,01.

Figura 6. Índice da Mortalidade Materna Direta (IMMD) por IDH (A) e município (B) estratificados por escolaridade

A tabela 13 apresenta a análise descritiva para as variáveis Índice da Mortalidade Materna Direta por municípios na região do Grande ABC Paulista e escolaridade (anos de estudo). Observa-se que há diferenças para a faixa de escolaridade de 8 a 11 anos onde o município de Santo André difere dos demais, exceto o município de São Bernardo do Campo $(\mathrm{p}<0,01)$. 
Tabela 13. Índice da Mortalidade Materna por municípios e escolaridade (anos de estudo)

\begin{tabular}{|c|c|c|c|c|c|c|}
\hline \multirow[b]{2}{*}{ Municípios } & \multicolumn{6}{|c|}{ Índice da mortalidade materna por escolaridade (anos de estudo) } \\
\hline & 1 a 3 & 4 a 7 & 8 a 11 & 12 a mais & Nenhuma & Ignorado \\
\hline \multicolumn{7}{|l|}{ Diadema } \\
\hline Média $\pm d p$ & $3,7 \pm 6,5$ & $6,5 \pm 7,3$ & $2,8 \pm 5,9$ & $3,8 \pm 6,6$ & $0 \pm 0$ & $9,4 \pm 12,9$ \\
\hline Mínimo-Máximo & $0-15,9$ & $0-15,9$ & $0-14,8$ & $0-15,0$ & $0-0$ & $0-34,2$ \\
\hline \multicolumn{7}{|l|}{ Mauá } \\
\hline Média \pm dp & $8,9 \pm 12,5$ & $8,7 \pm 14,6$ & $7,2 \pm 9,9$ & $1,1 \pm 4,3$ & $0 \pm 0$ & $7,7 \pm 15,5$ \\
\hline Mínimo-Máximo & $0-34,8$ & $0-45,4$ & $0-30,5$ & $0-16,7$ & $0-0$ & $0-49,6$ \\
\hline \multicolumn{7}{|l|}{ Ribeirão Pires } \\
\hline Média $\pm d p$ & $0 \pm 0$ & $6,8 \pm 26,6$ & $0 \pm 0$ & $0 \pm 0$ & $7,9 \pm 20,9$ & $6,9 \pm 26,9$ \\
\hline Mínimo-Máximo & $0-0$ & $0-103,3$ & $0-0$ & $0-0$ & $0-63,5$ & $0-104,3$ \\
\hline \multicolumn{7}{|l|}{ Rio Grande da Serra } \\
\hline Média $\pm d p$ & $31,3 \pm 64,9$ & $49,9 \pm 91,2$ & $28,6 \pm 59,8$ & $8,2 \pm 32,0$ & $0 \pm 0$ & $8,5 \pm 33,2$ \\
\hline Mínimo-Máximo & $0-169,0$ & $0-287,7$ & $0-164,7$ & $0-124,2$ & $0-0$ & $0-128,8$ \\
\hline \multicolumn{7}{|l|}{ Santo André } \\
\hline Média $\pm d p$ & $4,8 \pm 6,7$ & $9,8 \pm 14,6$ & $5,5 \pm 7,7$ & $2,9 \pm 6,6$ & $0 \pm 0$ & $9,8 \pm 16,7$ \\
\hline Mínimo-Máximo & $0-21,6$ & $0-40,7$ & $0-23,2$ & $0-22,6$ & $0-0$ & $0-63,3$ \\
\hline \multicolumn{7}{|l|}{ São Bernardo do Campo } \\
\hline Média $\pm d p$ & $3,3 \pm 5,4$ & $9,9 \pm 10,0$ & $9,5 \pm 11,5$ & $1,8 \pm 3,7$ & $0,5 \pm 1,9$ & $7,2 \pm 14,5$ \\
\hline Mínimo-Máximo & $0-17,6$ & $0-35,7$ & $0-35,7$ & $0-9,0$ & $0-7,5$ & $0-44,2$ \\
\hline \multicolumn{7}{|l|}{ São Caetano do Sul } \\
\hline Média $\pm d p$ & $3,8 \pm 14,8$ & $11,1 \pm 30,4$ & $0 \pm 0$ & $11,3 \pm 31,7$ & $0 \pm 0$ & $11,3 \pm 43,8$ \\
\hline Mínimo-Máximo & $0-57,4$ & $0-104,8$ & $0-0$ & $0-113,1$ & $0-0$ & $0-169,6$ \\
\hline Nível de significância ${ }^{\&}$ & 0,09 & $\mathbf{0 , 1 0}$ & $<0,01$ & $\mathbf{0 , 3 9}$ & 0,18 & $\mathbf{0 , 0 8}$ \\
\hline
\end{tabular}

\&:Teste kruskal-Wallis 
As tabelas 14A e 14 B apresentam a análise descritiva para as variáveis Índice da Mortalidade Materna Direta por causas (CID 10) ${ }^{26}$ e grupo de estudo. Observa-se que não há diferenças entre os dois grupos de estudo.

Tabela 14A. Índice Mortalidade Materna Direta por causas (CID 10) e grupo de estudo

\begin{tabular}{|c|c|c|c|c|c|c|}
\hline & \multicolumn{6}{|c|}{ Índice da Mortalidade Materna Causas (CID 10) } \\
\hline & NE & Outras & $\begin{array}{c}\text { Infecções } \\
\text { prévias }\end{array}$ & $\begin{array}{c}\text { Infecção } \\
\text { puerperal }\end{array}$ & $\begin{array}{c}\text { Hemorragia } \\
\text { e outros }\end{array}$ & Eclâmpsia \\
\hline \multicolumn{7}{|l|}{ Grupo Total } \\
\hline Média \pm dp & $0,1 \pm 1,0$ & $5,1 \pm 11$ & $1,4 \pm 4,7$ & $2,1 \pm 7,7$ & $7,9 \pm 21,5$ & $6,6 \pm 17,0$ \\
\hline Mínimo-Máximo & $0-10,8$ & $0-59,9$ & $0-29,1$ & $0-68,4$ & $0-155,0$ & $0-128,8$ \\
\hline \multicolumn{7}{|l|}{ Grupo 1} \\
\hline Média $\pm d p$ & $0,2 \pm 1,6$ & $5,2 \pm 8,6$ & $1,4 \pm 3,3$ & $1,9 \pm 4,6$ & $4,8 \pm 8,0$ & $2,9 \pm 5,7$ \\
\hline Mínimo-Máximo & $0-10,8$ & $0-27,5$ & $0-11,3$ & $0-23,2$ & $0-27,5$ & $0-21,9$ \\
\hline \multicolumn{7}{|l|}{ Grupo 2} \\
\hline Média $\pm d p$ & $0 \pm 0$ & $5,1 \pm 12,5$ & $1,5 \pm 5,6$ & $2,2 \pm 9,4$ & $10,1 \pm 27,4$ & $9,4 \pm 21,7$ \\
\hline Mínimo-Máximo & $0-0$ & $0-59,9$ & $0-29,1$ & $0-68,4$ & $0-155,0$ & $0-128,8$ \\
\hline Nível de significância $^{\&}$ & 0,25 & 0,22 & $\mathbf{0 , 3 5}$ & $\mathbf{0 , 3 5}$ & $\mathbf{0 , 8 2}$ & 0,26 \\
\hline
\end{tabular}

Tabela 14B. Índice Mortalidade Materna Direta por causas (CID 10) e grupo de estudo (continuação)

\begin{tabular}{|c|c|c|c|c|c|c|c|}
\hline & \multicolumn{7}{|c|}{ Índice da Mortalidade Materna Causas (CID 10) } \\
\hline & Complicações $^{\text {a }}$ & $\begin{array}{l}\text { Aborto } \\
\text { NE }\end{array}$ & $\begin{array}{c}\text { Embolia } \\
\text { origem } \\
\text { obstétrica }\end{array}$ & $\begin{array}{c}\text { Outros } \\
\text { produtos } \\
\text { anormais da } \\
\text { concepção } \\
\end{array}$ & $\begin{array}{c}\text { Outros } \\
\text { traumas } \\
\text { obstétricos }\end{array}$ & $\begin{array}{c}\text { Diabete } \\
\text { melito na } \\
\text { gravidez }\end{array}$ & Assistência $^{b}$ \\
\hline \multicolumn{8}{|l|}{ Grupo Total } \\
\hline Média \pm dp & $4,1 \pm 20,3$ & $4,2 \pm 16,3$ & $0,4 \pm 2,2$ & $0,2 \pm 1,6$ & $0,2 \pm 1,5$ & $0,1 \pm 1,3$ & $0,1 \pm 1,3$ \\
\hline Mínimo-Máximo & $0-151,0$ & $0-128,8$ & $0-15,9$ & $0-11,7$ & $0-14,1$ & $0-13,5$ & $0-10,9$ \\
\hline \multicolumn{8}{|l|}{ Grupo 1} \\
\hline Média \pm dp & $0,7 \pm 3,0$ & $1,9 \pm 5,0$ & $0,7 \pm 2,5$ & $0,4 \pm 1,8$ & $0,1 \pm 1,1$ & $0 \pm 0$ & $0,4 \pm 2,0$ \\
\hline Mínimo-Máximo & $0-17,6$ & $0-22,5$ & $0-10,8$ & $0-9,0$ & $0-7,7$ & $0-0$ & $0-10,9$ \\
\hline \multicolumn{8}{|l|}{ Grupo 2} \\
\hline Média $\pm d p$ & $6,6 \pm 26,5$ & $6,0 \pm 21,0$ & $0,2 \pm 2,0$ & $0,2 \pm 1,5$ & $0,2 \pm 1,8$ & $0,2 \pm 1,7$ & $0 \pm 0$ \\
\hline Mínimo-Máximo & $0-151,0$ & $0-128,8$ & $0-15,9$ & $0-11,7$ & $0-14,1$ & $0-13,5$ & $0-0$ \\
\hline Nível de significân & ncia $^{\&} \quad 0,49$ & 0,92 & 0,09 & 0,41 & $\mathbf{0 , 8 5}$ & $\mathbf{0 , 3 9}$ & $\mathbf{0 , 1 0}$ \\
\hline
\end{tabular}


A figura 7 apresenta o índice de MMD por grupos IDH (A) e por municípios (B) estratificados pelas causas do óbito classificadas pela Classificação Internacional de Doenças $(\text { CID } 10)^{26}$. Observa-se que as causas principais da mortalidade materna são Hemorragias/Tromboses/Embolias e Eclâmpsias em Ribeirão Pires e Rio Grande da Serra respectivamente, quando comparados a outros municípios (C), porém sem significância quando comparados os grupos estratificados por IDH (A).

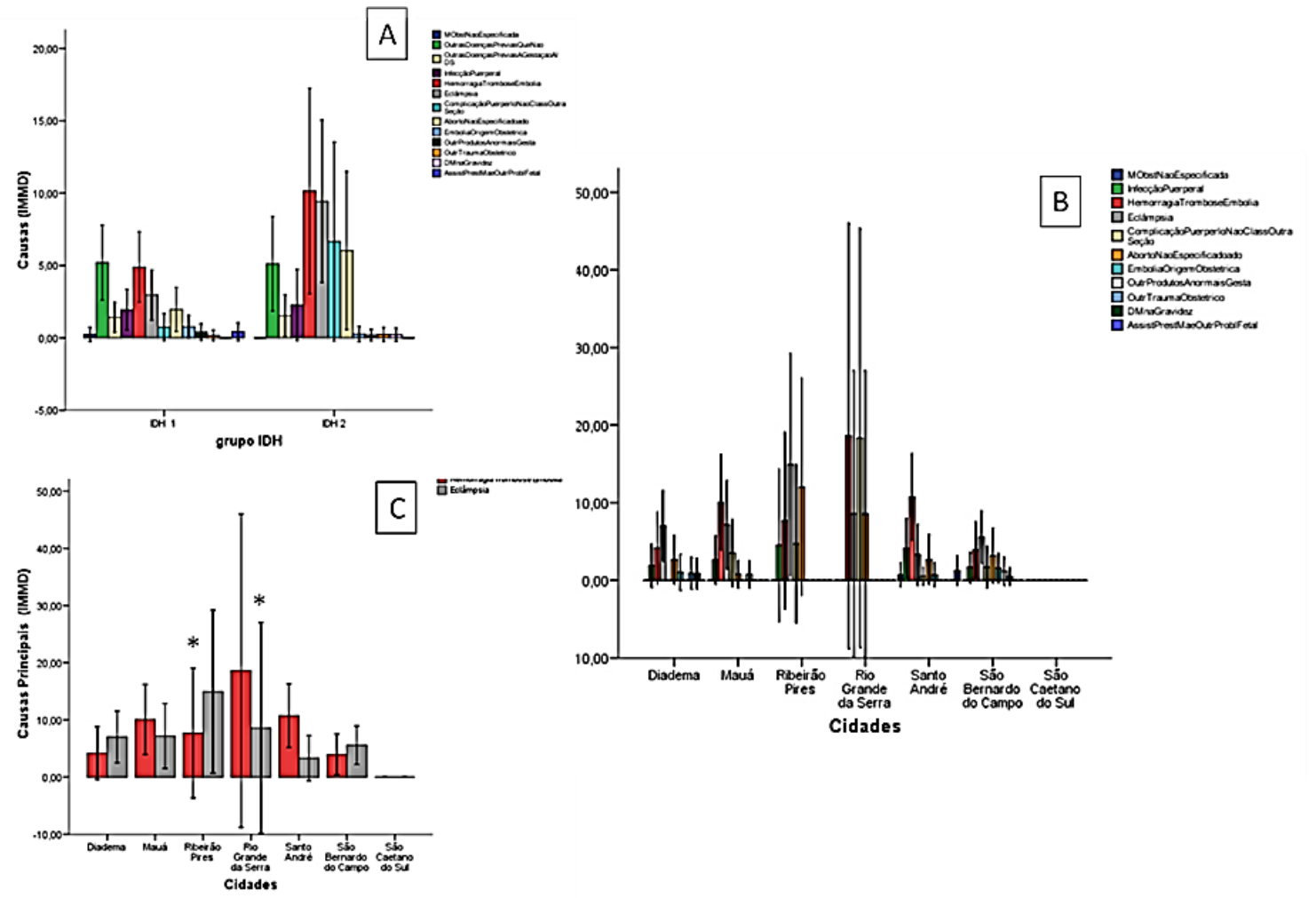

Valores expressos por média e IC95\%; IMMD: Índice da Mortalidade Materna Direta; IDH: Índice de Desenvolvimento Humano: IDH 1: IDH muito alto (municípios Santo André, São Bernardo do Campo e São Caetano do Sul); IDH 2: IDH alto (municípios Diadema, Mauá, Ribeirão Pires e Rio Grande da Serra); *p $\leq 0,02$.

Figura 7. IMMD causas (CID 10), por grupo IDH (A), por municípios (B) e pelas causas principais por municípios (C) 
As tabelas 15A e 15B apresentam a análise descritiva para as variáveis Índice da Mortalidade Materna Direta por municípios na região do Grande ABC Paulista e causa $(\mathrm{CID} 10)^{26}$ do óbito. Observa-se que há diferenças entre Mortalidade Materna Direta por outras doenças prévias onde os municípios de São Caetano do Sul e Rio Grande da Serra diferem dos municípios de Mauá, Ribeirão Pires e São Bernardo do Campo ( $p<0,01)$. Já para hemorragia apenas o município de Rio Grande da Serra difere de São Caetano do Sul (p<0,01); e para eclâmpsia o município de São Caetano do Sul difere de Ribeirão Pires ( $\mathrm{p}=0,02)$.

Tabela 15A. Índice da Mortalidade Materna Direta por causas (CID 10) e municípios

\begin{tabular}{|c|c|c|c|c|c|c|}
\hline \multirow[b]{2}{*}{ Municípios } & \multicolumn{6}{|c|}{ Índice da mortalidade materna por Causas (CID 10) } \\
\hline & $\begin{array}{c}\text { Não } \\
\text { especificada }\end{array}$ & $\begin{array}{l}\text { Outras doenças prévias } \\
\text { que não complicaram } \\
\text { no parto ou puerpério }\end{array}$ & $\begin{array}{l}\text { Infecções } \\
\text { prévias a } \\
\text { gestação }\end{array}$ & $\begin{array}{l}\text { Infecção } \\
\text { puerperal }\end{array}$ & Hemorragia & Eclâmpsia \\
\hline \multicolumn{7}{|l|}{ Diadema } \\
\hline Média $\pm d p$ & $0 \pm 0$ & $4,7 \pm 10,2$ & $4,5 \pm 10,0$ & $1,9 \pm 5,0$ & $4,2 \pm 8,3$ & $7,0 \pm 8,1$ \\
\hline Mínimo-Máximo & $0-0$ & $0-30,1$ & $0-29,1$ & $0-15,0$ & $0-29,1$ & $0-22,4$ \\
\hline \multicolumn{7}{|l|}{ Mauá } \\
\hline Média $\pm d p$ & $0 \pm 0$ & $7,8 \pm 9,0$ & $1,6 \pm 4,2$ & $2,6 \pm 5,5$ & $10,0 \pm 11,0$ & $7,1 \pm 10,2$ \\
\hline Mínimo-Máximo & $0-0$ & $0-24,6$ & $0-12,4$ & $0-15,2$ & $0-30,5$ & $0-33,4$ \\
\hline \multicolumn{7}{|l|}{ Ribeirão Pires } \\
\hline Média $\pm d p$ & $0 \pm 0$ & $7,8 \pm 20,8$ & $0 \pm 0$ & $4,5 \pm 17,6$ & $7,7 \pm 20,4$ & $14,9 \pm 25,7$ \\
\hline Mínimo-Máximo & $0-0$ & $0-59,9$ & $0-0$ & $0-68,4$ & $0-63,5$ & $0-59,9$ \\
\hline \multicolumn{7}{|c|}{ Rio Grande da Serra } \\
\hline Média $\pm d p$ & $0 \pm 0$ & $0 \pm 0$ & $0 \pm 0$ & $0 \pm 0$ & $18,6 \pm 49,4$ & $8,5 \pm 33,2$ \\
\hline Mínimo-Máximo & $0-0$ & $0-0$ & $0-0$ & $0-0$ & $0-155,0$ & $0-128,8$ \\
\hline \multicolumn{7}{|l|}{ Santo André } \\
\hline Média $\pm d p$ & $0,7 \pm 2,7$ & $7,4 \pm 9,5$ & $2,0 \pm 4,3$ & $4,1 \pm 6,8$ & $10,7 \pm 10,0$ & $3,3 \pm 7,1$ \\
\hline Mínimo-Máximo & $0-10,8$ & $0-25,9$ & $0-11,3$ & $0-23,2$ & $0-27,5$ & $0-21,9$ \\
\hline \multicolumn{7}{|c|}{ São Bernardo do Campo } \\
\hline Média $\pm d p$ & $0 \pm 0$ & $8,1 \pm 9,9$ & $2,1 \pm 3,7$ & $1,7 \pm 3,5$ & $3,9 \pm 6,4$ & $5,5 \pm 6,0$ \\
\hline Mínimo-Máximo & $0-0$ & $0-27,5$ & $0-8,9$ & $0-9,0$ & $0-17,8$ & $0-18,1$ \\
\hline \multicolumn{7}{|c|}{ São Caetano do Sul } \\
\hline Média $\pm d p$ & $0 \pm 0$ & $0 \pm 0$ & $0 \pm 0$ & $0 \pm 0$ & $0 \pm 0$ & $0 \pm 0$ \\
\hline Mínimo-Máximo & $0-0$ & $0-0$ & $0-0$ & $0-0$ & $0-0$ & $0-0$ \\
\hline $\begin{array}{l}\text { Nível de } \\
\text { significância }^{\&}\end{array}$ & $\mathbf{0 , 4 2}$ & $<\mathbf{0 , 0 1}$ & $\mathbf{0 , 0 9}$ & 0,09 & $<0,01$ & $\mathbf{0 , 0 2}$ \\
\hline
\end{tabular}


Tabela 15B Índice da Mortalidade Materna por causas (CID 10) e municípios

\begin{tabular}{|c|c|c|c|c|c|c|c|}
\hline \multirow[b]{2}{*}{ Municípios } & \multicolumn{7}{|c|}{ Índice da Mortalidade Materna por causas (CID 10) } \\
\hline & $\begin{array}{c}\text { Complicações } \\
\text { no puerpério } \\
\text { não } \\
\text { classificadas } \\
\text { em } \\
\text { outra seção }\end{array}$ & $\begin{array}{c}\text { Aborto } \\
\text { não } \\
\text { especifica } \\
\text { do }\end{array}$ & $\begin{array}{c}\text { Embolia } \\
\text { origem } \\
\text { obstétrica }\end{array}$ & $\begin{array}{c}\text { Outros } \\
\text { produtos } \\
\text { anormais } \\
\text { da } \\
\text { concepção }\end{array}$ & $\begin{array}{c}\text { Outros } \\
\text { traumas } \\
\text { obstétricos }\end{array}$ & $\begin{array}{c}\text { Diabete } \\
\text { Melito }\end{array}$ & $\begin{array}{c}\text { Assist } \\
\text { prest mae } \\
\text { outr probl } \\
\text { fet conhec } \\
\text { susp }\end{array}$ \\
\hline \multicolumn{8}{|l|}{ Diadema } \\
\hline Média $\pm d p$ & $0 \pm 0$ & $0 \pm 5,6$ & $0 \pm 4,1$ & $0 \pm 0$ & $0 \pm 3,6$ & $0 \pm 3,4$ & $0 \pm 0$ \\
\hline Mínimo-Máximo & $0-0$ & $0-14,8$ & $0-15,9$ & $0-0$ & $0-14,1$ & $0-13,5$ & $0-0$ \\
\hline \multicolumn{8}{|l|}{ Mauá } \\
\hline Média $\pm d p$ & $3,5 \pm 7,7$ & $0,8 \pm 3,1$ & $0 \pm 0$ & $0,7 \pm 3,0$ & $0 \pm 0$ & $0 \pm 0$ & $0 \pm 0$ \\
\hline Mínimo-Máximo & $0-25,5$ & $0-12,3$ & $0-0$ & $0-11,7$ & $0-0$ & $0-0$ & $0-0$ \\
\hline \multicolumn{8}{|l|}{ Ribeirão Pires } \\
\hline Média $\pm d p$ & $4,7 \pm 18,3$ & $12,0 \pm 25,1$ & $0 \pm 0$ & $0 \pm 0$ & $0 \pm 0$ & $0 \pm 0$ & $0 \pm 0$ \\
\hline Mínimo-Máximo & $0-70,9$ & $0-70,9$ & $0-0$ & $0-0$ & $0-0$ & $0-0$ & $0-0$ \\
\hline \multicolumn{8}{|c|}{ Rio Grande da Serra } \\
\hline Média \pm dp & $18,3 \pm 48,7$ & $8,5 \pm 33,2$ & $0 \pm 0$ & $0 \pm 0$ & $0 \pm 0$ & $0 \pm 0$ & $0 \pm 0$ \\
\hline Mínimo-Máximo & $0-151,0$ & $0-128,8$ & $0-0$ & $0-0$ & $0-0$ & $0-0$ & $0-0$ \\
\hline \multicolumn{8}{|l|}{ Santo André } \\
\hline Média \pm dp & $0,5 \pm 2,1$ & $2,6 \pm 5,7$ & $0,7 \pm 2,7$ & $0 \pm 0$ & $0 \pm 0$ & $0 \pm 0$ & $1,2 \pm 3,4$ \\
\hline Mínimo-Máximo & $0-8,1$ & $0-18,1$ & $0-10,8$ & $0-0$ & $0-0$ & $0-0$ & $0-10,9$ \\
\hline \multicolumn{8}{|c|}{ São Bernardo do Campo } \\
\hline Média $\pm d p$ & $1,6 \pm 4,8$ & $3,2 \pm 6,3$ & $1,5 \pm 3,3$ & $1,2 \pm 3,1$ & $0,5 \pm 2,0$ & $0 \pm 0$ & $0 \pm 0$ \\
\hline Mínimo-Máximo & $0-17,6$ & $0-22,5$ & $0-9,0$ & $0-9,0$ & $0-7,7$ & $0-0$ & $0-0$ \\
\hline \multicolumn{8}{|c|}{ São Caetano do Sul } \\
\hline Média $\pm d p$ & $0 \pm 0$ & $0 \pm 0$ & $0 \pm 0$ & $0 \pm 0$ & $0 \pm 0$ & $0 \pm 0$ & $0 \pm 0$ \\
\hline Mínimo-Máximo & $0-0$ & $0-0$ & $0-0$ & $0-0$ & $0-0$ & $0-0$ & $0-0$ \\
\hline Nível de significâ & $\mathrm{cia}^{\&} \mathbf{0 , 4 0}$ & 0,38 & 0,11 & 0,19 & 0,54 & 0,42 & 0,06 \\
\hline
\end{tabular}

\&:Teste kruskal-Wallis 
A tabela 16 apresenta os índices da Mortalidade Materna Direta (IMMD) total e por grupo IDH estratificados por período de ocorrência do óbito. Observamos que não há diferenças entre os grupos estratificados por IDH.

Tabela 16. Índice da Mortalidade Materna Direta (IMMD) total e por IDH estratificados por período de ocorrência do óbito

\begin{tabular}{|c|c|c|c|c|c|c|}
\hline & Gravidez & $\begin{array}{c}\text { Puerpério } \\
\text { até } 1 \text { ano }\end{array}$ & $\begin{array}{l}\text { Puerpério } \\
\text { até } 42 \\
\text { dias }\end{array}$ & $\begin{array}{c}\text { Puerpério } 43 \\
\text { dias a menos } \\
\text { de } 1 \text { ano }\end{array}$ & $\begin{array}{c}\text { Não } \\
\text { informado }\end{array}$ & $\begin{array}{c}\text { Não } \\
\text { gravidez ou } \\
\text { puerpério }\end{array}$ \\
\hline \multicolumn{7}{|l|}{ Grupo total } \\
\hline Média $\pm d p$ & $9,2 \pm 22,8$ & $2,6 \pm 14,1$ & $11,8 \pm 25,1$ & $0,5 \pm 2,8$ & $12,0 \pm 33,6$ & $0,1 \pm 0,9$ \\
\hline Mínimo-Máximo & $0-169,7$ & $0-128,9$ & $0-151,1$ & $0-16,7$ & $0-241,3$ & $0-9,2$ \\
\hline \multicolumn{7}{|l|}{ Grupo 1} \\
\hline Média $\pm d p$ & $11,5 \pm 29,3$ & $2,7 \pm 9,8$ & $9,0 \pm 14,4$ & $0,2 \pm 1,6$ & $6,4 \pm 13,2$ & $0,2 \pm 1,4$ \\
\hline Mínimo-Máximo & $0-169,7$ & $0-56,6$ & $0-53,6$ & $0-11,0$ & $0-56,6$ & $0-9,2$ \\
\hline \multicolumn{7}{|l|}{ Grupo 2} \\
\hline Média $\pm d p$ & $7,4 \pm 16,4$ & $2,5 \pm 16,7$ & $13,8 \pm 30,7$ & $0,8 \pm 3,4$ & $16,3 \pm 42,6$ & $0 \pm 0$ \\
\hline Mínimo-Máximo & $0-71,0$ & $0-128,9$ & $0-151,1$ & $0-16,7$ & $0-241,3$ & $0-0$ \\
\hline Nível de significância & 0,2 & $\mathbf{0 , 3}$ & $\mathbf{0 , 9}$ & 0,4 & $\mathbf{0 , 9}$ & $\mathbf{0 , 2}$ \\
\hline
\end{tabular}

\&:Teste kruskal-Wallis 
A figura 8 apresenta os índices da Mortalidade Materna Direta (IMMD) por IDH (A) e por municípios (B). Observamos que São Caetano do Sul apresenta maior índice de óbitos maternos diretos no período entre gravidez $(\mathrm{p}=0,02)$, Rio Grande da Serra entre 42 dias de puerpério $(\mathrm{p}=0,01)$ e Mauá de puerpério aos 43 dias $(\mathrm{p}=0,03)$ quando comparados a outros municípios (figura 8B). Não há diferenças neste quesito quanto aos grupos estratificados por IDH
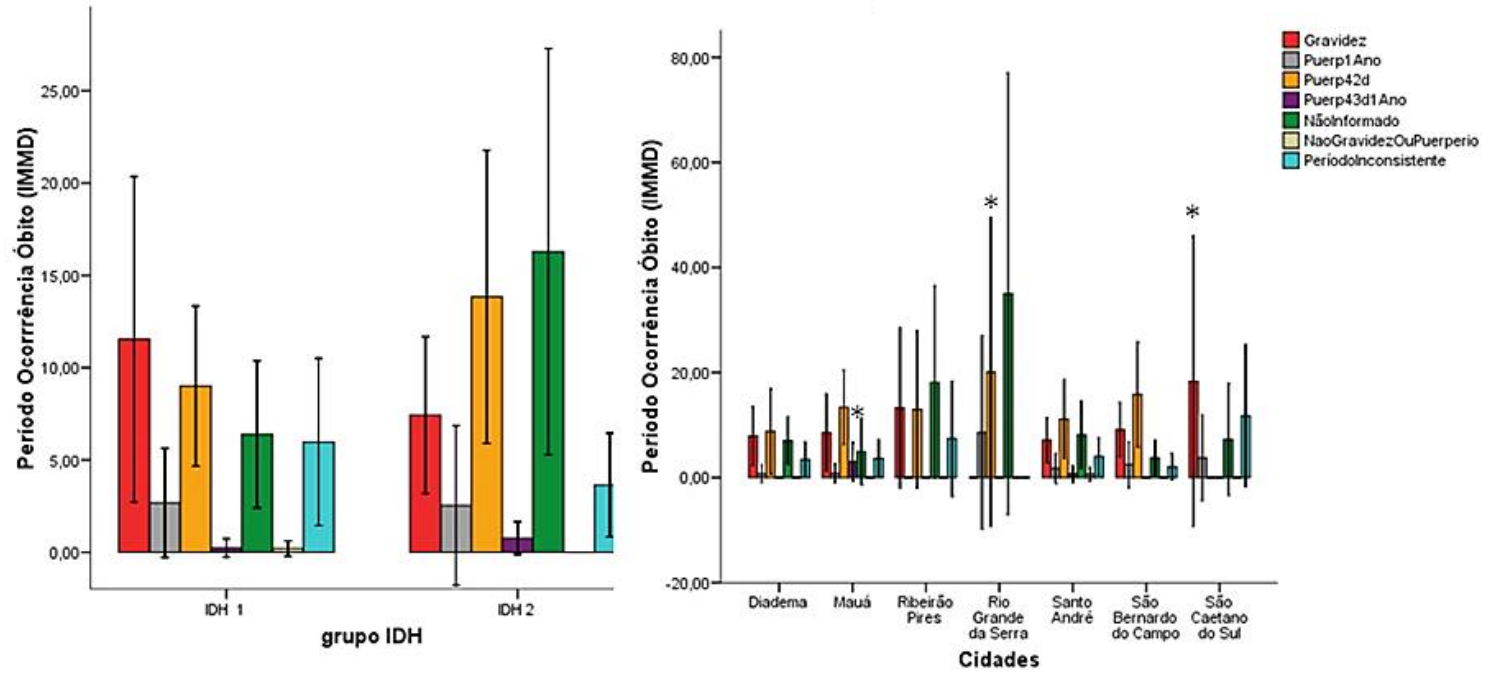

Valores expressos por média e IC95\%; IMMD: Índice da Mortalidade Materna Direta; IDH: Índice de Desenvolvimento Humano: IDH 1: IDH muito alto (municípios Santo André, São Bernardo do Campo e São Caetano do Sul); IDH 2: IDH alto (municípios Diadema, Mauá, Ribeirão Pires e Rio Grande da Serra); ${ }^{*} \mathrm{p} \leq 0,03$.

Figura 8. Índices da Mortalidade Materna Direta (IMMD) por grupo IDH (A) e municípios (B) estratificados por período de ocorrência do óbito

A tabela 17 apresenta a análise descritiva para as variáveis Índice da Mortalidade Materna Direta por municípios na região do Grande ABC Paulista, e período de ocorrência do óbito entre gravidez ou puerpério. Observa-se que há diferenças entre os municípios para as variáveis gravidez $(\mathrm{p}=0,02)$ e puerpério ate 42 
dias $(\mathrm{p}=0,01)$ onde o município de Rio Grande da Serra difere de São Caetano do Sul. Já para a variável puerpério 43 dias a menos de 1 ano o município de Mauá difere dos demais $(\mathrm{p}=0,03)$.

Tabela 17. IMMD por municípios e período da gravidez ou puerpério

\begin{tabular}{|c|c|c|c|c|c|c|c|}
\hline \multirow[b]{2}{*}{ Municípios } & \multicolumn{7}{|c|}{ Período Gravidez/Puerpério } \\
\hline & Gravidez & $\begin{array}{l}\text { Puerpério } \\
\text { até 1ano }\end{array}$ & $\begin{array}{l}\text { Puerpério } \\
\text { até } 42 \text { dias }\end{array}$ & $\begin{array}{c}\text { Puerpério } \\
\text { 43dias a } \\
\text { menos de } \\
\text { 1ano }\end{array}$ & $\begin{array}{c}\text { Período } \\
\text { não } \\
\text { informado }\end{array}$ & $\begin{array}{c}\text { Não } \\
\text { Gravidez ou } \\
\text { puerpério }\end{array}$ & $\begin{array}{c}\text { Período } \\
\text { inconsistente }\end{array}$ \\
\hline \multicolumn{8}{|l|}{ Diadema } \\
\hline Média $\pm d p$ & $7,9 \pm 10,1$ & $0,7 \pm 2,9$ & $8,8 \pm 14,4$ & $0 \pm 0$ & $7,0 \pm 8,1$ & $0 \pm 0$ & $3,4 \pm 6,0$ \\
\hline Mínimo-Máximo & $0-29,1$ & $0-11,2$ & $0-43,6$ & $0-0$ & $0-22,8$ & $0-0$ & $0-15,0$ \\
\hline \multicolumn{8}{|l|}{ Mauá } \\
\hline Média $\pm d p$ & $8,5 \pm 13,2$ & $0,8 \pm 3,1$ & $13,4 \pm 12,6$ & $3,0 \pm 6,4$ & $4,9 \pm 11,2$ & $0 \pm 0$ & $3,6 \pm 6,3$ \\
\hline Mínimo-Máximo & $0-47,0$ & $0-12,3$ & $0-33,4$ & $0-16,7$ & $0-37,2$ & $0-0$ & $0-15,1$ \\
\hline \multicolumn{8}{|l|}{ Ribeirão Pires } \\
\hline Média $\pm d p$ & $13,2 \pm 27,5$ & $0 \pm 0,0$ & $12,9 \pm 26,9$ & $0 \pm 0$ & $18,1 \pm 33,0$ & $0 \pm 0$ & $7,4 \pm 19,7$ \\
\hline Mínimo-Máximo & $0-70,9$ & $0-0,0$ & $0-70,9$ & $0-0$ & $0-103,3$ & $0-0$ & $0-59,7$ \\
\hline \multicolumn{8}{|l|}{ Rio Grande da Serra } \\
\hline Média $\pm d p$ & $0 \pm 0$ & $8,5 \pm 33,2$ & $20,1 \pm 53,0$ & $0 \pm 0$ & $35,0 \pm 75,8$ & $0 \pm 0$ & $0 \pm 0$ \\
\hline Mínimo-Máximo & $0-0$ & $0-128,8$ & $0-151,0$ & $0-0$ & $0-241,2$ & $0-0$ & $0-0$ \\
\hline \multicolumn{8}{|l|}{ Santo André } \\
\hline Média $\pm d p$ & $7,1 \pm 7,5$ & $1,7 \pm 5,0$ & $11,1 \pm 13,6$ & $0,7 \pm 2,8$ & $8,1 \pm 11,6$ & $0,6 \pm 2,3$ & $4,0 \pm 6,1$ \\
\hline Mínimo-Máximo & $0-20,7$ & $0-18,1$ & $0-34,8$ & $0-10,9$ & $0-40,7$ & $0-9,1$ & $0-18,1$ \\
\hline \multicolumn{8}{|l|}{ São Bernardo do Campo } \\
\hline Média $\pm d p$ & $9,1 \pm 9,3$ & $2,4 \pm 7,8$ & $15,8 \pm 18,0$ & $0 \pm 0$ & $3,7 \pm 6,0$ & $0 \pm 0$ & $2,1 \pm 4,6$ \\
\hline Mínimo-Máximo & $0-26,7$ & $0-30,0$ & $0-53,5$ & $0-0$ & $0-17,6$ & $0-0$ & $0-15,0$ \\
\hline \multicolumn{8}{|l|}{ São Caetano do Sul } \\
\hline Média $\pm d p$ & $18,3 \pm 49,8$ & $3,7 \pm 14,6$ & $0 \pm 0$ & $0 \pm 0$ & $7,2 \pm 19,1$ & $0 \pm 0$ & $11,7 \pm 24,4$ \\
\hline Mínimo-Máximo & $0-169,6$ & $0-56,5$ & $0-0$ & $0-0$ & $0-56,5$ & $0-0$ & $0-62,2$ \\
\hline Nível de significância ${ }^{\&}$ & $\mathbf{0 , 0 2}$ & $\mathbf{0 , 8 6}$ & $\mathbf{0 , 0 1}$ & $\mathbf{0 , 0 3}$ & $\mathbf{0 , 5 9}$ & $\mathbf{0 , 4 2}$ & 0,44 \\
\hline
\end{tabular}


A tabela 18 apresenta a análise descritiva para as variáveis Índice da Mortalidade Materna Direta total e por grupo IDH por residência estratificados por local de ocorrência do óbito materno. Observa-se quase total predominância de partos hospitalares independente do grupo analisado, sem diferenças entre os grupos.

Tabela 18. IMMD por local de ocorrência do óbito

\begin{tabular}{lccc}
\hline \hline & \multicolumn{3}{c}{ Local ocorrência óbito materno } \\
\cline { 2 - 4 } & & Domicílio & Outros \\
\hline Grupo Total & $40,1 \pm 52,0$ & $0,1 \pm 1,1$ & $0,5 \pm 2,5$ \\
\hline Média \pm dp & $0-282,8$ & $0-9,0$ & $0-15,0$ \\
Mínimo-Máximo & & & $0,6 \pm 2,2$ \\
\hline Grupo 1 & $34,8 \pm 45,0$ & $0,3 \pm 1,7$ & $0-9,0$ \\
\hline Média \pm dp & $0-282,8$ & $0-9,0$ & \\
Mínimo-Máximo & & & $0,5 \pm 2,7$ \\
\hline Grupo 2 & $44,1 \pm 56,7$ & $0 \pm 0$ & $0-15,0$ \\
\hline Média $\pm d p$ & $0-257,7$ & $0-0$ & $\mathbf{0 , 4 6}$ \\
\hline Mínimo-Máximo & $\mathbf{0 , 7 9}$ & $\mathbf{0 , 1}$ & \\
\hline Nível de significância ${ }^{\&}$ &
\end{tabular}

\&:Teste U de Mann-Whitney, Grupo 1-IDH Muito Alto; Grupo 2=IDH Alto

A figura 9 apresenta os índices da Mortalidade Materna Direta (IMMD) por grupo IDH (A) e por municípios (B) estratificada por local de ocorrência do óbito. Observamos que quase a totalidade de óbitos maternos ocorreram em ambiente hospitalar para ambos grupos estratificados por IDH (9A) como para os municípios isolados (9B). Além disso, somente os municípios de Diadema e São Bernardo do 
Campo apresentaram óbitos maternos ocorridos fora do ambiente hospitalar ou residencial $(\mathrm{p}=0,03)$
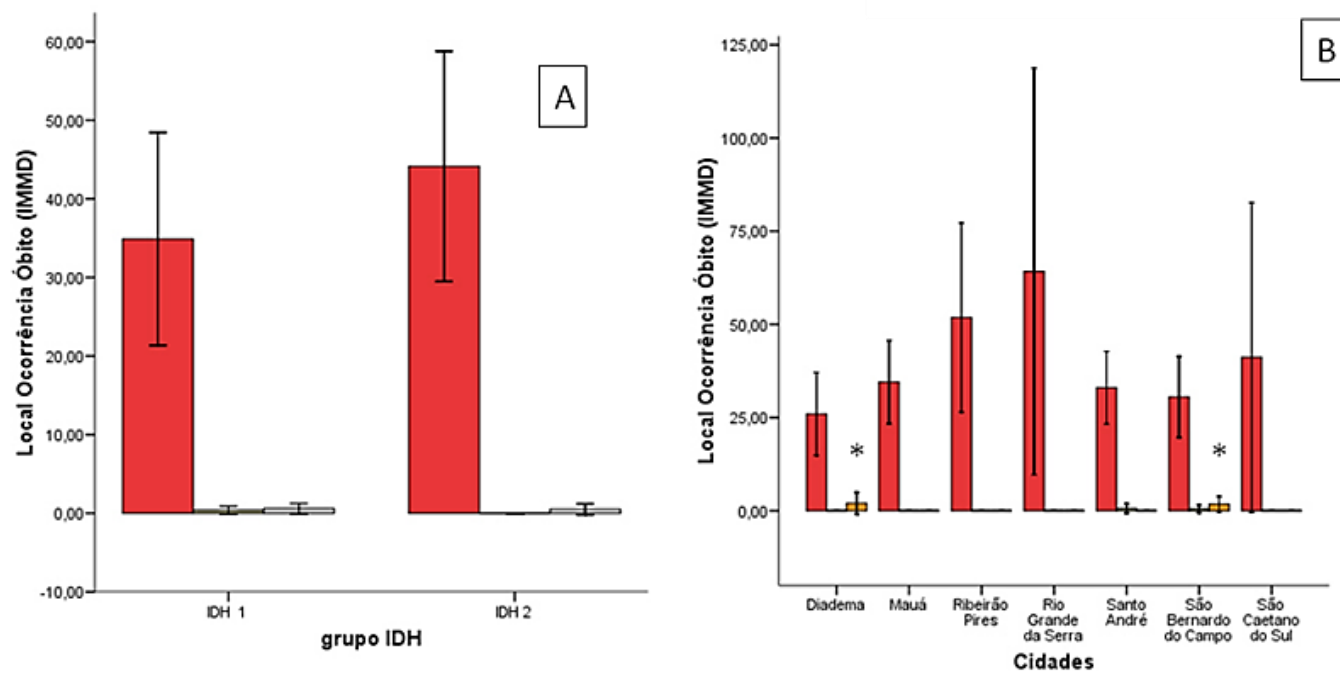

Valores expressos por média e IC95\%; IMMD: Índice da Mortalidade Materna Direta; IDH: Índice de Desenvolvimento Humano: IDH 1: IDH muito alto (municípios Santo André, São Bernardo do Campo e São Caetano do Sul); IDH 2: IDH alto (municípios Diadema, Mauá, Ribeirão Pires e Rio Grande da Serra); *p=0,03.

Figura 9. Índice da Mortalidade Materna Direta (IMMD) por IDH (A) e por municípios (B) estratificados por local de ocorrência do óbito

A tabela 19 apresenta a análise descritiva para as variáveis Índice da Mortalidade Materna Direta por municípios na região do Grande ABC Paulista, e local de ocorrência do óbito. Observa-se que há diferenças para o local denominado outros (não hospitalar ou residência, $\mathrm{p}=0,03$ ). Na análise entre os municípios, apenas Diadema e São Bernardo do Campo apresentaram óbitos maternos diretos fora do ambiente hospitalar ou residencial $(\mathrm{p}=0,03)$. 
Tabela 19. Índice da Mortalidade Materna Direta (IMMD) por municípios estratificada por local de ocorrência do óbito

\begin{tabular}{|c|c|c|c|}
\hline \multirow[b]{2}{*}{ Municípios } & \multicolumn{3}{|c|}{ Local } \\
\hline & Hospital & Domicílio & Outros \\
\hline \multicolumn{4}{|l|}{ Diadema } \\
\hline Média $\pm d p$ & $25,9 \pm 20,0$ & $0 \pm 0$ & $1,9 \pm 5,2$ \\
\hline Mínimo-Máximo & $0-72,7$ & $0-0$ & $0-15,0$ \\
\hline \multicolumn{4}{|l|}{ Mauá } \\
\hline Média $\pm d p$ & $34,5 \pm 20,1$ & $0 \pm 0$ & $0 \pm 0$ \\
\hline Mínimo-Máximo & $0-66,9$ & $0-0$ & $0-0$ \\
\hline \multicolumn{4}{|l|}{ Ribeirão Pires } \\
\hline Média $\pm d p$ & $51,8 \pm 45,8$ & $0 \pm 0$ & $0 \pm 0$ \\
\hline Mínimo-Máximo & $0-141,9$ & $0-0$ & $0-0$ \\
\hline \multicolumn{4}{|l|}{ Rio Grande da Serra } \\
\hline Média \pm dp & $64,1 \pm 98,5$ & $0 \pm 0$ & $0 \pm 0$ \\
\hline Mínimo-Máximo & $0-257,7$ & $0-0$ & $0-0$ \\
\hline \multicolumn{4}{|l|}{ Santo André } \\
\hline Média $\pm d p$ & $33,0 \pm 17,5$ & $0,6 \pm 2,3$ & $0 \pm 0$ \\
\hline Mínimo-Máximo & $10,9-73,2$ & $0-9,0$ & $0-0$ \\
\hline \multicolumn{4}{|l|}{ São Bernardo do Campo } \\
\hline Média $\pm d p$ & $30,5 \pm 19,6$ & $0,5 \pm 1,9$ & $1,7 \pm 3,7$ \\
\hline Mínimo-Máximo & $0-71,4$ & $0-7,5$ & $0-9,0$ \\
\hline \multicolumn{4}{|l|}{ São Caetano do Sul } \\
\hline Média \pm dp & $41,1 \pm 75,0$ & $0 \pm 0$ & $0 \pm 0$ \\
\hline Mínimo-Máximo & $0-282,8$ & $0-0$ & $0-0$ \\
\hline Nível de significância $^{*}$ & 0,45 & 0,54 & $\mathbf{0 , 0 3}$ \\
\hline
\end{tabular}

\&:Teste kruskal-Wallis 
A tabela 20 apresenta a análise descritiva para as variáveis Índice da Mortalidade Materna Direta total e por grupo IDH por residência estratificado por investigação de fichas de notificação da vigilância epidemiológica (VE) ${ }^{41}$. Observa-se que não há diferenças entre os dois grupos de estudo.

Tabela 20. Índice Mortalidade Materna Direta por investigação e grupo de estudo

\begin{tabular}{|c|c|c|c|c|}
\hline & $\begin{array}{c}\text { Investigado } \\
\text { com ficha }\end{array}$ & $\begin{array}{c}\text { Investigado } \\
\text { sem ficha }\end{array}$ & $\begin{array}{c}\text { Não } \\
\text { investigado }\end{array}$ & Não se aplica \\
\hline \multicolumn{5}{|l|}{ Grupo Total } \\
\hline Média $\pm d p$ & $2,9 \pm 11,1$ & $1,8 \pm 11,5$ & $8,2 \pm 28,6$ & $31,3 \pm 60,3$ \\
\hline Mínimo-Máximo & $0-68,4$ & $0-91,0$ & $0-206,1$ & $0-282,8$ \\
\hline \multicolumn{5}{|l|}{ Grupo 1} \\
\hline Média $\pm d p$ & $2,9 \pm 11,3$ & $2,3 \pm 14,0$ & $4,1 \pm 11,3$ & $23,6 \pm 46,2$ \\
\hline Mínimo-Máximo & $0-54,7$ & $0-91,0$ & $0-56,5$ & $0-282,8$ \\
\hline \multicolumn{5}{|l|}{ Grupo 2} \\
\hline Média $\pm d p$ & $2,9 \pm 11,1$ & $1,4 \pm 9,3$ & $11,3 \pm 36,4$ & $37,0 \pm 68,9$ \\
\hline Mínimo-Máximo & $0-68,4$ & $0-68,7$ & $0-206,1$ & $0-257,7$ \\
\hline Nível de significância $^{*}$ & $\mathbf{0 , 7 8}$ & $\mathbf{0 , 7 7}$ & 0,79 & 0,75 \\
\hline
\end{tabular}

\&:Teste U de Mann-Whitney, Grupo 1-IDH Muito Alto; Grupo 2=IDH Alto 
A figura 10 apresenta os índices da mortalidade materna direta (IMMD) por grupo IDH (A) e por municípios (B) estratificados por investigação de fichas de notificação. Observamos predominância de fichas não investigadas em ambos os grupos estratificados por IDH (A) quanto nos municípios isolados (B).
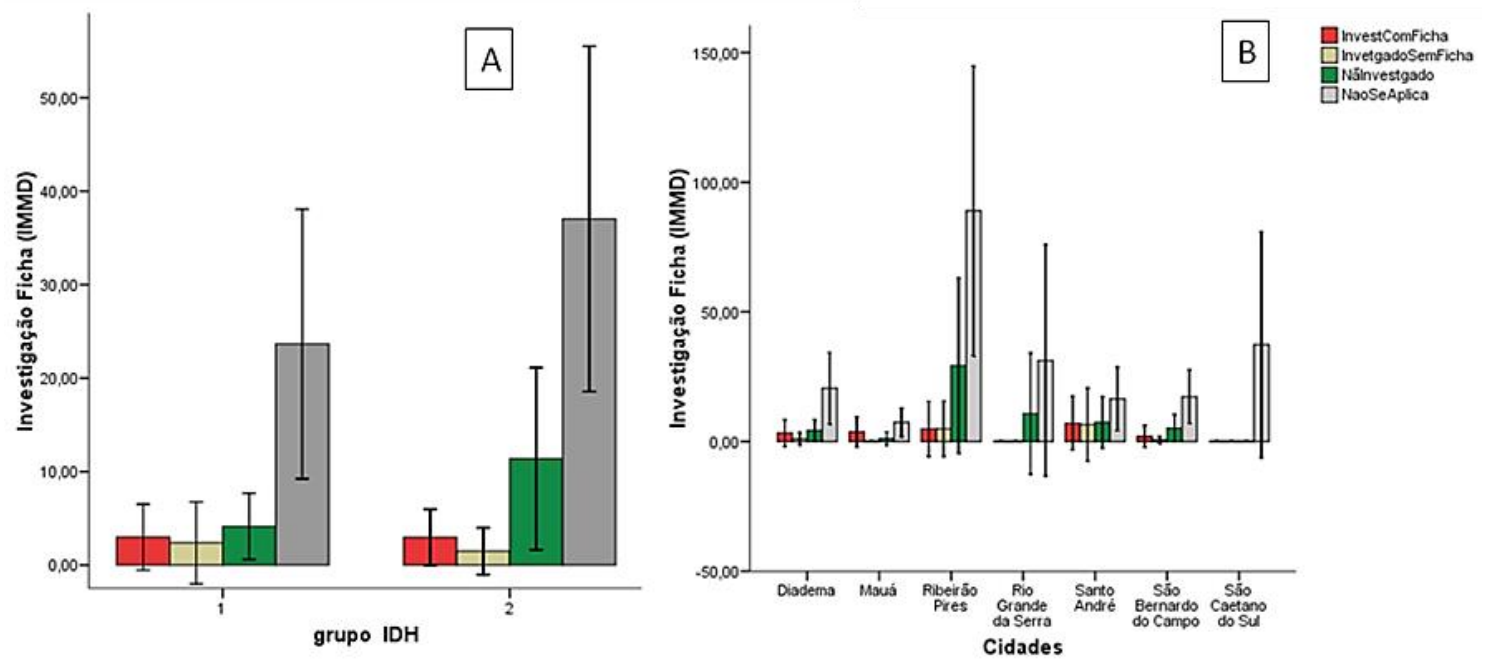

Valores expressos por média e IC95\%; IMMD: Índice da Mortalidade Materna Direta; IDH: Índice de Desenvolvimento Humano: IDH 1: IDH muito alto (municípios Santo André, São Bernardo do Campo e São Caetano do Sul); IDH 2: IDH alto (municípios Diadema, Mauá, Ribeirão Pires e Rio Grande da Serra).

Figura 10. Índice da Mortalidade Materna Direta por grupo IDH (A), municípios (B), estratificados por investigação de fichas de notificação do óbito materno 
A tabela 21 apresenta a análise para as variáveis Índice da Mortalidade Materna Direta por municípios grupos (IDH) na região do Grande ABC Paulista, e investigação de óbitos. Observa-se que não há diferenças entre os municípios.

Tabela 21. Índice da Mortalidade Materna por investigação e municípios

\begin{tabular}{|c|c|c|c|c|}
\hline \multirow[b]{2}{*}{ Municípios } & \multicolumn{4}{|c|}{ Investigação óbitos maternos } \\
\hline & Com ficha & Sem ficha & Não investigado & Não se aplica \\
\hline \multicolumn{5}{|l|}{ Diadema } \\
\hline Média $\pm d p$ & $3,2 \pm 8,8$ & $1,0 \pm 3,9$ & $4,3 \pm 7,1$ & $20,5 \pm 23,7$ \\
\hline Mínimo-Máximo & $0-30,1$ & $0-14,8$ & $0-15,9$ & $0-72,7$ \\
\hline \multicolumn{5}{|l|}{ Mauá } \\
\hline Média \pm dp & $3,7 \pm 10,0$ & $0 \pm 0$ & $1,1 \pm 4,3$ & $7,3 \pm 9,4$ \\
\hline Mínimo-Máximo & $0-34,5$ & $0-0$ & $0-16,2$ & $0-30,3$ \\
\hline \multicolumn{5}{|l|}{ Ribeirão Pires } \\
\hline Média $\pm d p$ & $4,8 \pm 18,2$ & $4,9 \pm 18,3$ & $29,2 \pm 58,3$ & $88,9 \pm 96,6$ \\
\hline Mínimo-Máximo & $0-68,4$ & $0-68,7$ & $0-206,1$ & $0-217,1$ \\
\hline \multicolumn{5}{|l|}{ Rio Grande da Serra } \\
\hline Média $\pm d p$ & $0 \pm 0$ & $0 \pm 0$ & $10,7 \pm 40,3$ & $31,2 \pm 77,1$ \\
\hline Mínimo-Máximo & $0-0$ & $0-0$ & $0-151,0$ & $0-257,7$ \\
\hline \multicolumn{5}{|l|}{ Santo André } \\
\hline Média $\pm d p$ & $7,0 \pm 17,9$ & $6,5 \pm 24,3$ & $7,3 \pm 17,0$ & $16,4 \pm 21,1$ \\
\hline Mínimo-Máximo & $0-54,7$ & $0-91,0$ & $0-56,5$ & $0-63,3$ \\
\hline \multicolumn{5}{|l|}{ São Bernardo do Campo } \\
\hline Média $\pm d p$ & $1,9 \pm 7,3$ & $0,6 \pm 2,4$ & $5,1 \pm 9,0$ & $17,2 \pm 17,9$ \\
\hline Mínimo-Máximo & $0-27,5$ & $0-9,0$ & $0-26,7$ & $0-52,5$ \\
\hline \multicolumn{5}{|l|}{ São Caetano do Sul } \\
\hline Média $\pm d p$ & $0 \pm 0$ & $0 \pm 0$ & $0 \pm 0$ & $37,3 \pm 75,3$ \\
\hline Mínimo-Máximo & $0-0$ & $0-0$ & $0-0$ & $0-282,8$ \\
\hline Nível de significância ${ }^{\&}$ & 0,61 & $\mathbf{0 , 8 0}$ & 0,20 & $\mathbf{0 , 3 0}$ \\
\hline
\end{tabular}

\&:Teste kruskal-Wallis 


\subsection{Análises da Tendência Temporal}

A figura 11 apresenta a série temporal dos índices da Mortalidade Materna Direta e Indireta. Apesar da tendência de queda de ambos os índices no decorrer do período de estudo e grandes oscilações de valores entre os anos de 1997 a 2001 atingindo níveis de quase 60 para IMMD e quase 50 para IMMI, não há diferença estatística no tempo para ambos os IMM (IMMI: p=0,48; IMMD: $p=0,21$ ). Houve queda de 43\% nos IMMD de 1997 a 2011.

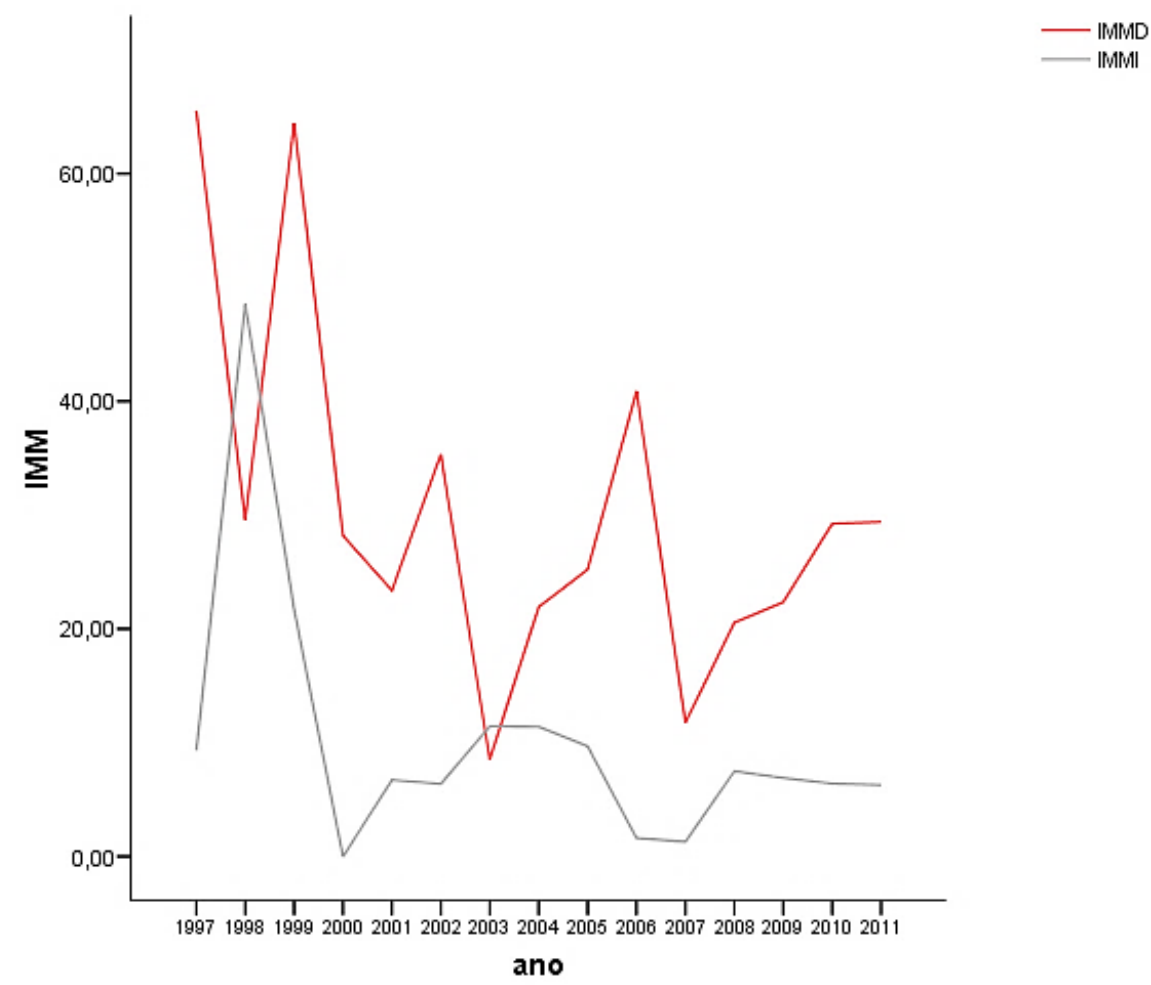

IMM (Índices da Mortalidade Materna) ; IMMD: Índices da Mortalidade Materna Direta; IMMI: Índices da Mortalidade Materna Indireta.

Figura 11. Índices da Mortalidade Materna Direta e Indireta por ano de estudo 
A figura 12 apresenta a série temporal do IMMD sinalizando os momentos das medidas públicas para controle da Mortalidade Materna Direta. Observamos que os dados se mantém oscilantes porém com tendência a queda mais homogênea a partir de 2000.

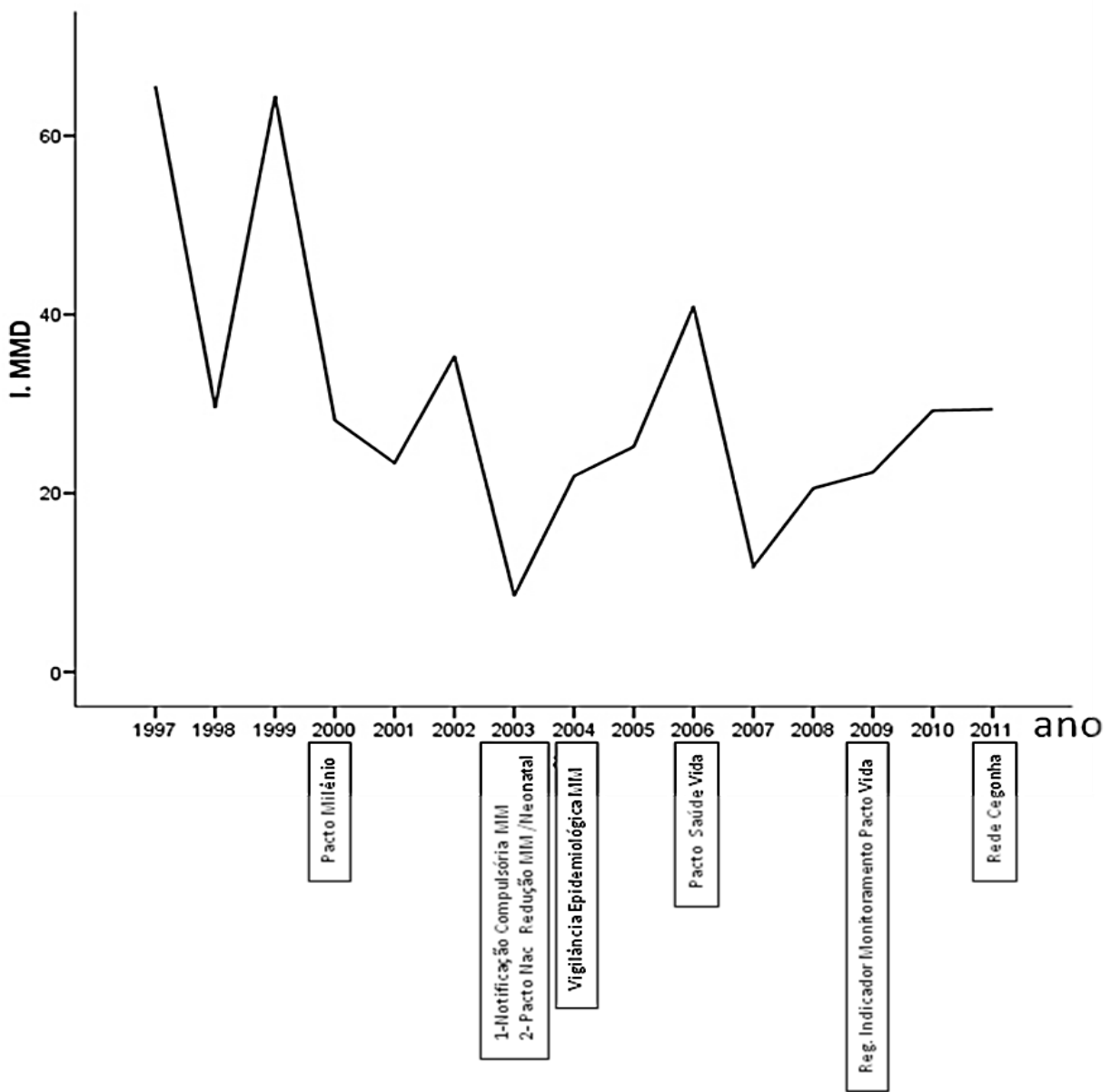

IMM (Índices da Mortalidade Materna) ; IMMD: Índices da Mortalidade Materna Direta.

Figura 12. Série temporal e medidas públicas para controle da MM 
A figura 13 apresenta série temporal dos Índices da Mortalidade Materna Direta por municípios . Observa-se grande oscilação dos dados principalmente no município de Rio Grande da Serra em todo período e em Ribeirão Pires no ano de 2010.

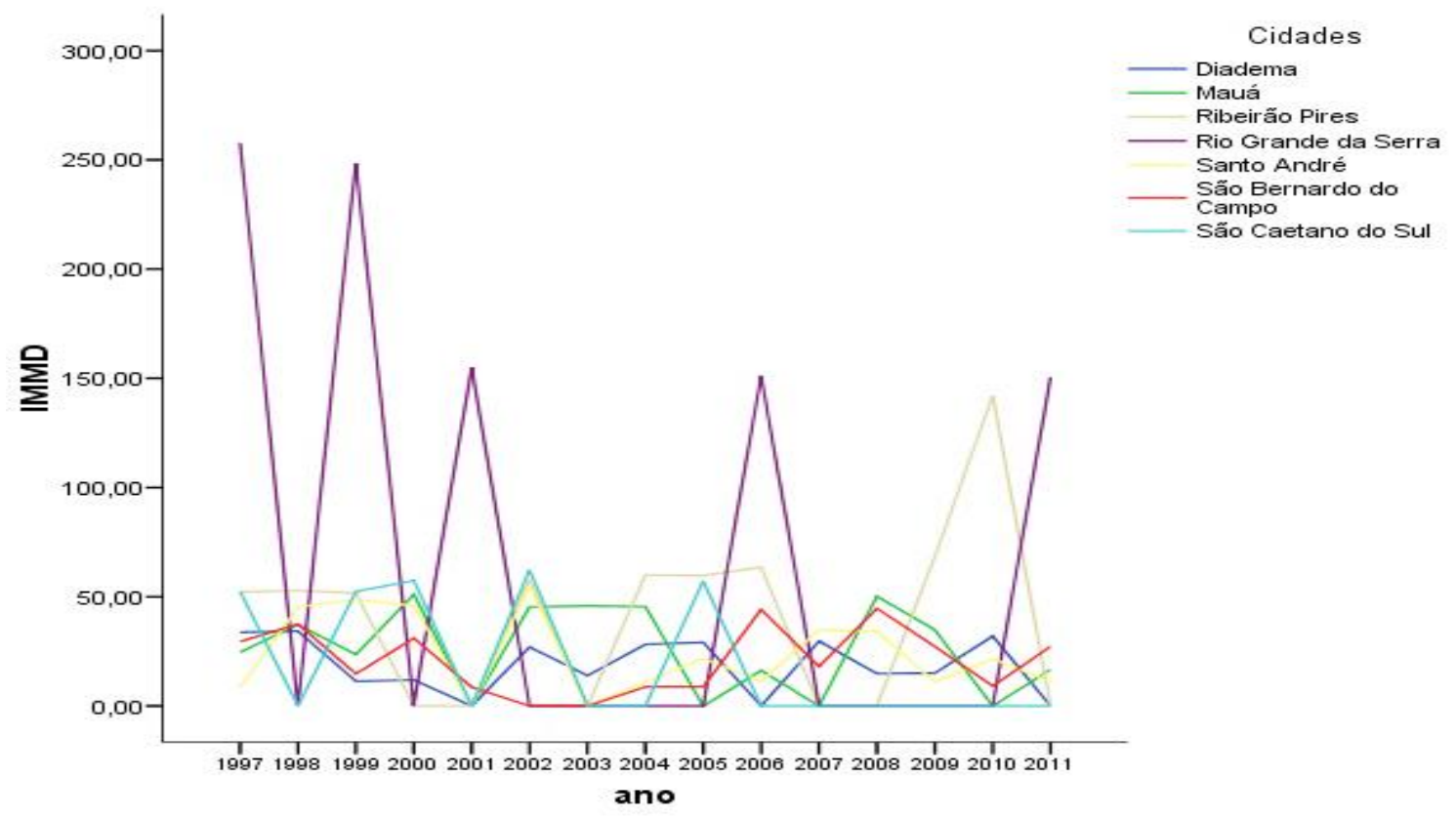

IMMD: Índice da Mortalidade Materna Direta. Municípios: Diadema, Mauá, Ribeirão Pires, Rio Grande da Serra, Santo André, São Bernardo do Campo, São Caetano do Sul.

Figura 13. Série Temporal dos Índices da Mortalidade Materna Direta (IMMD) por municípios

A figura 14 apresenta a série temporal por municípios (A: Diadema, B: Mauá, C: Ribeirão Pires, D: Rio Grande da Serra, E: Santo André, F: São Bernardo do Campo, G: São Caetano do Sul). Observa-se grande a variabilidade dos dados ao longo do período. Observa-se também tendência estável em níveis mínimos no município de São Caetano do Sul a partir de 2006. 


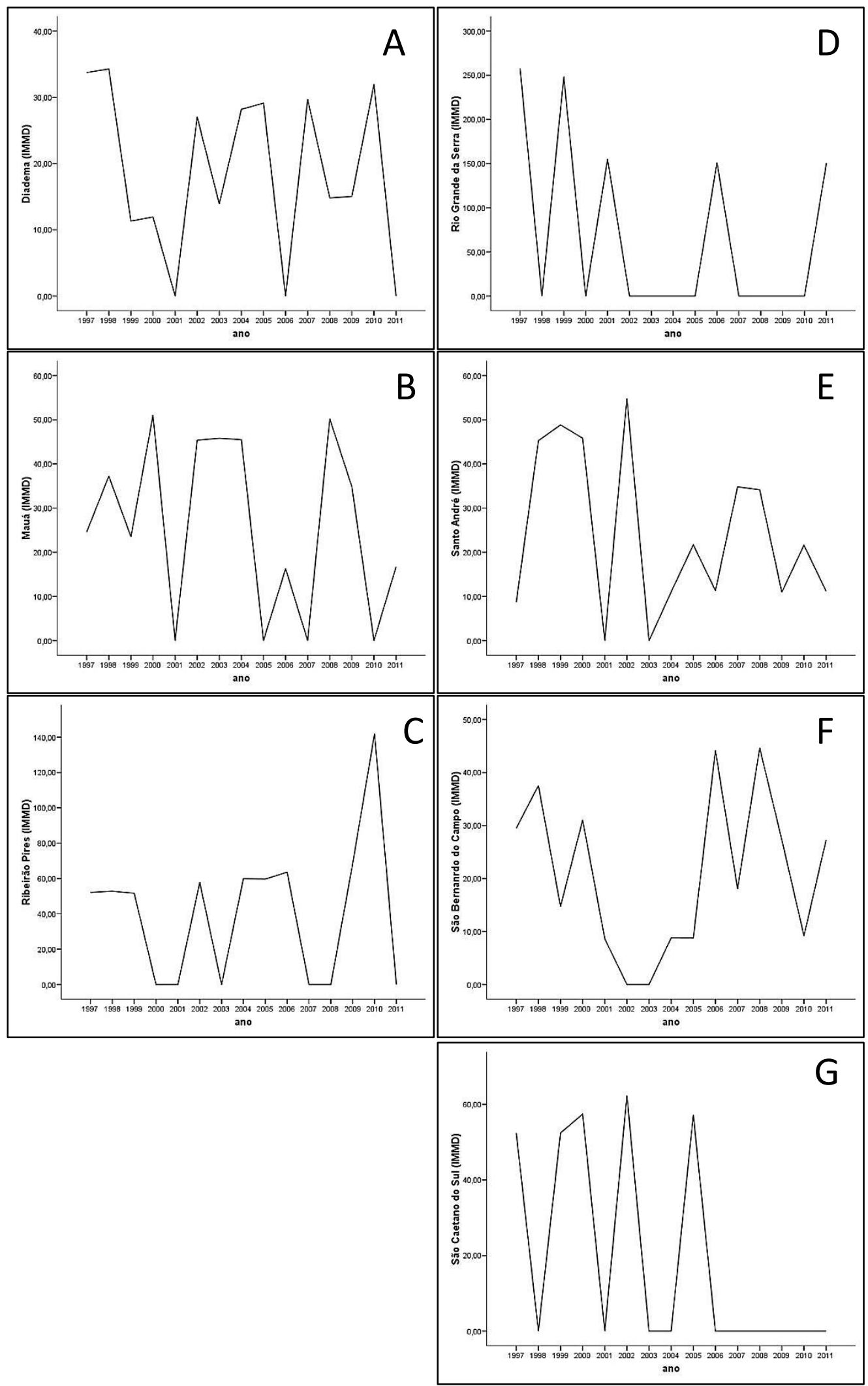

IMMD: Índice da Mortalidade Materna Direta; A; Diadema; B:Mauá; C: Ribeirão Pires; D: Rio Grande da Serra; E:Santo André; F: São Bernardo do Campo; G: São Caetano do Sul.

Figura 14. Série temporal por municípios do estudo 
A figura 15 expressa a série temporal dos Índices da Mortalidade Materna Direta por IDH. Observamos que o grupo 2 apresenta maiores oscilações dos dados e índices maiores que o grupo 1 em quase todo o período do estudo. As análises estatísticas não demonstraram diferenças entre os grupos (IDH 1: $p=0,182$; IDH 2: $\mathrm{p}=0,705)$.

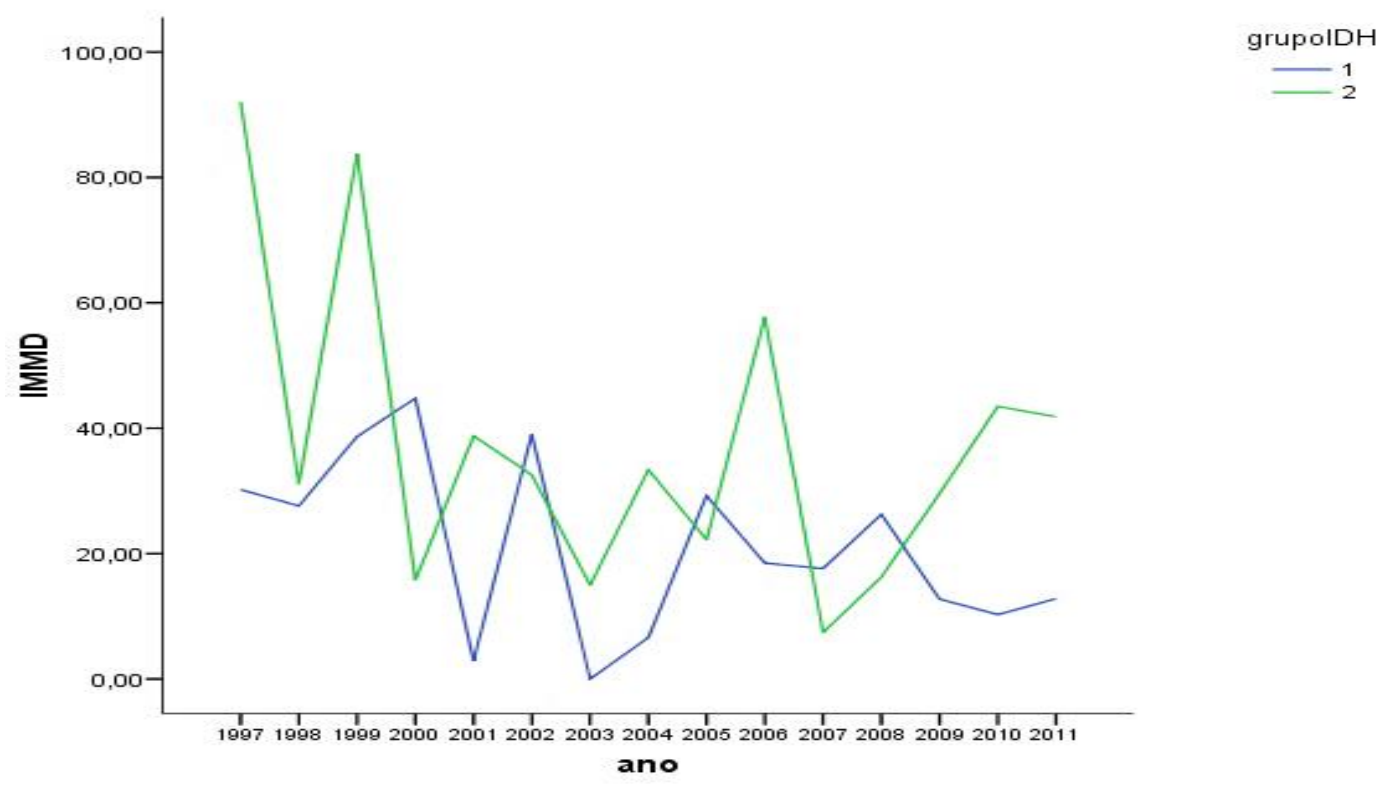

IMMD: Índice da Mortalidade Materna Direta; IDH: Índice de Desenvolvimento Humano.

Figura 15. Série temporal dos Índices da Mortalidade Materna Direta (IMMD) por IDH: grupo 1 e 2

A figura 16 apresenta a série temporal do IMMD por etnia. Observamos predominância da etnia branca em quase a totalidade das etnias em todo o período analisado. Apesar da etnia negra ter-se mostrado diferente entre os grupos IDH nas análises prévias, não há diferenças entre os municípios pela análise ao longo do tempo. Porém, este gráfico demonstra ser discreta a frequência da etnia negra, com incrementos 
nos seus índices nos períodos 2002 e 2006, fatos estes que devem ser interpretados com cautela. Há diferença no quesito etnia ignorada, onde em 1997 ocorreram os maiores IMMD $(34,49(0-128,87), \mathrm{p}<0,01)$ quando comparados aos outros anos com índices abaixo de $2,0(0-15,05)$.

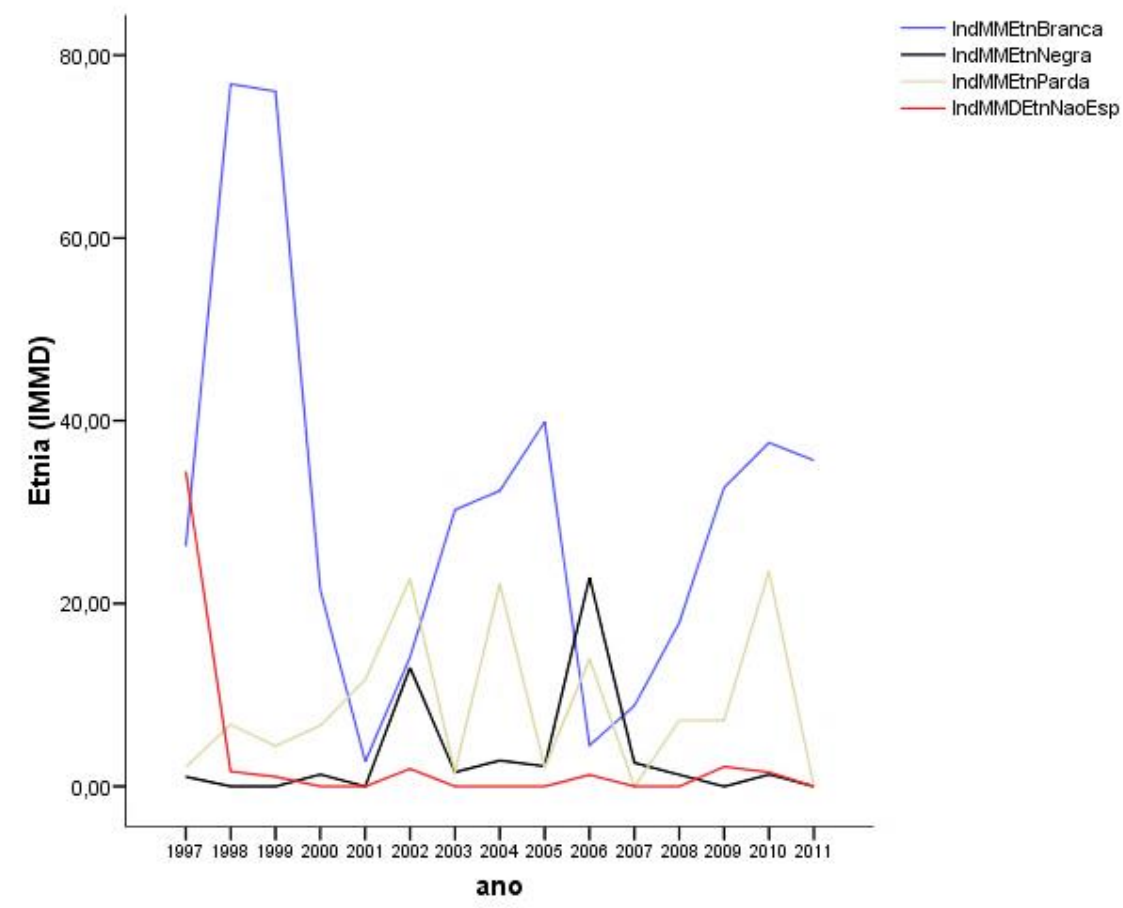

IMMD: Índice da Mortalidade Materna Direta, IndMMEtn: Índice da MMD por etnia, etnia branca, negra, parda , IndMMEtnNaoEsp: IMMD por etnia não especificada

Figura 16. IMMD por etnia, série temporal

A figura 17 apresenta um painel da série temporal do IMMD por todos os estratos do estado civil (A) e pelo estado civil viúvo (B). Há predomínio do estado civil solteiro (valor médio máximo de 55,14(0-287,77) em 2004) seguido pelo estado civil casado (valor médio máximo de 42,38 (0-120,63) em 1998) no decorrer do período 
estudado (A). Observa-se que há diferença ao longo do tempo para a categoria viúvo ( $\mathrm{p}=0,04, \mathrm{~A})$. Pelo teste de comparações múltiplas de Dunn, temos que o ano de 2009 difere dos demais mostrando um incremento da mortalidade materna de mulheres viúvas neste período ( $\mathrm{p}=0,04, \mathrm{~A}$ e B). Porém o gráfico $15 \mathrm{~B}$ mostra que este parâmetro apresenta pico em 2009 ( 24,19 (0-169,2) em 2009) e está praticamente ausente nos outros anos analisados sugerindo esta significância matemática não corresponder à significância clínica epidemiológica.
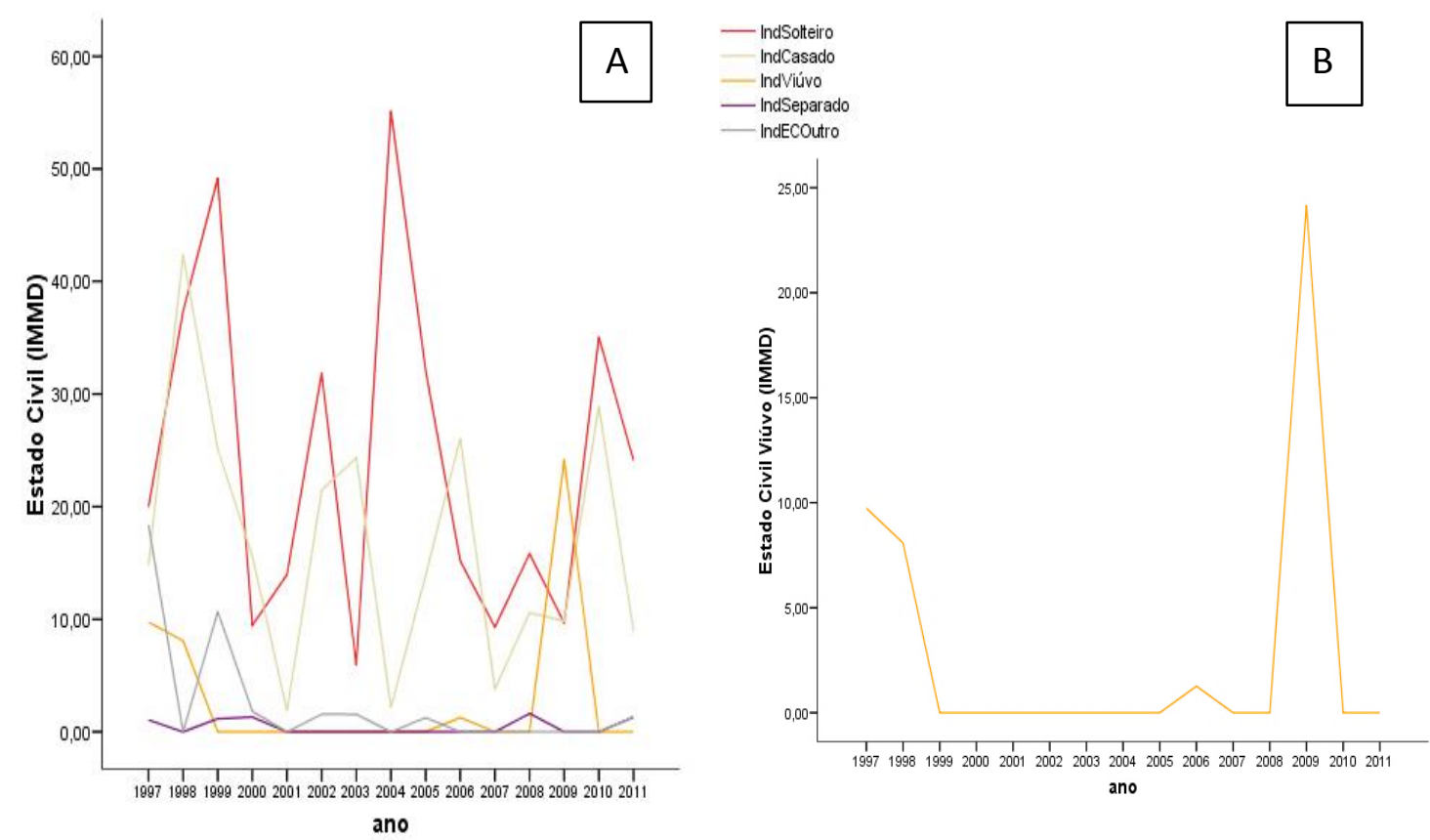

IMMD: Índice da Mortalidade Materna Direta. IndSolteiro, IndCasado, IndViúvo, IndSeparado, IndOutro.

Figura 17. Série temporal IMMD estratificado por estado civil 
A Figura 18 apresenta o painel da série temporal do IMMD por estratos da escolaridade (A) em realce para o estrato entre 4 a 7 anos da escolaridade (B). Observa-se que há diferença ao longo do tempo para a categoria escolaridade de 4 a 7 anos $(p=0,03, A)$ com incremento nos IMMD nesta faixa de escolaridade no ano de 2004 (50,88 (0-287,77) em 2004, p=0,03) diferindo dos anos: 1997, 1998, 2000, 2001, 2003, 2007, 2009, 2011. Há também grande oscilação dos dados no período.
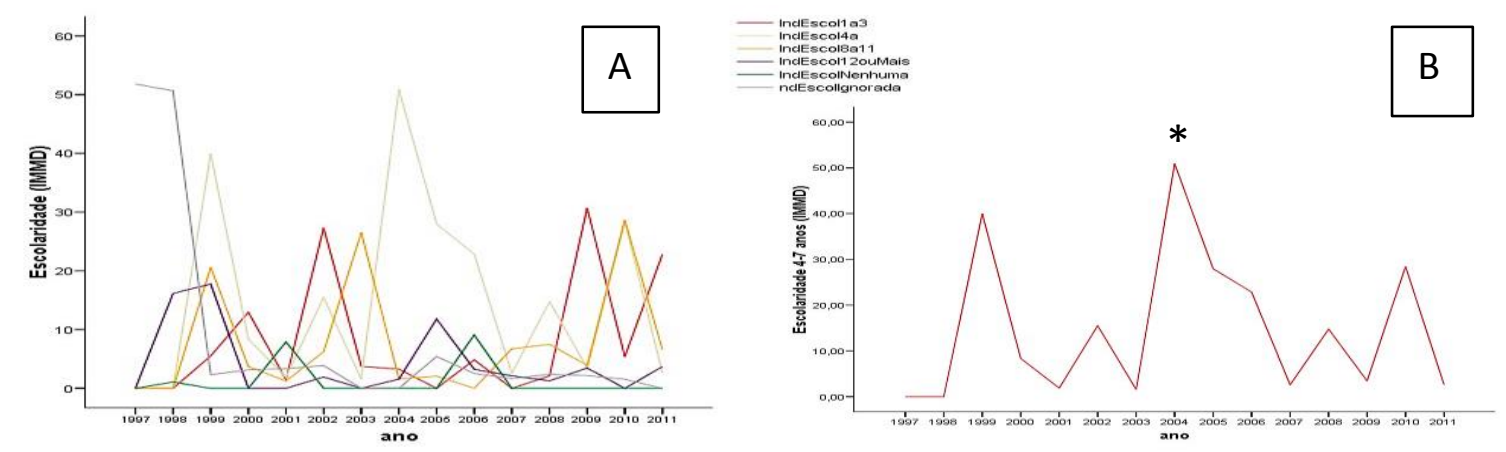

IMMD: Índice da Mortalidade Materna; IndEscol: Índice da Mortalidade Materna por escolaridade;1-3: 1 a 3 anos; 47: 4 a 7 anos; $8-11: 8$ a 8 anos; 12 ou mais: 12 ou mais anos; * $\mathrm{p}=0,03$.

Figura 18. IMMD escolaridade, série temporal

A figura 19 apresenta a série temporal do IMMD por causas classificadas pela Classificação Internacional de Doenças $(\text { CID 10 })^{26}$ (A) e pelas causas principais de óbitos maternos (B). Observamos que Hemorragias/Tromboses/Embolias (pico de 22,15 (0-155,04) em 2001) seguido de Eclâmpsias (valor médio máximo 22,68 (0-128,87) em 1997) predominam como causa do óbito materno ao longo de quase todo período do estudo. Não há diferença no tempo entre as causas obstétricas (CID10) ${ }^{26}$. 

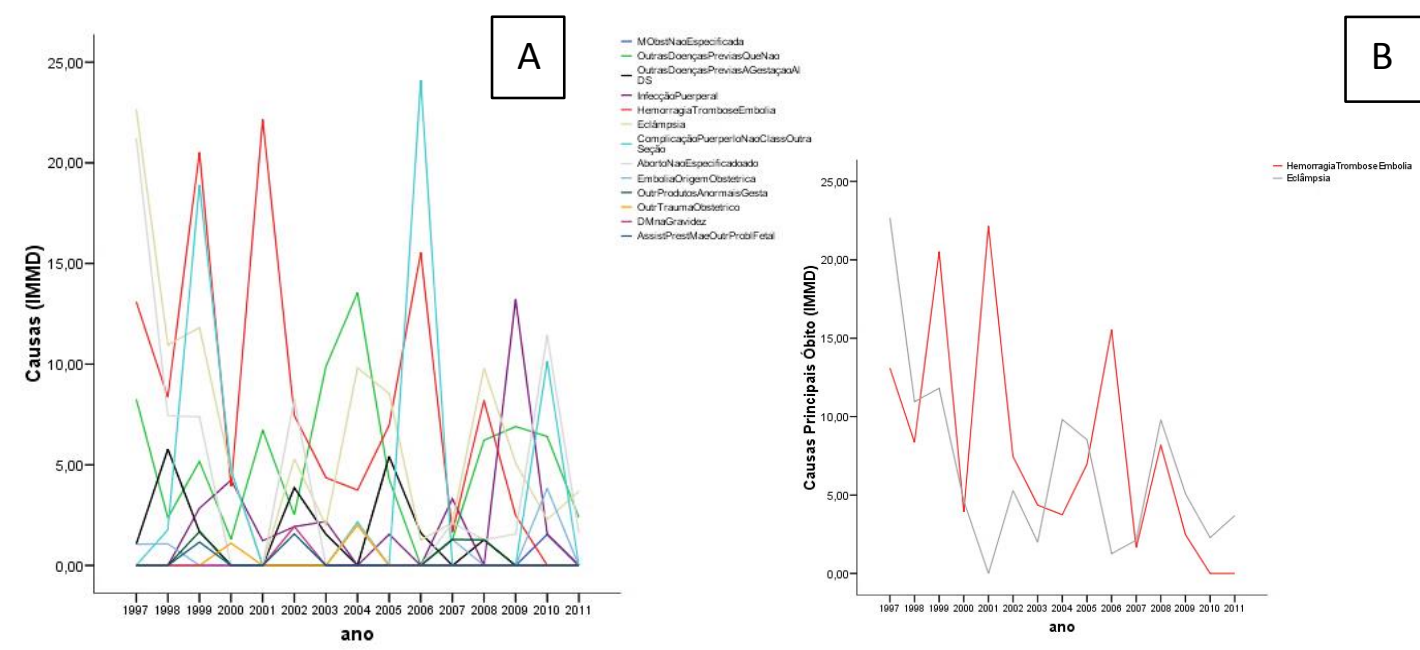

IMMD: Índice da Mortalidade Materna Direta; MObst: mortalidade obstétrica (IMMD e causa obstétrica).

Figura 19. IMMD causas (CID 10), série temporal.

A figura 20 apresenta um painel de série temporal das principais causas (CID10) ${ }^{26}$ dos óbitos maternos estratificadas por IDH. Observa-se que apesar da tendência da predominância destas causas no grupo 2 estratificado por IDH, não há diferenças destas causas no tempo (Hemorragia/Trombose/Embolia Total: $p=0,17$, IDH1: $p=0,45$ e IDH2: $p=0,65$ Figura A; Eclâmpsia Total: $p=0,67$, IDH 1: $p=0,52$ e IDH2: $p=0,67$ Figura $B$ )
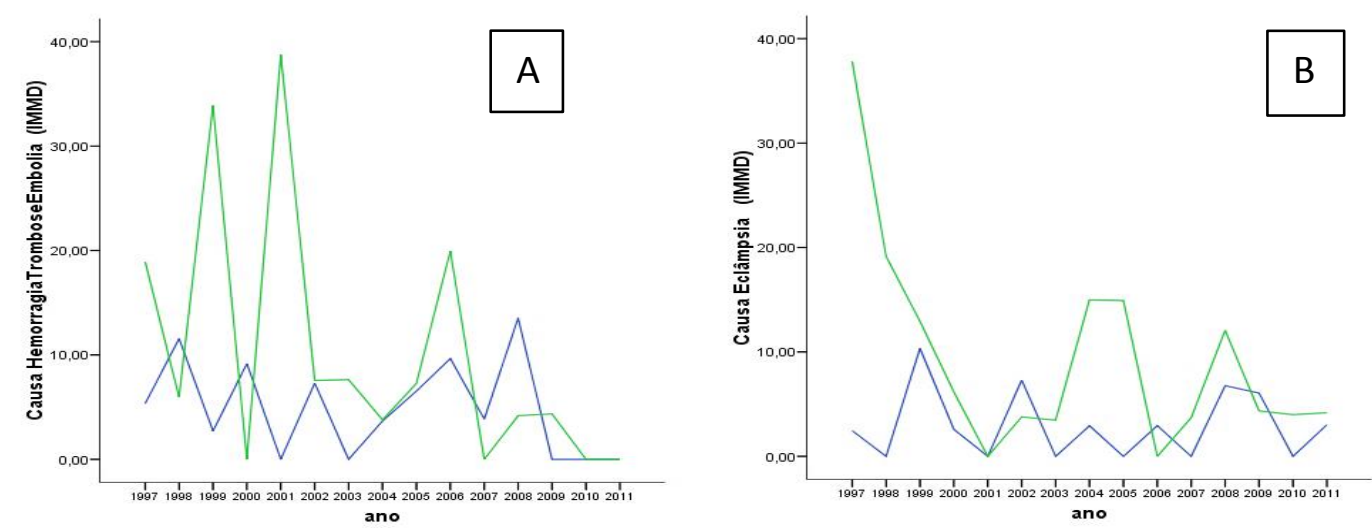

IMMD: Índice da Mortalidade Materna Direta. Grupo IDH 1, 2.

Figura 20. Série Temporal causas principais dos óbitos por IDH 
A figura 21 apresenta série temporal dos IMMD por faixa etária. Pelo teste de Kruskal-Wallis, observa-se que há diferenças entre os anos para a faixa etária de 25 a 29 anos $(\mathrm{p}=0,05)$. Pelo teste de comparações múltiplas de Dunn temos que o ano de 1997 $(11,72(0-52,16)$ difere de $1998(35,67(0-120,63)$, e o ano de 1998 difere dos demais $(\mathrm{p}=0,05)$.
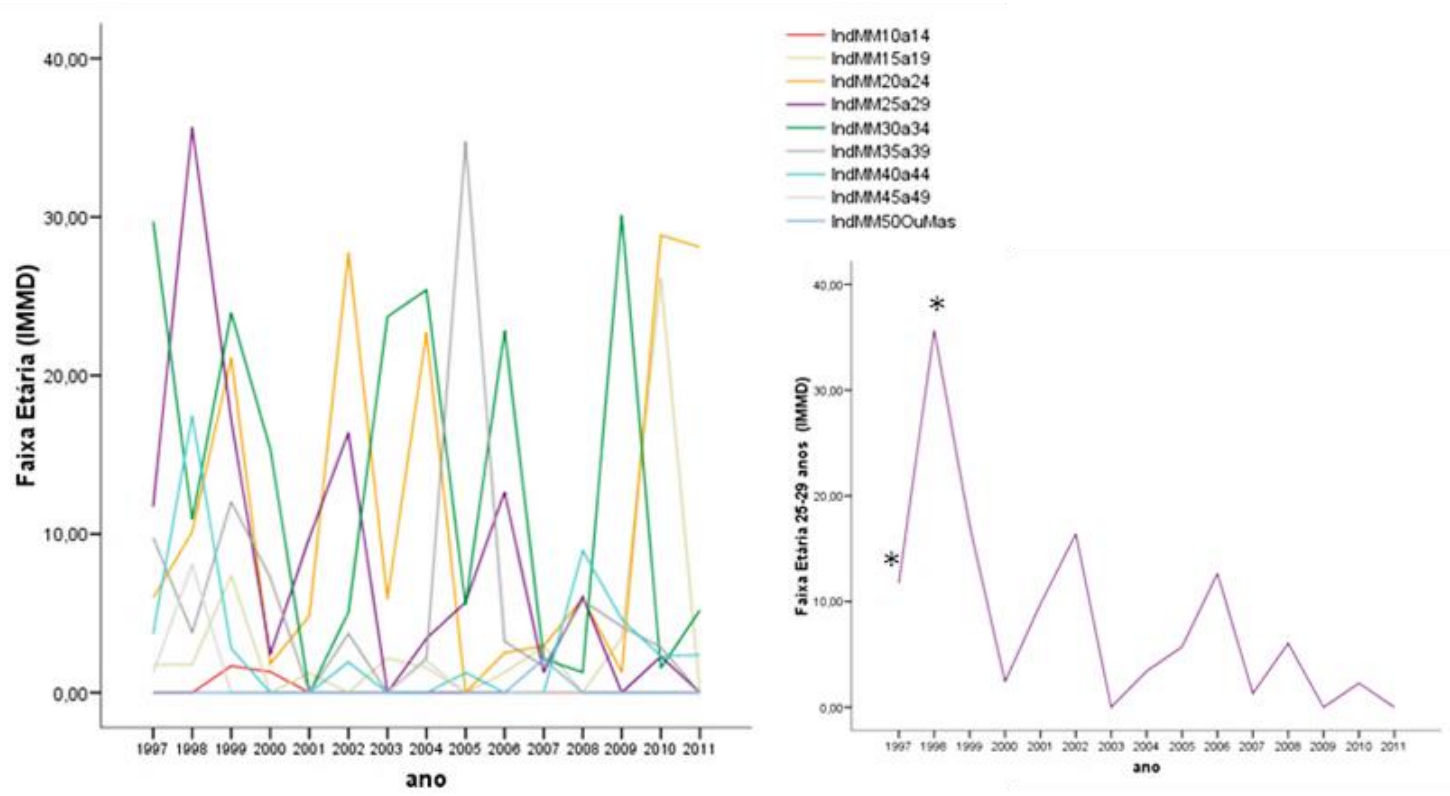

IMMD: Índice de Mortalidade Materna; * $\mathrm{p}=0,05, \alpha=5 \%$.

Figura 21. Série Temporal IMMD por faixa etária

A figura 22 apresenta a série temporal dos Índices da Mortalidade Materna Direta (IMMD) estratificados por período de ocorrência do óbito. Observamos predomínio do período não informado do óbito no início do estudo com decréscimo a partir de 2000. Porém o período dos óbitos maternos até os 42 dias de puerpério, mostra-se em ascensão neste milênio. Os períodos que mostraram-se significativos 
foram o puerpério até 1 ano, período não informado e período inconsistente. O período puerpério até 1 ano apresenta valores em 1997 de 24,06 (0-128,87) e em 1998 de 14,96 $(0-56,56)$, a partir dos quais passa a ser ausente ao longo do período restante, sugerindo talvez notificação inadequada $(\mathrm{p}<0,01)$. O período não informado apresenta diferença entre os anos de $1998(59,97(0-241,25)$ e $1997(35,60(0-128,87)$ e os períodos após 2004 que apresentaram níveis de IMMD abaixo de 4,14 (0-17,6), p<0,01, Figura 21A). O período inconsistente apresentou diferença no ano $2005(18,25(0-59,7), \mathrm{p}=0,02)$ quando comparado aos anos a partir de 2006 cujos IMMD foram abaixo de 2,15 (0$15,08)$.
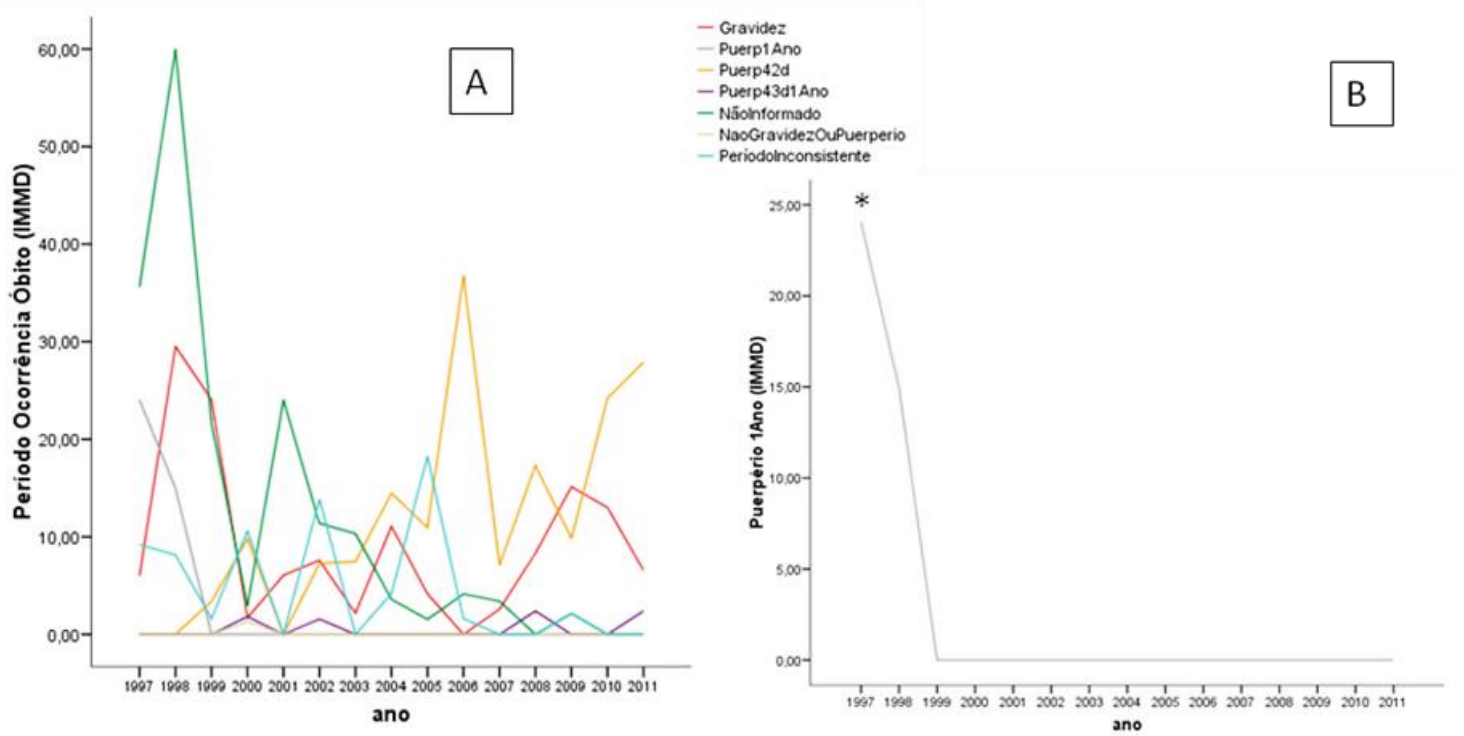

IMMD: Índice da Mortalidade Materna Direta; *p<0,01. Gravidez, Puerp: puerpério 1 ano, 42d: 42 dias, 43d 1 ano: 43 dias a 1 ano, Não informado, Não gravidez ou puerpério, Período inconsistente.

Figura 22. Série temporal IMMD por período de ocorrência do óbito 
A figura 23 apresenta a série temporal dos IMMD por local de ocorrência do óbito. Observa-se que o local de ocorrência dos óbitos maternos foram quase totalidade no ambiente hospitalar ao longo de todo período de estudo atingindo pico de 75,76 (0-282,81) em 1998. Há diferença no quesito IMMD domicílio onde apresenta notificação discreta apenas em $1998(2,37(0-9,06), \mathrm{p}=0,01)$ e ausente nos outros anos de estudo.

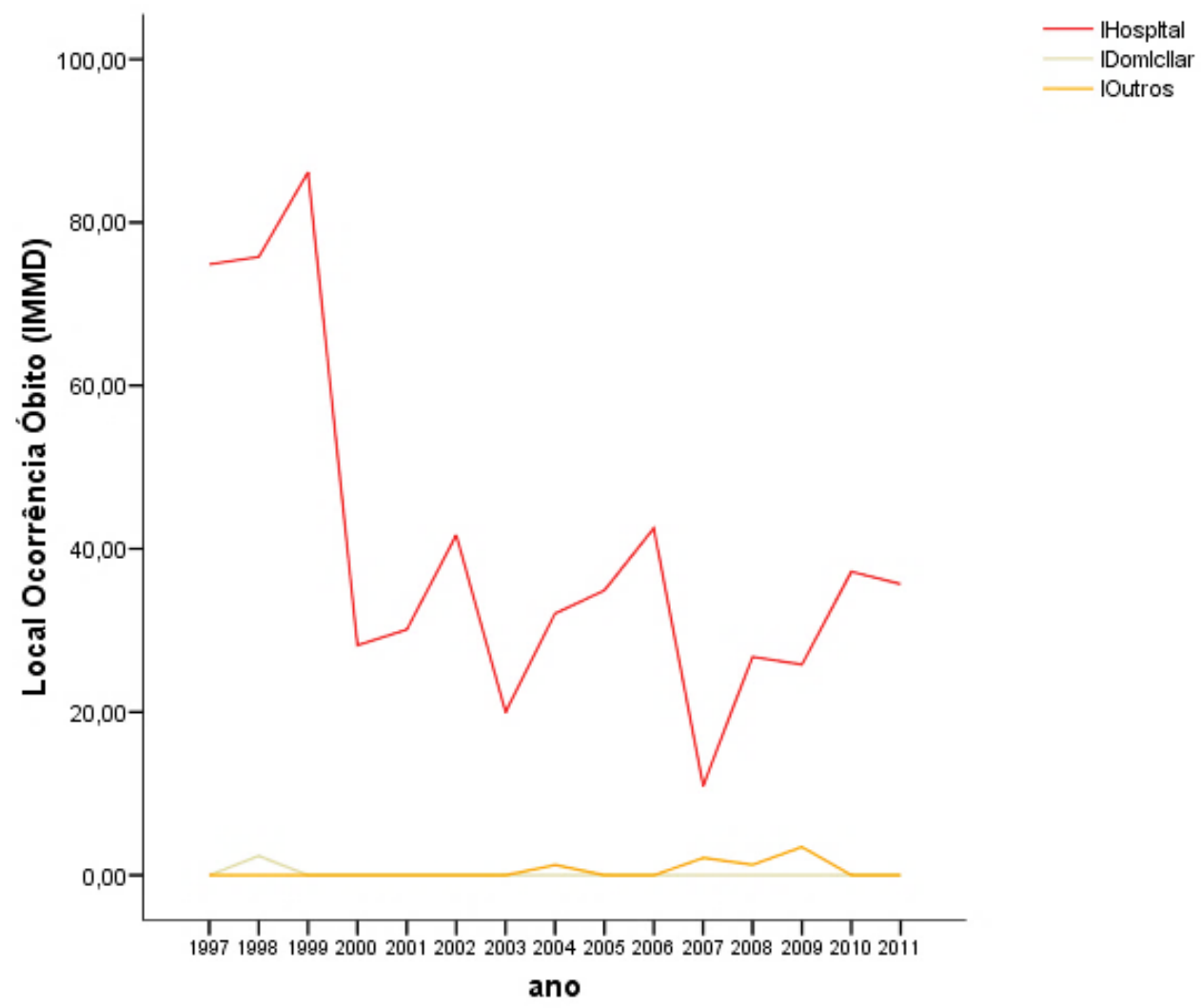

IMMD: Índice da Mortalidade Materna Direta.Ihospital, IDomiciliar, IOutros.

Figura 23. Série temporal dos IMMD por local de ocorrência do óbito 
A figura 24 apresenta a série temporal dos IMMD por investigação de ficha de notificação. Observamos que as investigações iniciaram-se em 2005 como "Não Investigado". No ano seguinte aparecem "investigação sem fichas" (valor médio máximo 22,83 $(0-91,05)$ em 2008, p<0,01) e na sequência, "investigação com fichas" (valor médio máximo 24,38 $(0-68,4)$, em 2009, p<0,01). Os dados sugerem que as medidas das notificações compulsórias iniciadas em 2003, associadas a Vigilância Epidemiológica iniciada em 2004, possam ter contribuído para estes resultados.

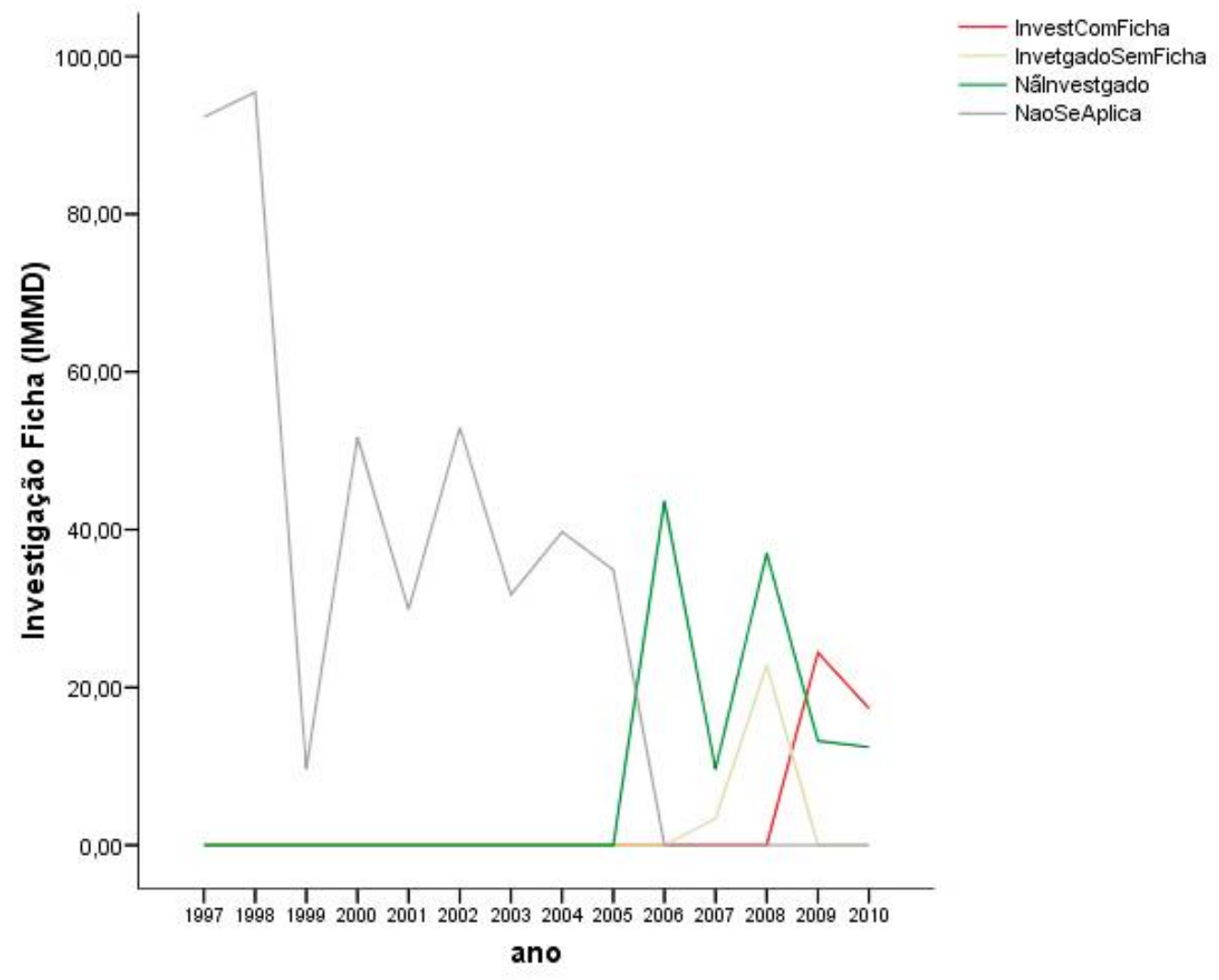

IMMD: Índice da Mortalidade Materna Direta. IMMD Invest com ficha, sem ficha, não investigada, não se aplica.

Figura 24. Série temporal dos IMMD por ficha de investigação do óbito. 


\subsection{Análise da Tendência Temporal Pela Regressão Linear}

As análises de associação da tendência temporal foram feitas por Regressão Linear $^{51}$ entre os Índices da Mortalidade Materna Direta, Indireta dos municípios e o tempo de estudo. Para estas análises os dados de IMMD e IMMI dos municípios de Diadema, Mauá, Ribeirão Pires, Rio Grande da Serra, Santo André, São Bernardo do Campo, São Caetano do Sul foram submetidos a transformação matemática (raiz-quadrada) para atingirem proximidade da normalidade.

A figura 25 apresenta a análise da tendência para o Índice da Mortalidade Materna Direta (IMMD) e período de estudo. Observa-se queda no Índice da Mortalidade ao longo do tempo com redução de $-0,23$ ao ano $\left(\mathrm{p}=0,04 ; \mathrm{R}^{2}=0,031\right.$; Beta= -0,23; equação: ano=2004,94+(-0,23xRDireta), onde RDireta é a raiz quadrada do Índice da Mortalidade Materna Direta). Valores expressos por raiz quadrada do Índice da Mortalidade Materna Direta e intervalo de confiança.

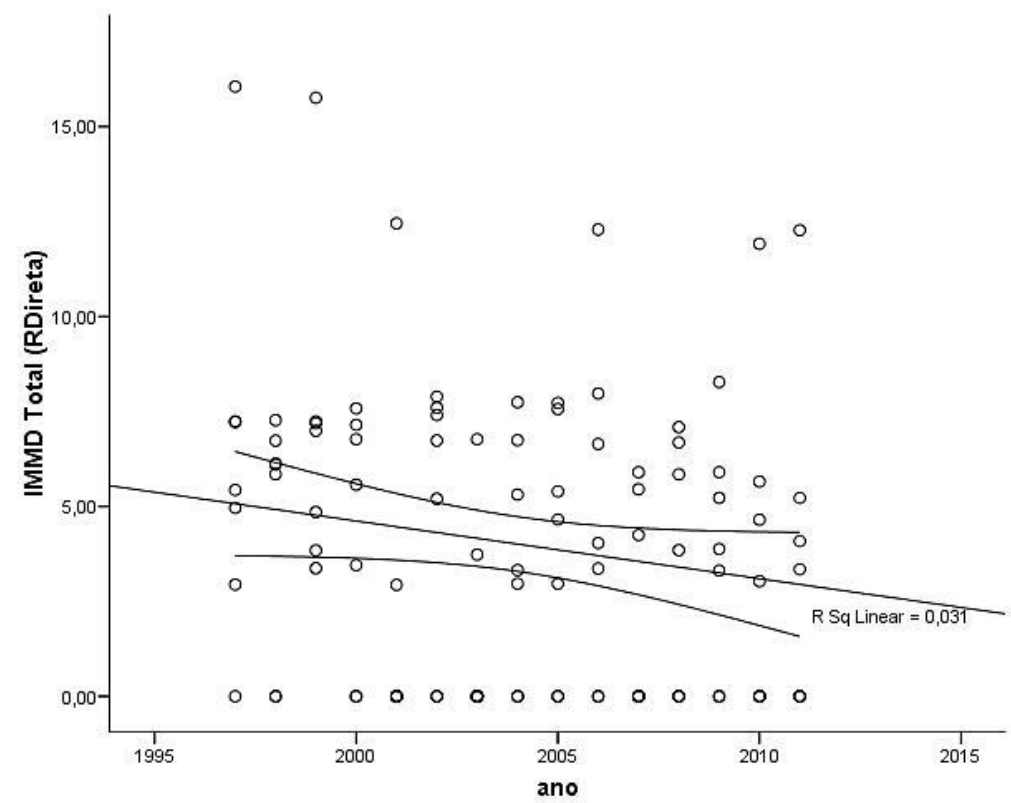

IMMD: Índice da Mortalidade Materna Direta; municípios totais: municípios da região do Grande ABC Paulista; Valores expressos por RIMMD: raiz quadrada e intervalo de confiança dos Índices da Mortalidade Materna Direta; RSqLinear: $\mathrm{R}^{2}$ da regressão linear; $\mathrm{p}=0,04 ; \alpha=5 \%$.

Figura 25. Tendência para a Mortalidade Materna Direta no tempo 
A figura 26 apresenta a tendência temporal dos índices da Mortalidade Materna nos municípios da região do Grande ABC Paulista. Não há significância de tendência entre os municípios e o tempo do estudo com exceção do município de São Caetano do Sul (figura 27).

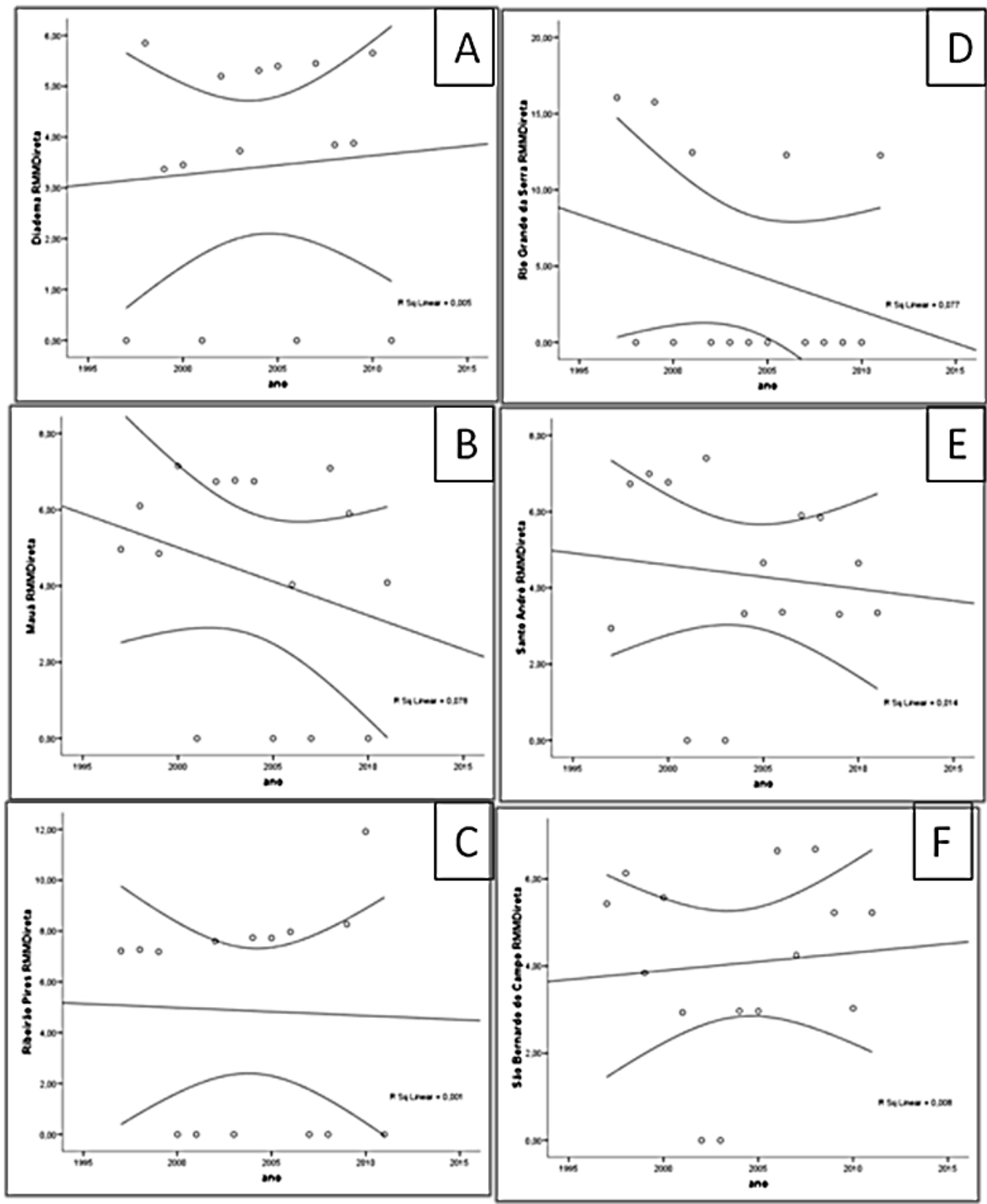

IMMD: Índice da Mortalidade Materna Direta ; A: Diadema; B: Mauá; C: Ribeirão Pires; D: Rio Grande da Serra; E: Santo André; F: São Bernardo do Campo; valores expressos por RIMMD: raiz quadrada e intervalo de confiança do Índice da Mortalidade Materna Direta de cada município da região do Grande ABC Paulista; RSqLinear: $\mathrm{R}^{2}$ da regressão linear;

Figura 26. Regressão Linear dos IMMD por municípios pelo tempo 
A figura 27 apresenta a tendência temporal analisada por regressão linear da raiz quadrada dos Índices da Mortalidade Materna Direta do município de São Caetano do Sul. Há relação negativa com tendência de redução dos IMMD de -0,67/ano neste município ( $p=0,03 ; \mathrm{R}^{2}=0,299$; Beta= -0,67; equação: ano= 2005,67-0,67xRDireta, onde RDireta é a raiz quadrada do Índice da Mortalidade Materna Direta).

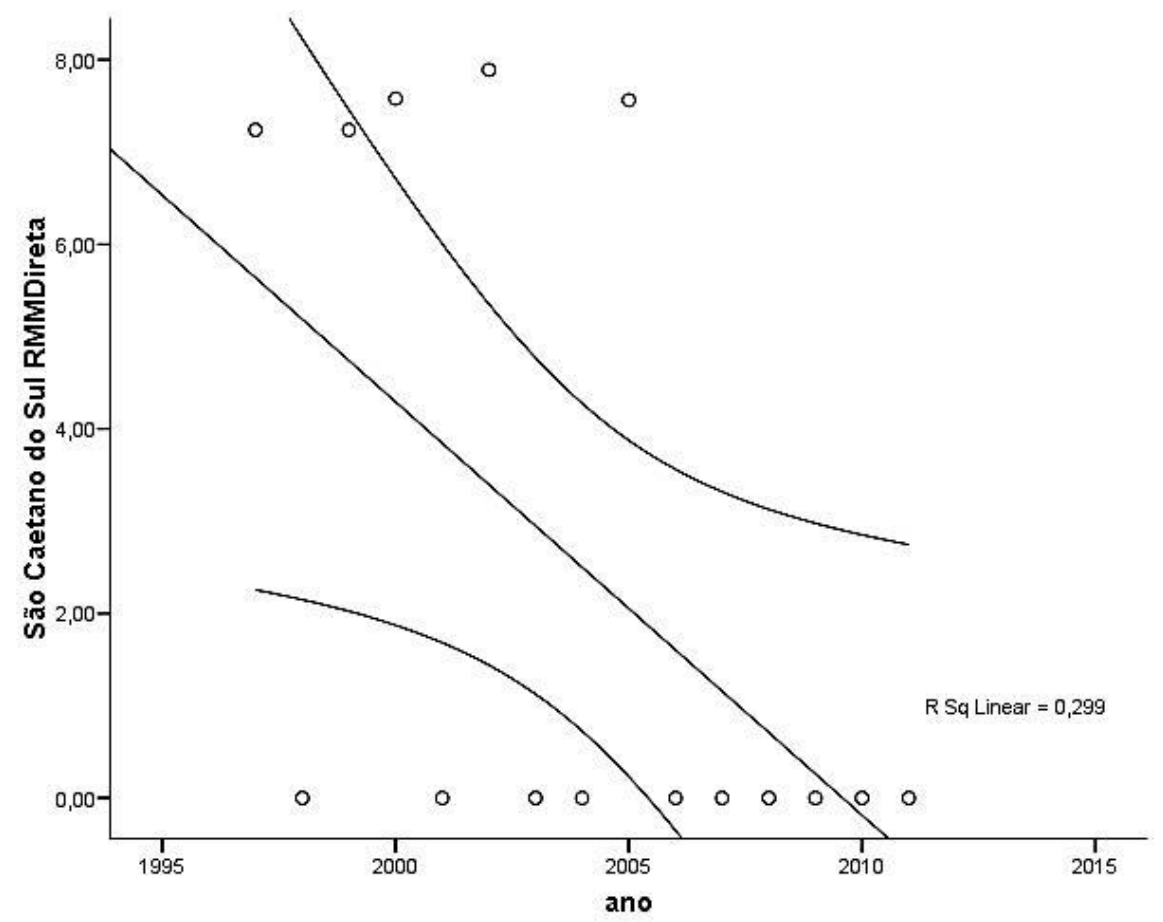

IMMD: Índice da Mortalidade Materna Direta; valores expressos por RIMMD: raiz quadrada e intervalo de confiança do Índice da Mortalidade Materna Direta de São Caetano do Sul; RSqLinear: ${ }^{2}$ da regressão linear; $p=0,03 ; \alpha=5 \%$.

Figura 27. Regressão Linear IMMD São Caetano do Sul pelo tempo 
A figura 28 apresenta o painel da tendência temporal dos Índices da Mortalidade Materna Direta no tempo estratificados por IDH (grupo 1= gráfico 19A; grupo 2= gráfico 19B). Observamos tendência de redução maior no grupo $\operatorname{IDH}=1 \quad(p=0,11$; R2=0,06; Beta= -0,37; equação: ano= 2005,34 -0,37 x RDireta, figura 26A) em relação ao grupo $2(p=0,15 ; R 2=0,04 ;$ Beta $=-0,19$; equação: ano=2004,83 $-0,19 x$ RDireta, onde RDireta é a raiz quadrada do Índice da Mortalidade Materna Direta) (figura 26B).

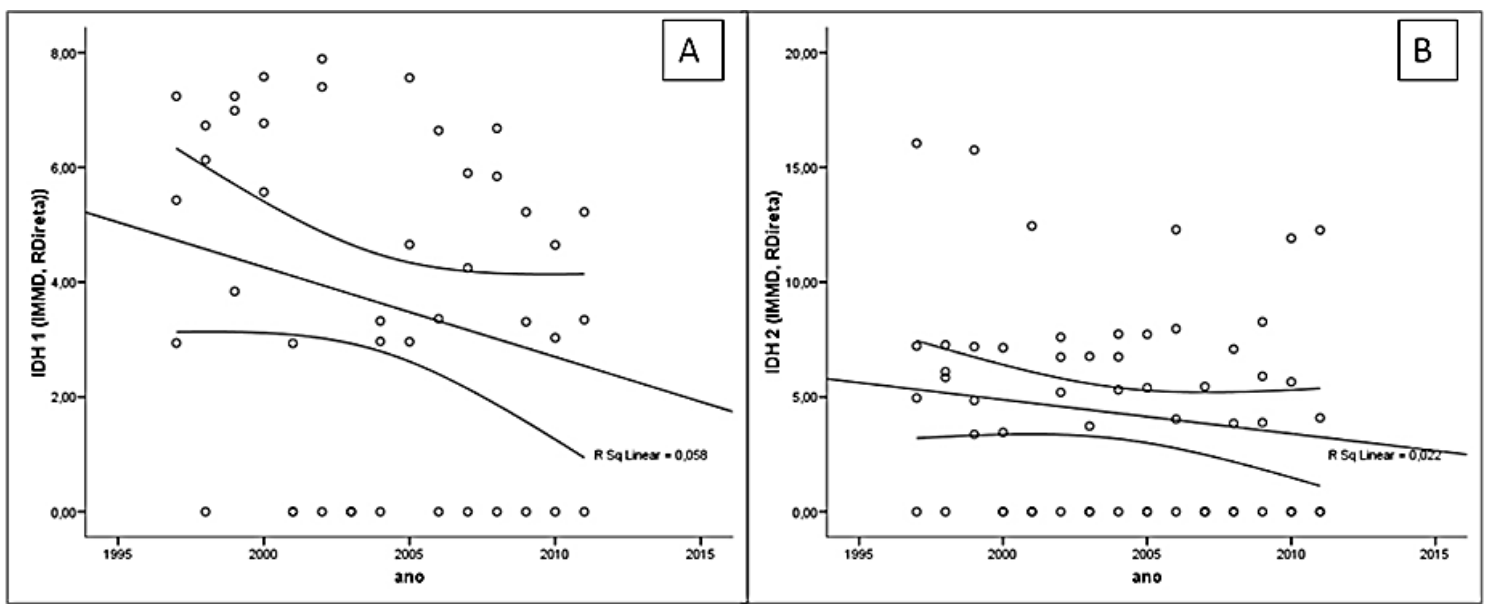

IMMD: Índice da Mortalidade Materna Direta; Valores expressos por RIMMD: raiz quadrada e intervalo de confiança do Índice da Mortalidade Materna Direta dos grupos IDH; RSqLinear: R² da regressão linear; A: IDH 1; B: IDH2; IDH: Índice de Desenvolvimento Humano.

Figura 28. Regressão Linear dos IMMD por IDH 1 (A) e 2 (B) e tempo de estudo 
A figura 29 apresenta um painel com a tendência temporal dos IMMD total dos municípios (A) e por grupos IDH 1 (B) e 2 (C) neste milênio (a partir do ano 2000). Observamos que há tendência decrescente com predomínio no grupo IDH 1 (B), com queda de $-0,368$ por ano (beta $=-0,368, r 2=0,058, p=0,112, x=2005,339-(0,368 . y)$. Não há relação entre o tempo e todos os municípios $\left(r^{2}=0,0\right.$, beta=+0,004, constante: $2005,48, p=0,97, A)$ e IDH $2\left(r^{2}=0,003\right.$, beta $=+0,53$, constante: $\left.2005,33, p=0,72, C\right)$.

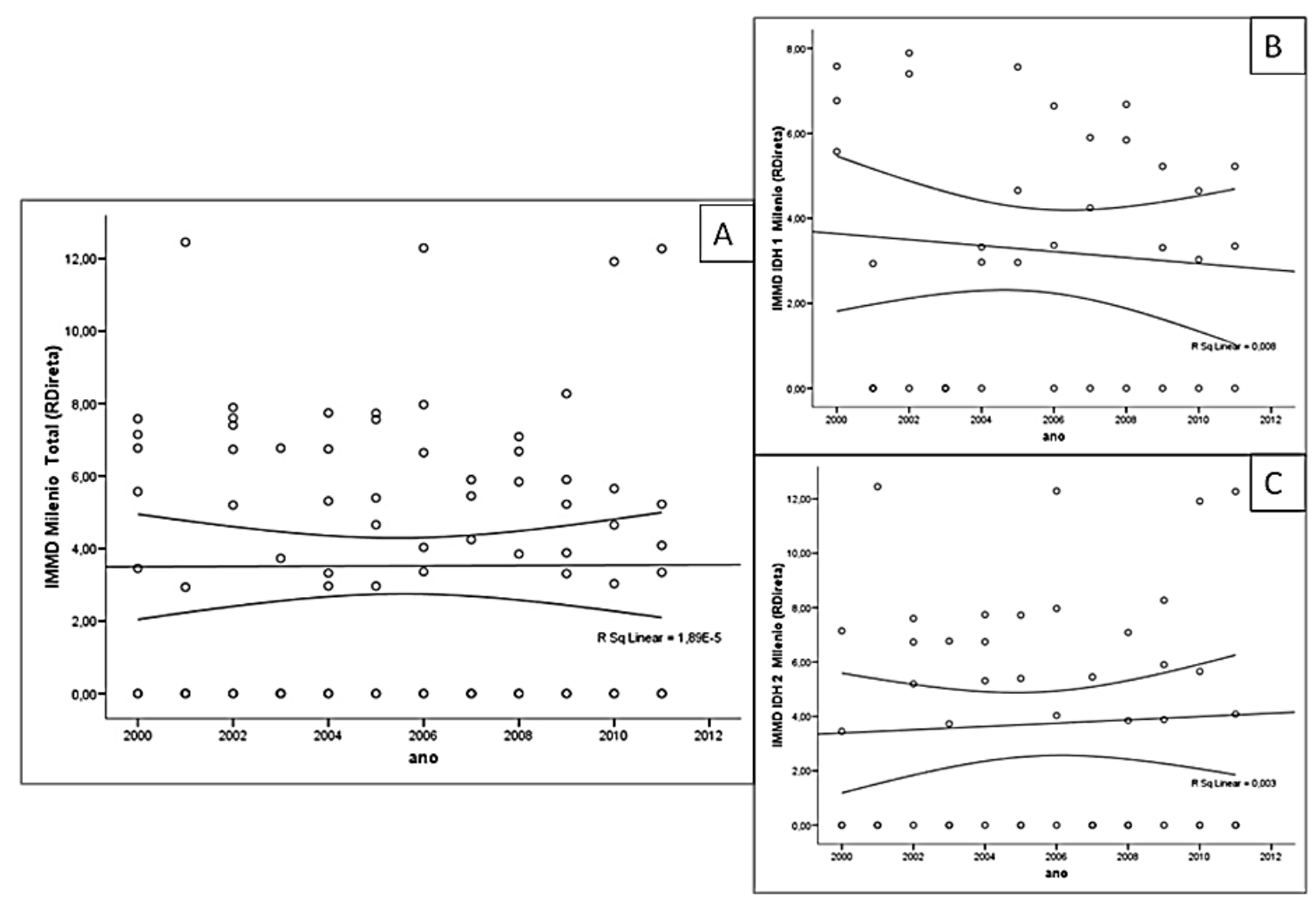

IMMD: Índice da Mortalidade Materna Direta; valores expressos por RIMMD: raiz quadrada e intervalo de confiança do Índice da Mortalidade Materna Direta dos municípios da região do Grande ABC Paulista e grupos IDH após o ano 2000; IDH: Índice de Desenvolvimento Humano.

Figura 29. Série Temporal Milênio municípios total e Grupos IDH 
A figura 30 apresenta as análises no milênio por municípios (Diadema (A), Mauá (B), Ribeirão Pires (C),Rio Grande da Serra (D), Santo André ( E), São Bernardo do Campo (F), São Caetano do Sul (G). Observa-se que São Caetano do Sul (G) apresenta tendência de decréscimo de $-0,53$ por ano $(\mathrm{p}=0,076, \mathrm{R} 2=0,282$, constante=2006,557, beta=-0,53). Quando estimada o IMMD de São Caetano do Sul em 2015, pela equação da regressão linear, obtivemos queda de $65,10 \%$ em relação ao ano 2000. Os outros municípios não apresentaram tendência estatística.

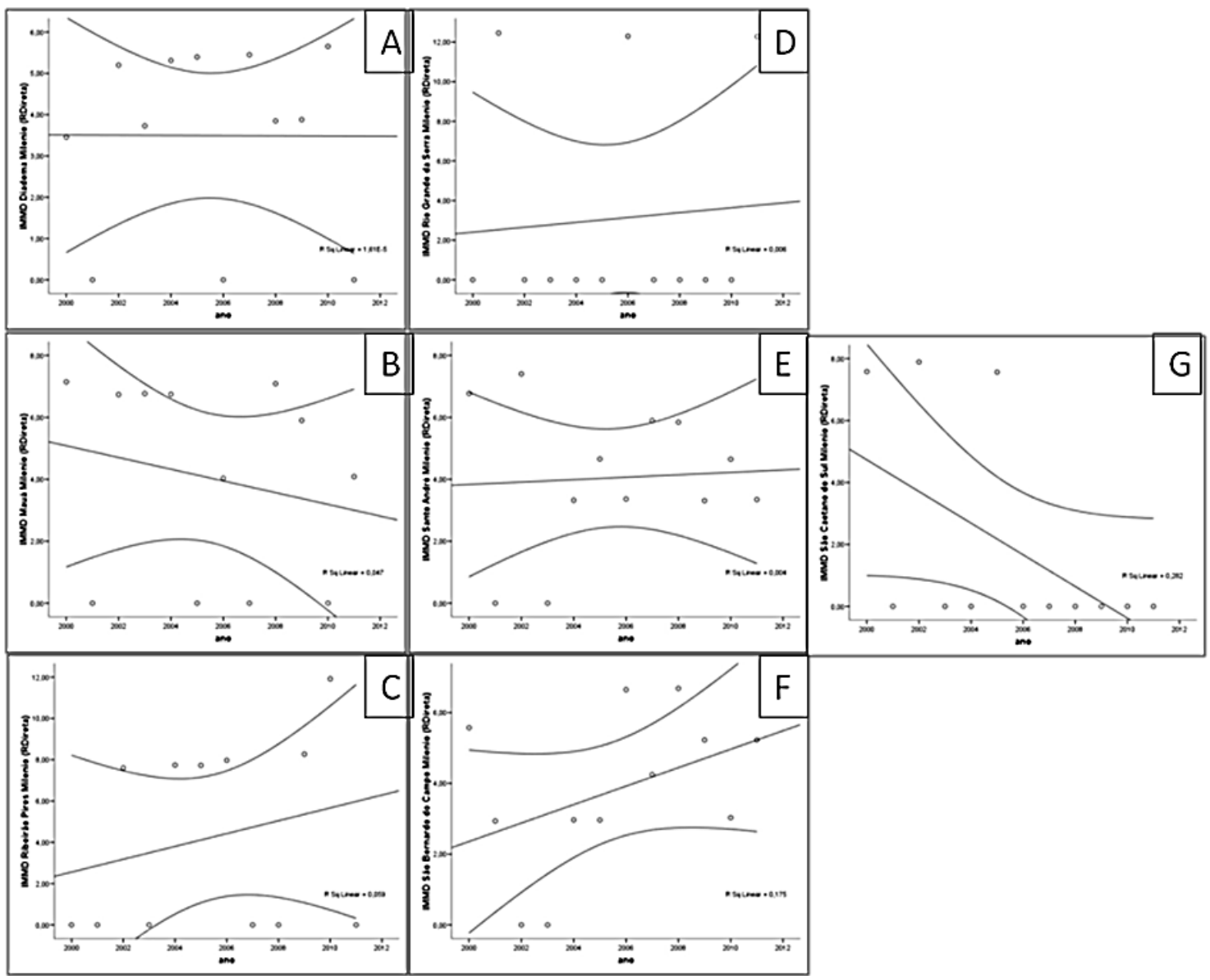

IMMD: Índice da Mortalidade Materna Direta; valores expressos por RIMMD: raiz quadrada e intervalo de confiança do Índice da Mortalidade Materna Direta dos municípios da região do Grande ABC Paulista após ano 2000; A: Diadema; B: Mauá; C: Ribeirão Pires; D: Rio Grande da Serra; E: Santo André; F: São Bernardo do Campo; G: São Caetano do Sul; RSqLinear: $\mathrm{R}^{2}$ da regressão linear.

Figura 30. Série Temporal Milênio por município 
A Figura 31 ressalta a visualização da tendência temporal do IMMD por todos os municípios (municípios totais, A, C) e São Caetano do Sul no tempo total do estudo (15 anos, B) e pós ano 2000 (D). Confirmamos a queda na Mortalidade Materna Direta total no período total do estudo $\left(\mathrm{r}^{2}=0,04\right.$, beta=-0,23, constante: $2004,94, \mathrm{p}=0,04$, Figura A) devido a São Caetano do Sul $\left(r^{2}=0,299\right.$; beta= -0,67, constante: 2005,67, p=0,03, Figura B). Após o ano 2000, não há relação entre o tempo e IMMD de todos os municípios $\left(r^{2}=0,0\right.$, beta $=+0,004$, constante:2005,48, p=0,97, Figura C) apesar de São Caetano do Sul ainda tender a demonstrar queda neste milênio $\left(r^{2}=0,282\right.$, beta=-0,53, constante:2006,56, $p=0,07$, Figura D). Os outros municípios não apresentaram relação entre os IMMD ao longo do tempo total ou neste milênio quando analisados pela regressão linear.

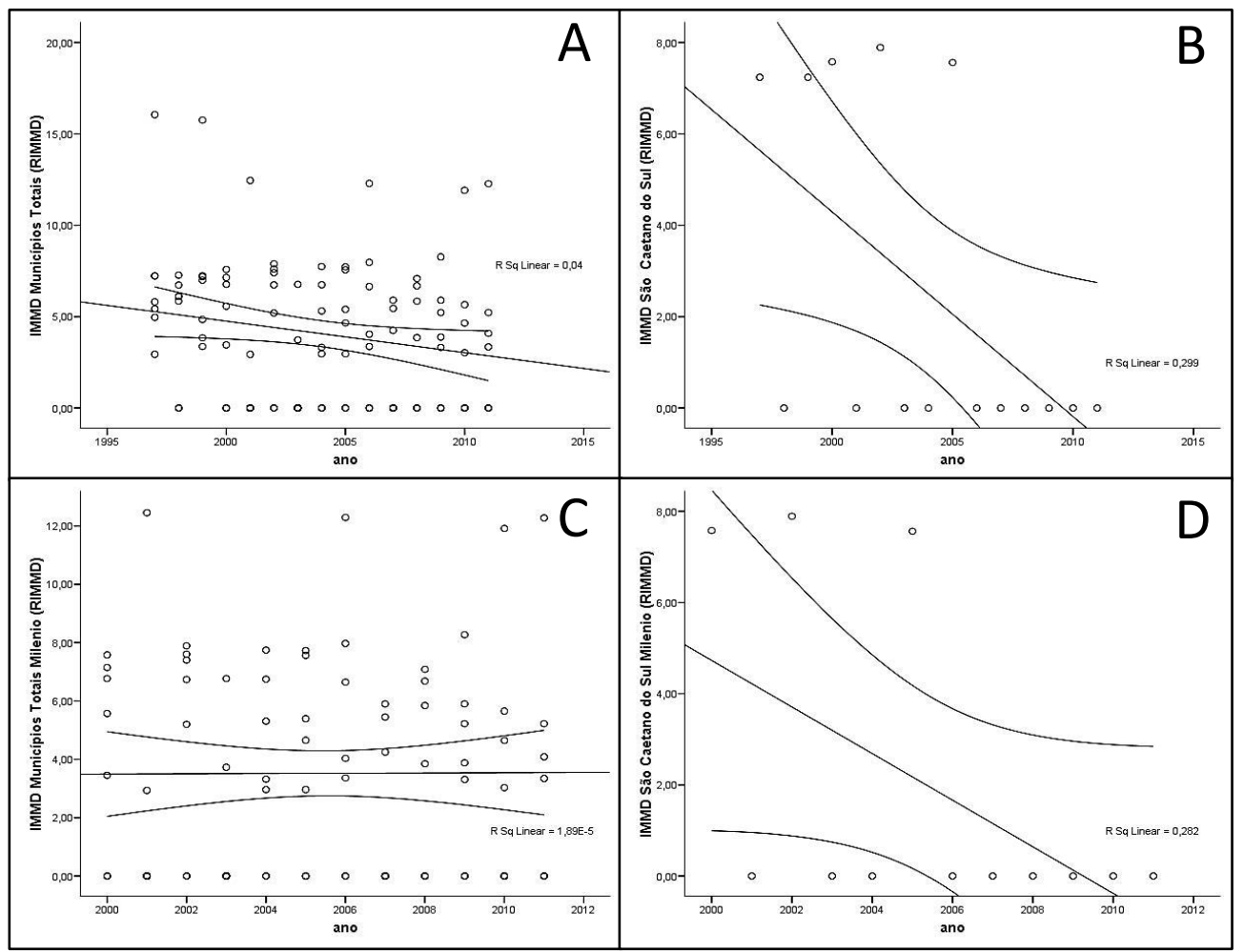

IMMD: Índice da Mortalidade Materna Direta; valores expressos por RIMMD: raiz quadrada e intervalo de confiança do Índice da Mortalidade Materna Direta dos municípios da região do Grande ABC Paulista (A, C) e São Caetano do Sul (B, C) tempo total 15 anos (A, B) e pós (C,D) o após o ano de 2000; RSqLinear: $\mathrm{R}^{2}$ da regressão linear; A:p=0,04; $\mathrm{B}: \mathrm{p}=0,03 ; \mathrm{C}: \mathrm{p}=0,97 ; \mathrm{D}: \mathrm{p}=0,07 ; \alpha=5 \%$.

Figura 31. Tendência Temporal do Índice da Mortalidade Materna Direta por municípios Totais e São Caetano do Sul Tempo Total (15 anos) e Pós ano 2000 
A Figura 32 refere-se à Mortalidade Materna Indireta (MMI), após a transformação pela raiz quadrada dos IMMI, quando analisada sua série temporal no tempo total do estudo pela regressão linear. Obtemos queda no município de Santo André (r2=0,468, beta=-0,485, constante:2001,265, p=0,005, Figura 32 A) e tendência a aumento no município de São Bernardo do Campo (r2=0,226, beta $=+0,485$, constante: 2004,74, $\mathrm{p}=0,06$, Figura $32 \mathrm{~B}$ ), nos municípios totais ( $r 2=0,034$, beta $=-0,184$, constante $=2004,47, p=0,06$, Figura 32 C) e no grupo IDH1 (IDH 1: r2=0,075, beta=-0,274, constante: 2004,8, p=0,06, Figura 32 D), sem relação do tempo do estudo com os outros municípios, ou por estratificação por IDH 2 (IDH2: r2=0,01, beta=-0,101, constante: 2004,24, p=0,442), Figura 32.

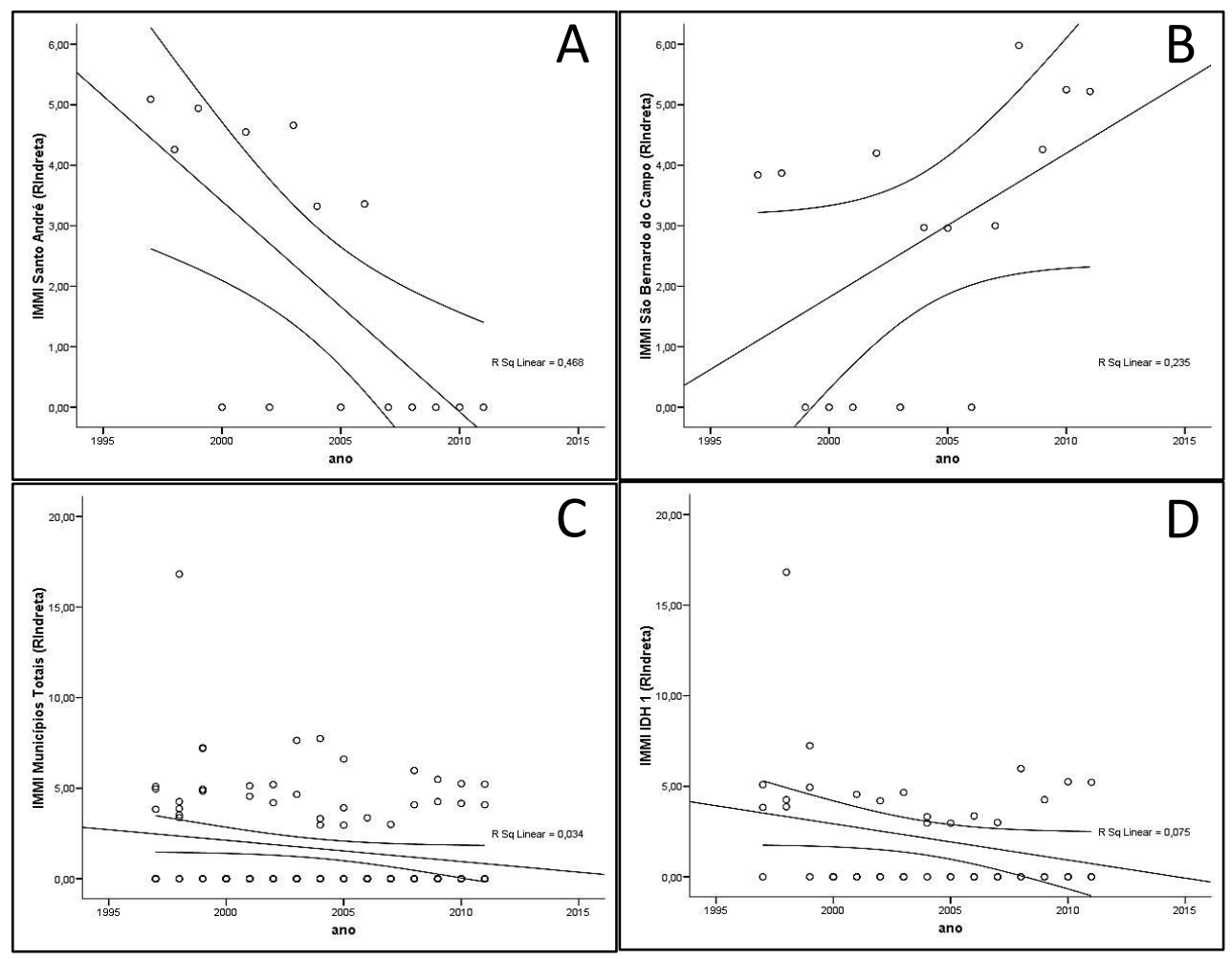

IMMI: Índice da Mortalidade Materna Direta e Indireta; valores expressos por RIMMI: raiz quadrada e intervalo de confiança do Índice da Mortalidade Materna Direta e Indireta dos municípios de Santo André (A), São Bernardo do Campo (B), municípios totais (C) e grupo IDH 1 (D) em todo o período do estudo. Percebeu-se queda dos IMMI em Santo André $(p=0,005)$ e tendência a aumento em São Bernardo do Campo $(p=0,06)$, municípios totais $(p=0,06)$ e grupo IDH 1 ( $\mathrm{p}=0,06), \alpha=5 \%$; RSqLinear: $\mathrm{R}^{2}$ da regressão linear.

Figura 32. Tendência Temporal dos IMMI pelo período do estudo 
A figura 33 apresenta o painel das regressões lineares do IMMI (após transformação pela raiz quadrada dos dados) após o ano 2000. Os únicos municípios que apresentaram relação neste milênio no tempo foram Mauá $(\mathrm{r} 2=0,388$, beta=+0,623, constante:2003,98, p=0,03, Figura 33 A) e São Bernardo do Campo (r2=0,531, beta $=+0,728$, constante:2002,26, p=0,007, Figura 33 B) ambos demonstrando aumento expressivo dos IMMI no período. Os outros grupos (municípios totais, outros municípios e grupos IDH) não expressaram relação do IMMI com o milênio pela regressão linear. Os dados de aumento dos IMMI (mortalidade materna inevitável) no período nos municípios de maior população, podem sugerir maior aumento da urbanização destes municípios. Os resultados de aumento no tempo do IMMI para Santo André e São Bernardo do Campo, ambos os municípios do grupo IDH 1, se confrontam com os dados encontrados no município de São Caetano do Sul que expressou IMMI indetectáveis (zero) no decorrer do milênio (Figura 33C). Porém, relembramos que na tabela 5, São Caetano do Sul havia apresentado os maiores índices de MM inevitável entre os municípios. A figura 33D expõe os IMMI em São Caetano do Sul em todo o período de estudo e evidencia que os altos IMMI ocorreram apenas em 1997-1998 (Figura 33D). 


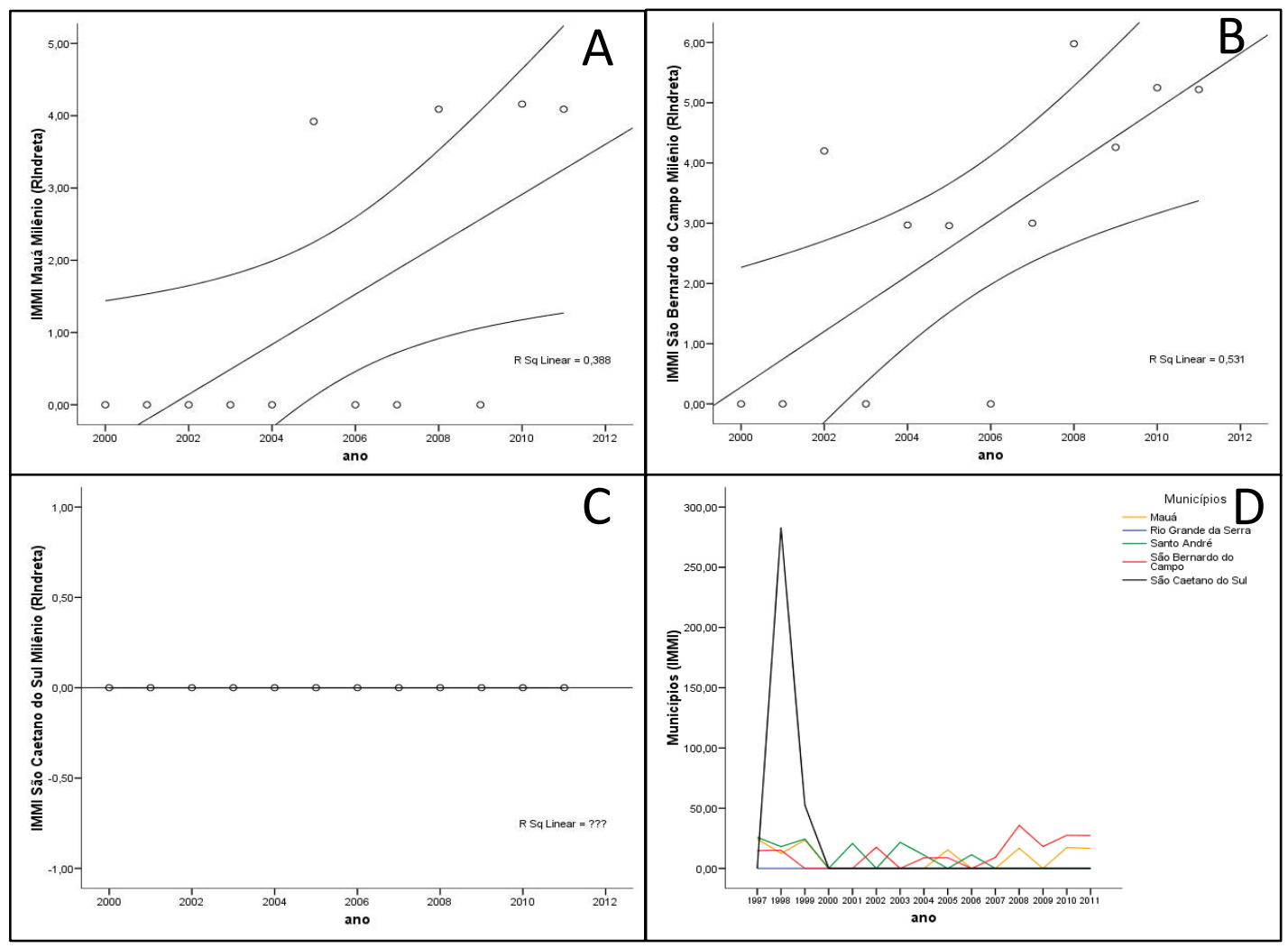

IMMI: Índice da Mortalidade Materna Direta e Indireta; valores expressos por RIMMI: raiz quadrada e intervalo de confiança do Índice da Mortalidade Materna Direta e Indireta dos municípios de Mauá (A), São Bernardo do Campo (B), São Caetano do Sul (C) de 200 a 2011. A figura 32 D demonstra o IMMI no período total do estudo. Percebeu-se aumento dos IMMI em Mauá ( $\mathrm{p}=0,03)$ e aumento expressivo em São Bernardo do Campo $(\mathrm{p}=0,007), \alpha=5 \%$. Não há relação entre o tempo após o ano 2000 e o município de São Caetano do Sul (C). Observar pico de IMMI no município São Caetano do Sul em 1998 e a ausência deste índice após esta data; RSqLinear: $\mathrm{R}^{2}$ da regressão linear.

Figura 33. Tendência Temporal dos IMMI após o ano 2000 
5 DISCUSSÃO 
Observamos que o perfil sociodemográfico da mortalidade materna na Região do Grande ABC Paulista no período de 1997 a 2011 é de mulheres brancas, faixa etária entre 20 a 34 anos de idade, solteiras, escolaridade entre 4 a 7 anos. As principais causas foram hemorragias/tromboses/embolias seguida por eclâmpsias, causas estas definidas como evitáveis pela OMS ${ }^{4,19}$. A quase totalidade das mortes maternas pelo local da ocorrência dos óbitos foram hospitalares e no puerpério imediato que compreende até 42 dias após o parto ou após interrupção da gravidez. Quanto à investigação dos óbitos pelas fichas de notificação instituídas pela vigilância epidemiológica (VE) após 2003, constatou-se que a maioria das fichas não foram investigadas ou continham dados inadequados de notificação (ignorados, inconsistentes, não informados), sugerindo subinformação dos dados no sistema DATASUS ${ }^{19,49}$. Os Índices da Mortalidade Materna Direta evitável ainda atingem níveis muito altos (segundo OMS) ${ }^{4}$ acima de 50 em alguns municípios, principalmente em Rio Grande da Serra e Ribeirão Pires, com predomínio nos finais dos anos 90. A queda da mortalidade materna em relação ao tempo foi significativa apenas em São Caetano do Sul com estimativa de queda no milênio de $65,1 \%$ até 2015 . A estratificação por $\operatorname{IDH}^{4,34,49}$ não mostrou diferenças entre os grupos na maioria das covariáveis analisadas.

Os resultados deste estudo espelharam parcialmente as estimativas nacionais e mundiais ${ }^{2,14}$.

O número de mães que morrem em todo o mundo por motivos relacionados ao ciclo gravídico puerperal, são alarmantes. 
O Brasil, segundo a Organização Mundial da Saúde (OMS) de 1990 a 2013, apresentou redução de 120 para 69 mães que morrem a cada 100 mil crianças nascidas vivas, portanto queda de $43 \%{ }^{4}$.

Nossos dados apontaram para queda de $43 \%$ da Mortalidade Materna Direta total por 15 anos no período estudado. Esta queda ocorreu principalmente devido ao município de São Caetano do Sul que representou a única redução significativa do IMMD no período. Quando analisados os resultados e considerando apenas pelo atual milênio, não houve relação entre mortalidade materna e tempo total na região estudada, sugerindo estagnação dos IMMD a partir do ano 2000. Porém, o município de São Caetano do Sul ainda expressou tendência a queda neste milênio, com estimativa de redução de $65,1 \%$ até 2015 , ainda aquém da proposta do Pacto do Milênio para o país que é de $75 \%$ para redução da $\mathrm{MM}^{5}$. Esses dados corroboram também para refletir a grande heterogeneidade entre municípios na região do Grande $\mathrm{ABC}$ Paulista.

Demonstrou-se através das análises de série temporal que o município de São Caetano do Sul, de maior $\mathrm{IDH}^{4}$, apresentou índices da Mortalidade Materna Direta (IMMD) classificados em baixo pela $\mathrm{OMS}^{4}$ e aceitável pelo MS- Brasil $^{20}$ e Índice da Mortalidade Materna Indireta (IMMI) considerado média pela $\mathrm{OMS}^{4}$ e recomendado pelo MS-Brasil $^{20}$. Este foi o único município na região que obteve queda no IMMD ao longo do período do estudo, com estimativas de alcançar as metas públicas de controle da mortalidade materna nacionais e internacionais até 2015, podendo se classificar como município de país desenvolvido (OMS) ${ }^{4}$. Porém, o município de Rio Grande da Serra comportou-se como município de países em desenvolvimento apresentando IMMD (morte evitável) altos (OMS) e considerados baixos segundo os critérios do MS-Brasil, contrapondo-se com IMMI (morte inevitável) de zero, considerado baixo para OMS e 
aceitável para o MS/Brasil ${ }^{4,31}$. A relação inversa entre os IMMI e IMMD do município de São Caetano do Sul e Rio Grande da Serra poderiam confirmar a relação de interdependência dos níveis socioeconômicos e dos índices da mortalidade materna de uma região, onde municípios com melhor qualidade educacional e de saúde, relacionamse aos menores índices da mortalidade materna ${ }^{1,47,49}$. De fato, na composição estrutural da assistência hospitalar com gestão SUS, a região do Grande ABC Paulista conta com 12 referências hospitalares municipais, 02 referências hospitalares estaduais e 02 referências hospitalares privadas (prestadoras - SUS) ${ }^{1,36,49}$. O município de Rio Grande da Serra é o único município na região do Grande $\mathrm{ABC}$ Paulista que não possui unidade de saúde hospitalar de média e alta complexidade para atendimento da população e referencia atendimentos secundários ou terciários para outros centros de referências hospitalares tais como: Mauá e Ribeirão Pires. Este fato pode contribuir para dificultar a acessibilidade da mulher grávida e doença severa com agravamento da situação da saúde da população assistida. Contudo, a avaliação que São Caetano do Sul apresenta altos IMMI deve ser interpretado com cuidado visto que, nas análises por série temporal, os IMMI em São Caetano estavam altos apenas em 1997 e 1998, tornando-se zero no restante do período analisado. Por outro lado, São Bernardo do Campo e Mauá apresentaram tendência ao aumento do IMMI no tempo quando analisados pela regressão linear, sugerindo que outros fatores externos ao ciclo gravídico puerperal devam estar influindo temporalmente neste IMMI. É possível que por serem mais populosos e com maior grau de urbanização sejam mais vulneráveis a mortes maternas inevitáveis por causas externas tais como: epidemias, acidentes e doenças não relacionadas ao ciclo gravídico puerperal. Outro fator a ser considerado seria a inadequação da notificação da MMI no município de São Caetano do Sul após o ano 2000. 
A estratificação por IDH não foi capaz de diferenciar os grupos na maioria dos quesitos analisados. Acreditamos que isto reflete às limitações deste índice que, apesar de mundialmente reconhecido e proposto pelo PNUD-OMS ${ }^{4,33,34}$, estratificou municípios sociodemográficos tão distintos, porém classificados em IDH muito próximos, considerados níveis altos, sem condições de discerni-los entre si. Optamos por trabalhar com o IDH, que apresenta validação externa e reconhecimento internacional, com confiabilidade científica e com limitações já testadas ${ }^{35}$. Vários autores criticam a classificação de desenvolvimento humano de um país ou região somente por um índice de bem estar social e econômico como o IDH devido às limitações inerentes a cada item no âmbito social, ambiental e auto-sustentabilidade ${ }^{52,53}$. Recomendam que as nações sejam qualificadas por uma agregação de índices complementares entre $\mathrm{si}^{52.53}$. Porém, quais os melhores índices e quais que devam ser agregados para esse julgamento ainda é controverso na literatura ${ }^{34,35,53}$. De fato, o IPRS criada pela Fundação $\operatorname{SEADE}^{36}$ para o Estado de São Paulo propõe a classificação de desenvolvimento socioeconômico através deste índice, que estratifica os municípios na região do Grande ABC Paulista em Grupo 1= municípios de Ribeirão Pires, Santo André e São Caetano do Sul; Grupo 2 = municípios de Diadema, Mauá e São Bernardo do Campo e Grupo 5 = município de Rio Grande da Serra. Porém, não há validação externa deste índice e nem confiabilidade e reconhecimento internacional ${ }^{36}$.

Houve predomínio da etnia branca entre as mães que faleceram na região analisada durante o ciclo gravídico puerperal. Acredita-se que a prevalência da etnia branca encontrada, deva ser interpretada com cautela, visto poder refletir a dificuldade em classificar a etnia (raça/cor) principalmente em regiões com alta miscigenação racial, como a encontrada no Brasil ${ }^{54,55,56}$. 
Ocorreu maior IMMD em mulheres de etnia negra no grupo IDH 1. Este dado sugere melhoria na qualidade da informação que abasteceu os sistemas oficiais neste grupo de municípios. Estes resultados apoiam estudos que referem vulnerabilidade associada aos fatores de riscos socioeconômicos das mulheres principalmente, pobres e afrodescendentes, onde aumenta o risco para o óbito materno ${ }^{24,55,57}$. O aumento nos índices da mortalidade materna da etnia afrodescendente e a diminuição de dados ignorados no período analisado poderiam reforçar melhoria na inclusão dos dados nas Declarações de Óbitos (DO). Porém, ao verificarmos a estratificação temporal deste quesito, percebeu-se que a notificação de negros é discreta frente a notificação da etnia branca, e quase ausente durante o período estudado com exceção dos anos 2002 e 2006, quando a notificação se torna mais expressiva apesar de ainda discreta. Portanto, esses dados apontam predominantemente para subnotificação e não necessariamente melhoria das notificações.

Interessantemente, as complicações que levaram ao óbito se manifestaram principalmente no período médio da idade fértil da mulher, faixa etária entre 20 e 24 e 30 a 34 anos de idade e não em idade considerada de gestação de alto risco definido pela Federação Brasileira de Ginecologia e Obstetrícia (FEBRASGO), entre os períodos na adolescência (menor que 19 anos) e final (pós 35 anos) do período da idade fértil da mulher ${ }^{19}$. Estes resultados podem sugerir que devam ocorrer orientação da anticoncepção da mulher na região do Grande $\mathrm{ABC}$ Paulista, pois as gestações complicadas que levaram ao óbito não predominaram na adolescência, e sim na metade do tempo da idade fértil da mulher.

O estado civil solteira é predominante nos períodos de estudo. Advém ao fato de que na sociedade em que as relações de gênero deixam de favorecer a mulher, o estado 
civil, principalmente as solteiras, coloca-as em situação de maior vulnerabilidade e susceptibilidade para a mortalidade materna, pois não dispõe do apoio familiar, dentre outras questões ${ }^{58}$. Ainda, no ano de 2009, houve um incremento da morte de mães viúvas, podendo sugerir falha na inclusão dos dados no sistema, nos outros anos.

Os índices da escolaridade dos óbitos maternos predominaram no intervalo de 4 a 7 anos de estudo. Estes dados estão em consonância com outros estudos já realizados, que sugerem que o óbito materno se manifesta principalmente nas populações mais vulneráveis socioeconomicamente $e^{59,60}$.

O DATASUS ${ }^{49}$ classificou os óbitos maternos de acordo com o local de residência e causas agrupadas de óbitos de mulheres em idade fértil, incluídas no Capítulo XV do Classificação Internacional de Doenças (CID 10) ${ }^{26}$. Invariavelmente, a maior ocorrência dos óbitos maternos na região do Grande ABC Paulista, advém de fatores hemorrágicos, circulatórios trombóticos, embólicos e eclâmpsias, causas sabidamente evitáveis da Mortalidade Materna Direta. Estas causas predominaram no município de menor poder socioeconômico, como Rio Grande da Serra: hemorragias/tromboses/embolias e também no município de Ribeirão Pires: eclâmpsia; sugerindo carência na assistência ao pré natal, parto ou puerpério ${ }^{16,49,61}$. As causas de mortes maternas nos municípios estudados, poderiam ter sido evitadas, corroborando com os dados do Ministério da Saúde do Brasil, que aponta causa evitável para óbito materno em $92 \%$ dos $\operatorname{casos}^{38,48,49}$.

Os municípios de Mauá, Ribeirão Pires e São Bernardo do Campo apresentaram maiores causas de óbitos maternos "outras doenças prévias que não complicaram no parto ou puerpério", portanto evidenciando ser causa da Mortalidade Materna Indireta, não evitável, característica de municípios com maiores IDH (OMS) ${ }^{4}$.Os índices da 
Mortalidade Materna Indireta (MMI) são "resultantes de doenças que existiam antes da gestação ou que se desenvolveram durante este período, não provocadas por causas obstétricas diretas, mas agravadas pelos efeitos fisiológicos da gravidez" "62. Entretanto, municípios distintos socioeconomicamente a saber: São Caetano do Sul e Rio Grande da Serra, apresentaram igualmente ausência de óbitos maternos neste quesito. É possível que esta causa do óbito materno não consiga estratificar os municípios analisados entre si por ser dependente de vários fatores externos distintos como epidemias, acidentes , intoxicações e doenças não relacionadas ao ciclo gravídico puerperal ${ }^{19,59}$; outra possibilidade seria inadequação da informação para o sistema oficial.

Outro fato interessante encontrado em nossos dados foi a ausência de Diabetes Gestacional. Este dado pode sugerir várias causas $^{26}$, entre elas citamos: notificação inadequada e baixa incidência desta morbidade em mulheres em idade fértil nesta região estudada.

Quanto ao período da ocorrência do óbito materno, houve decréscimo da mortalidade materna não informada, sugerindo melhoria na qualidade da informação/notificação do óbito materno neste quesito. Porém, ainda obtivemos maior concentração de óbitos em mães no puerpério imediato e tardio no município de Rio Grande da Serra, quando comparado com o município de São Caetano do Sul. Estes dados espelham maior carência da assistência a saúde da mulher no pré natal, parto e puerpério em Rio Grande da Serra. O município de São Caetano do Sul, por sua vez apresentou predomínio dos óbitos maternos durante a gravidez. Relembramos que o município de São Caetano do Sul, apresentou maiores IMMI que são considerados inevitáveis e independente da assistência à saúde no período do ciclo gravídico puerperal. Assim, é possível que causas de MMI como as externas possam ter 
contribuído para o óbito durante a gravidez. O período do óbito materno no puerpério tardio foi notificado somente nos municípios de Santo André e Mauá; no entanto, o município de Rio Grande da Serra apresentou quase a maioria das notificações para o período do óbito materno como "não informado". Estes resultados reafirmam predomínio da inadequação da informação/notificação em regiões mais vulneráveis e também pode sugerir omissão do estado gravídico da mulher, favorecendo mensuração irreal destas mortes ${ }^{28}$.

O fato dos óbitos maternos diretos evitáveis ocorrerem em quase sua totalidade em ambiente hospitalar aponta para a necessidade de melhoria no acesso e da qualidade da assistência em saúde na região ${ }^{12,55}$. No município de Rio Grande da Serra por apresentar estrutura de sistema de saúde mais fragilizado, o acesso à saúde global no ciclo gravídico puerperal é mais tardio e dificultoso, ocorrendo referenciamento da população a ser assistida para outros serviços de sáude fora do seu terrítório, podendo acarretar o aumento de eventos letais nos casos mais graves.

Observou-se altas taxas de óbitos maternos não investigados e não se aplica, em todas as covariáveis analisadas ${ }^{49}$. Estes dados sugerem notificações inadequadas ou subinformações sobre mortalidade materna obtidas pelo DATASUS ${ }^{49}$. Observamos que após a implantação da vigilância epidemiológica (2003) na região, aumentaram as notificações sem fichas (2006) e posteriormente com fichas (2008), demonstrando a latência de pelo menos 3 anos para que as implantações provavelmente tivessem efeito. Apesar de não haver diferenças significativas entre municípios, Ribeirão Pires, Rio Grande da Serra e Santo André, apresentaram os maiores índices de notificações de óbitos maternos diretos não investigados no período de estudo, refletindo latências maiores para cumprimento da obrigatoriedade da notificação da morte materna. 
Observamos que apesar de terem melhorado a notificação pós a implantação da vigilância epidemiológica no país, os dados ainda carecem de melhorias da inserção nos sistemas oficiais da notificação da mortalidade materna para total confiabilidade destes dados fornecidos pelo DATASUS ${ }^{41,49}$. Corroborando para esses dados Tognini S. et al ${ }^{48}$, no período de 1997 a 2005, identificaram 64,62\% a mais dos óbitos maternos na região do Grande $\mathrm{ABC}$ Paulista, quando comparadas as duas fontes de dados: a oficial pela Fundação Sistema Estadual de Análise de Dados $\left(\right.$ SEADE) ${ }^{36}$ e a do Comitê de Estudos da mortalidade materna (CEMM), demonstrando a eficiência e a importância da implantação e implementação dos Comitês de Estudos da Mortalidade Materna para a identificação, pesquisa e melhor classificação das mortes ocorridas ${ }^{48}$.

Várias medidas públicas foram implantadas no país para controle da mortalidade materna durante o período deste estudo e podem ter corroborado para os resultados obtidos, dentre elas podemos citar: o Programa de Humanização no Pré natal e Nascimento a partir do ano de 2000, a Notificação Compulsória da mortalidade materna a partir do ano de 2003, do Pacto Nacional pela Redução da mortalidade materna e Neonatal do ano de 2004, Pacto pela Saúde do ano de 2006, Vigilância Epidemiológica do ano de 2008, Regulamentação do Indicador de Monitoramento de Avaliação do Pacto pela Vida do ano de 2009, Rede Cegonha do ano de 2011. Apesar destas e todas as medidas públicas implantadas para controle da mortalidade materna evitável, não podemos afirmar qual foi o grau de contribuição de cada uma delas em nossos resultados. O que podemos evidenciar, é que apesar delas, ainda há indícios neste e em outros estudos da significante subnotificação dos dados da mortalidade materna em sistemas oficiais do país ${ }^{40,48}$. 
Vários fatores puderam ter contribuído para as ocorrências das mortes maternas nos municípios na região do Grande $\mathrm{ABC}$ Paulista encontrados neste estudo: ausência da assistência adequada à gestação, parto e puerpério, ocorrência que se destaca pela falta no acesso facilitado aos serviços de saúde, ao controle da natalidade, a qualidade desta assistência; dificuldade quanto ao acesso à educação, incluindo os fatores sociais e econômicos; a má distribuição dos recursos financeiros entre municípios, dificultando diretrizes e medidas públicas mais eficientes, principalmente com a finalidade de redução e prevenção destas mortes.

Para $\mathrm{Morse}^{45}$,existe pouca efetividade na implantação das políticas públicas voltadas para a melhoria da assistência à saúde da mulher, ainda que existam esforços para o seu enfrentamento.

Algumas limitações no estudo foram relevantes, tais como: estudo retrospectivo, observacional de série temporal, ecológico onde não se analisa o indivíduo e não se pode atribuir casualidade; vários fatores de confusão não são computados como assistência em saúde à cada município, a ocorrência da heterogeneidade entre municípios, imprecisões dos dados, notificações inadequadas, ocorrências de epidemias ao longo do período. Ainda assim, o estudo da mortalidade materna na região do Grande ABC Paulista para o período de 15 anos, indicou que embora várias medidas públicas tenham sido implantadas para a redução das mortes maternas evitáveis, provavelmente não serão atingidas as metas nacionais e internacionais pactuadas na totalidade dos municípios estudados, talvez com exceção do município de São Caetano do Sul.

Os dados deste estudo confirmam a iminente necessidade de melhorias das informações/notificações dos óbitos ocorridos em mães, para efetiva redução das trágicas mortes maternas na região do Grande ABC Paulista. 
Espera-se que o conhecimento do perfil da mortalidade materna na região do Grande ABC Paulista neste estudo, possa contribuir para o avanço de atitudes individuais e públicas do controle das mortes maternas evitáveis loco regionais e nacional.

As características demográficas, socioeconomicas e de fecundidade das mulheres brasileiras devem ser conhecidas para melhor estratégia de medidas públicas necessárias, além da participação ativa da sociedade para que exerçam sua função de construção de uma saúde melhor, capazes de realizar mudanças necessárias no âmbito da reversão deste terrível quadro da morte de mães no país.

Incontestavelmente, ainda existem muitos desafios para se alcançar a efetiva melhoria da qualidade de vida e saúde da população brasileira, em especial a atenção às mulheres no ciclo gravídico puerperal, apesar dos vários progressos já apresentados ao longo do tempo. 


\section{CONCLUSÕES}




\section{Na região do Grande ABC Paulista :}

Os índices da Mortalidade Materna Direta apresentaram redução de 43\% nos 15 anos estudados, porém não atingirão as metas propostas pelas medidas públicas nacionais e internacionais até o ano de 2015.

Apenas o município de São Caetano do Sul apresentou redução nos índices da Mortalidade Materna Direta com tendência à queda e mais próximo de atingir as metas propostas pelas medidas públicas nacionais e internacionais até o ano 2015.

O município de Rio Grande da Serra demonstrou piores índices da Mortalidade Materna Direta apesar de pertencer a IDH alto.

O Índice de Desenvolvimento Humano não estratificou os municípios entre si na maioria dos quesitos analisados.

Os óbitos maternos ocorreram predominantemente em mulheres brancas, 20 a 34 anos, solteiras e de baixa escolaridade, no período na gravidez ou no puerpério imediato, em hospitais.

As principais causas do óbito materno foram doenças da coagulação sanguínea e eclâmpsia, predominando em municípios pertencentes ao IDH 2: Diadema, Mauá, Ribeirão Pires e Rio Grande da Serra.

Ainda há grande subnotificação, inadequação e não investigação de óbitos maternos na região analisada. 
7 ANEXO 
Carta Comitê de Ética em Pesquisa

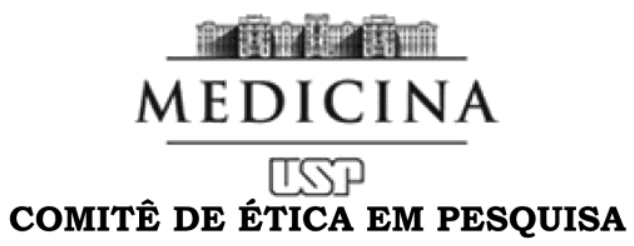

\section{APROVAÇÃo}

O Comitê de Ética em Pesquisa da Faculdade de Medicina da Universidade de São Paulo, em sessão de 14/12/2011, APROVOU o Protocolo de Pesquisa $n^{\circ}$ 289/11 intitulado: "IMPACTO DA POLÍTICA PÚBLICA NA MORTALIDADE MATERNA NA REGIÃO DO GRANDE ABC " apresentado pelo Departamento de Clínica Médica

Cabe ao pesquisador elaborar e apresentar ao CEPFMUSP, os relatórios parciais e final sobre a pesquisa (Resolução do Conselho Nacional de Saúde no 196, de 10/10/1996, inciso IX.2, letra "c").

Pesquisador (a) Responsável: Maria Lúcia Bueno Garcia Pesquisador (a) Executante: Silvana Tognini

CEP-FMUSP, 15 de Dezembro de 2011.

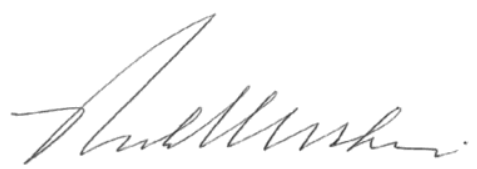

Prof. Dr. Paulo Eurípedes Marchiori

Vice-Coordenador interino

Comitê de Ética em Pesquisa 
1. Leite M.Colocando a saúde materna no centro das políticas de saúde pública. Revista Latino-Americana de Geografia e Gênero. 2013;4(1):48-57.

2. WHO global survey on maternal and perinatal health in Latin America. Lancet. 2006;367(9525):1819-29.

3. Hogan MC, Foreman KJ, Naghavi M, Ahn SY, Wang M, Makela SM, Murray CJ. Maternal mortality for 181 countries, 1980-2008: a systematic analysis of progress towards Millennium Development Goal 5. Lancet. 2010;375(9726):1609-23.

4. OMS. Organização Mundial da Saúde (OMS). Tendências da mortalidade materna. Banco Mundial. Fundo de População das Nações Unidas (UNFPA). Fundo das Nações Unidas para a Infância (UNICEF). Programa das Nacões Unidas para o Desenvolvimento (PNUD). 2013. Disponível em:http://www.onu.org.br/brasil.

5. ONU. United Nations. Objectivos do milênio. Campanha do Milênio das Nações Unidas: saúde materna.The Millennium Development Goals Report. 2007-2012. [citado novembro 2013] Disponível em: http://www.objectivo2015.org/pdf/mdg2007.pdf.

6. Oliveira AL, Silva EB, Oliveira W, organizadores. Percursos da crítica cultural: artigos e ensaios de estudantes do pós-crítica. Feira de Santana: UEFS Editora; Alagoinhas: Fábrica de Letras; 2011. p. 274.

7. Castro CM. Aspectos Emocionais do Puerpério. In:Kalckmann S, Batista LE, Castro CM, Lago T Di G, Souza SR, organizadores. Nascer com equidade: humanização do parto e do nascimento: questões raciais/cor e gênero. São Paulo: Instituto de Saúde; 2010. p. 247-54. 
8. Reis LGC, Pepe VLE, Caetano R. Maternidade segura no Brasil: o longo percurso para a efetivação de um direito. Physis. 2011;21(3):1139-59.

9. Marinho ACN, Paes NA. Mortalidade materna no estado da Paraíba: associação entre variáveis. Rev Esc Enferm USP. 2010;44(3):732-8.

10. Cecatti JG. Comparação entre dois métodos para investigação da mortalidade materna em município do Sudeste brasileiro. Rev Bras Ginecol Obstet. 2009;31(11):559-65.

11. Luizaga CTM, Gotlieb SLD, Jorge MHPM, Laurenti R. Mortes maternas: revisão do fator de correção para os dados oficiais. Epidemiol Serv Saúde. 2010;19(1):10-4.

12. Keffler K, Souza SRRK, Wall ML, Martins M, Moreira SDR. Características sociodemográficas e mortalidade materna em um hospital de referência na cidade de Curitiba - Paraná. Cogitare Enferm. 2010;15(3):500-5.

13. Maine D. Detours and shortcuts on the road to maternal mortality reduction [dissertation]. [Boston]: University School of Public Health. 2007; 370 p.

14. United Nations. Millennium Development Goals (MDGs). New York: 2013 [cited 2013 Oct 2]. Available from: http://www.un.org/millenniumgoals/

15. Laurenti R. Mortalidade materna: desafios para sua redução e a questão da mensuração e coleta de dados. In: Eurolac Conference. 2004. Abril 10-16; Recife.

16. Brasil. Secretaria de Atenção à Saúde. Departamento de Atenção Básica, Política Nacional de Atenção Básica. Brasília (DF); 2008. [citado em 1 abril 2013]. Disponível em: http://189.28.128.100/dab/docs/publicacoes/geral/pnab.pdf.

17. Souza NM, Brito GV, Vieira NC, Alves MSN, Elias FTS. Política para a redução da mortalidade materna informada por evidências. Anais CBMFC. 2013;(12):195. Maine D. Detours and shortcuts on the road to maternal mortality reduction [dissertation]. Boston: University School of Public Health; 2007. 
18. Brasil. Ministério da Saúde. Pactos pela Saúde. Secretaria de Atenção a Saúde. Departamento de Ações Programáticas mortalidade materna: relatório final. Brasília (DF); 2006. [citado em 2 junho 2013]. Disponível em: http://www.bvsms.saude.gov.br/publicacoes/cd_1103estudo_mortalidade_mulheres.pdf.

19. Brasil. Ministério da Saúde do Brasil.Secretaria de Atenção à Saúde. Departamento de Ações Programáticas e Estratégicas. Manual dos comitês da mortalidade materna. $3^{\mathrm{a}}$ ed. Brasília: (DF); 2007. [citado 25maio 2013]. Disponível em:http://portal.saude.gov.br/portal/arquivos/pdf/manual_obtido_maternoo.pdf.

20. Brasil. Ministério da Saúde do Brasil. Secretaria de Vigilância em Saúde. Saúde Brasil 2011: uma análise da situação de saúde e a vigilância da saúde da mulher. Brasília (DF): Ministério da Saúde do Brasil; 2012. Capítulo 14: Mortalidade materna no Brasil: principais causas de morte e tendências temporais no período de 1990 a 2010; p. 345-57.

21. IPEA. Instituto Pesquisa Econômica Aplicada; SP/MP. Secretaria de Planejamento e Investimentos estratégicos. Relatório Nacional de Acompanhamentos. Objetivos de Desenvolvimento do Milênio. 2010. [citado 19 junho 2013]. Disponível em: http://www.pnud.org.br/Docs/4_RelatorioNacionalAcompanhamentoODM.pdf.

22. Brasil. Agência Nacional de Saúde Suplementar (Brasil). Manual técnico para promoção da saúde e prevenção de riscos e doenças na saúde suplementar / Agência Nacional de Saúde Suplementar (Brasil). 4a ed. Rio de Janeiro: ANS; 2011.

23. Kwawukume EY. Changing policies and guidelines can make a difference. Int $J$ Gynaecol Obstet. 2010;111(2):103-4. Disponível em: www.figo.org

24. Volochko A. Mortalidade materna: determinantes sociopolíticos. In: Kalckmann S, Batista LE, Castro CM, Lago T Di G, Souza SR, organizadores. Nascer com equidade: humanização do parto e do nascimento: questões raciais/cor e gênero. São Paulo: Instituto de Saúde; 2010. p. 111-28. 
25. Van den Broek NR, Falconer AD. Maternal mortality and Millennium Development Goal 5. Br Med Bull. 2011;99(1):25-38.

26. OMS. Organização Mundial de Saúde (OMS). Classificação estatística internacional de doenças e problemas relacionados à saúde: CID:10. 10a revisão. São Paulo: Centro Colaborador da OMS para a Classificação de Doenças em Português/EDUSP; 2008.

27. Costa AAR, Ribas MSSS, Amorim MMR, Santos LC. Mortalidade materna na cidade do Recife. Rev Bras Ginecol Obstet. 2002;24(7):455-62.

28. Laurenti R, Jorge MHPM, Gotlieb SLD. A mortalidade materna nas capitais brasileiras: algumas características e estimativa de um fator de ajuste. Rev Bras Epidemiol. 2004;7(4); 449-60.

29. Sociedade Brasileira de Cardiologia. Diretriz da Sociedade Brasileira de Cardiologia para gravidez na mulher portadora de cardiopatia. Arq Bras Cardiol. 2009;93(6 Suppl 1):e110-e178.

30. Betrán AP, Wojdyla D, Posner SF, Gulmezoglu AM. National estimates for maternal mortality: an analysis based on the WHO systematic review of maternal mortality and morbidity. BMC Public Health. 2005;5:131.

31. Carrero Ioná. Mortalidade materna no estado do Rio Grande do Sul, Brasil, no período de 1999 a 2008 [doutorado]. Lajeado. UNIVATES; 2012.

32. Cook RJ, Dickens BM, Fathalla, MF. Saúde reprodutiva e direitos humanos: integrando medicina, ética e direito. Rio de Janeiro: Cepia/Oxford; 2004.

33. Berenger V, Verider-Chouchane A. Multidimensional measures of well-being: Standard of living and quality of life across countries. World Dev. 2007;35(7):1259-76. 
34. Chiappero-Martinetti E, von Jacobi N. Light and shade of multidimensional indexes. Qual life Italy. (Social Indicators Research Series). 2012;48:69-103.

35. Lustig N. Multidimensional indices of achievements and poverty: what do we gain and what do we lose? An introduction to JOEI Forum on multidimensional poverty. J Econ Inequal. 2011;9:227-34.

36. Fundação SEADE. Índice paulista de responsabilidade social. [citado 5 março 2014]. Disponível em: http://www.seade.gov.br/

37. OPAS. Organização Pan-Americana de Saúde. Indicadores básicos de saúde no Brasil: conceitos e aplicações/Rede Interagencial de Informações para a Saúde Ripsa - Brasília (DF): Publicação da OPAS; 2002.

38. Nyamtema AS, Urassa DP, Roosmalen J, Oba MDV, Tavares MSG. Análise da mortalidade materna do município de Ribeirão Preto - SP - no período de 1991 a 1995. Rev Latino Am Enferm. 2001;9(3):70-6.

39. de Miranda Pereira DR, Pinto MR, Ferreira ARS, Ferreira RN. Perfil das condições de saúde das capitais brasileiras na perspectiva dos Objetivos de Desenvolvimento do Milênio (ODM). Rev Serviço Público. 2014;60(2):141.

40. Fundação SEADE. Índice paulista de responsabilidade social. [citado 5 março 2014]. Disponível em: http://www.seade.gov.br/

41. Brasil. Ministério da Saúde. Secretaria de Vigilância em Saúde. Departamento de Análise de Situação em Saúde. Guia de vigilância epidemiológica do óbito materno. Brasília (DF); Série A. Normas e Manuais Técnicos; 2009. 84 p. : il. Disponível em: http://bvsms.saude.gov.br/bvs/publicacoes/guia_vigilancia_epidem_obito_materno.pdf 
42. Campos DS, Divino EA, Miranda EF, Nascimento AOB. O enfermeiro no contexto da saúde da família frente à prevenção da mortalidade materna. UNI Ciências. 2010;14(2):159-75.

43. Hill K, Thomas K, AbouZahr C, Walker N, Say L, Inoue M, et al. Estimates of maternal mortality worldwide between 1990 and 2005: an assessment of available data. Lancet. 2007;370(9595):1311-9.

44. Sirken MG, Rosenberg HM, Chevarley FM, Curtin LR. The quality of cause-ofdeath statistics. Am J Public Health. 1987;77(2):137-9.

45. Morse ML, Fonseca SC, Barbosa MD, Calil MB, Eyer FPC. Maternal mortality in Brazil: what has the scientific literature shown in the last 30 years? Cad Saúde Pública. 2011;27(4) 623-38.

46. Estado de São Paulo. Lei no 14.544 de 14 de setembro de 2011. Programa Rede de Proteção à Mãe Paulista. Assembleia Legislativa. Poder Executivo I DOE 15/09/2011. Diário Oficial do Estado de São Paulo. 2011;121(175). Disponível em: www.imprensaoficial.com.br.

47. IBGE. Instituto Brasileiro de Geografia e Estatística. [citado 5 março 2013]. Disponível em: http://www.IBGE.2013.gov.br.

48. Tognini S, Garcia MLB, Braga ALF, Martins LC. Perfil da mortalidade materna na Região do Grande ABC de 1997 a 2005. Rev Assoc Med Bras. 2011;57(4):409-14.

49. Brasil. Ministério da Saúde do Brasil. DATASUS. Sistema de Informação sobre Mortalidade (SIM). [base de dados da Internet]. 2007 [citado 1 out 2007]. Disponível em: Disponível em: http://tabnet.datasus.gov.br/cgi/sim/mat10descr.htm\#descvar. 
50. CNES - DATADUS. 2013. [citado 2 fevereiro 2013]. Disponível em: http://cnes.datasus.gov.br/Mod_Ind_Equipes.asp.

51. Callegari-Jacques SM. Bioestatística: princípios e aplicações. Porto Alegre: Artmed;2003.

52. Chakravarty SR. A generalized human development index. Rev Dev Econ. 2003;7(1):99-114.

53. Klugman J, Rodrigues F, Choi HJ. The HDI 2010: new controversies old critiques. $J$ Econ Inequal. 2011;9(2):249-88.

54. Ayres JRCM, França IJ, Calazans GJ, Saletti HCF. Vulnerabilidade e prevenção em tempos de AIDS. In: Barbosa RM, Parker R, organizadores. Sexualidade pelo avesso: direitos, identidades e poder. São Paulo: Editora 34; 1999. p. 49-72.

55. Batista LE. Mulheres e homens negros: saúde, doença e morte [tese]. Araraquara. Universidade Estadual Paulista; 2002.Disponível em: http://www.isaude.sp.gov.br/teses/luis03.pdf.

56. Zama N, Teixeira AF, Pereira WR, Barbosa DA, Vianna LAC. Mortalidade materna e sua interface com a raça em Mato Grosso. Rev Bras Saúde Mater Infant. 2012;12(1):27-35.

57. Lopes F. Experiências desiguais ao nascer, viver, adoecer e morrer: tópicos em saúde da população negra no Brasil. In: Batista LE, Kalckmann S, organizadores. Seminário saúde da população negra Estado de São Paulo. São Paulo: Instituto de Saúde; 2004. p. 53-101.

58. Lima AG, Oliveira IBB, Menezes MLN, Leite RCA. Síndromes hipertensivas graves - estudo descritivo com adolescentes atendidas em maternidade escola. Rev RENE. 2012;13(2):408-18. Disponível em: http://www.revistarene.ufc.br/revista/index.php/revista/article/view/224/pdf. 
59. Martins AL. Mortalidade materna de mulheres negras no Brasil. Cad Saúde Pública. 2006;22(11):2473-79.

60. Kent A. World maternal mortality rates. Rev Obstet Gynecol. 2010;3(4):193-4.

61. Villar J, Valladares E, Wojdyla D, Zavaleta N, Carroli G, Velazco A, Shah A, Campodónico L, Bataglia V, Faundes A, Langer A, Narvárez A, Donner A, Romero M, Reynoso S, Simônia de Pádua K, Giordano D, Kublickas M, Acosta A. Caesarean delivery rates and pregnancy outcomes: the 2005

62. Ruiz MR, Wirtz V, Nigenda G. Organizational elements of health service related to a reduction in maternal mortality: The cases of Chile and Colombia. HealthPolicy.2009;90(2-3):149-55. 


\section{APÊNDICES}


Tabela 1. Municípios e IDH

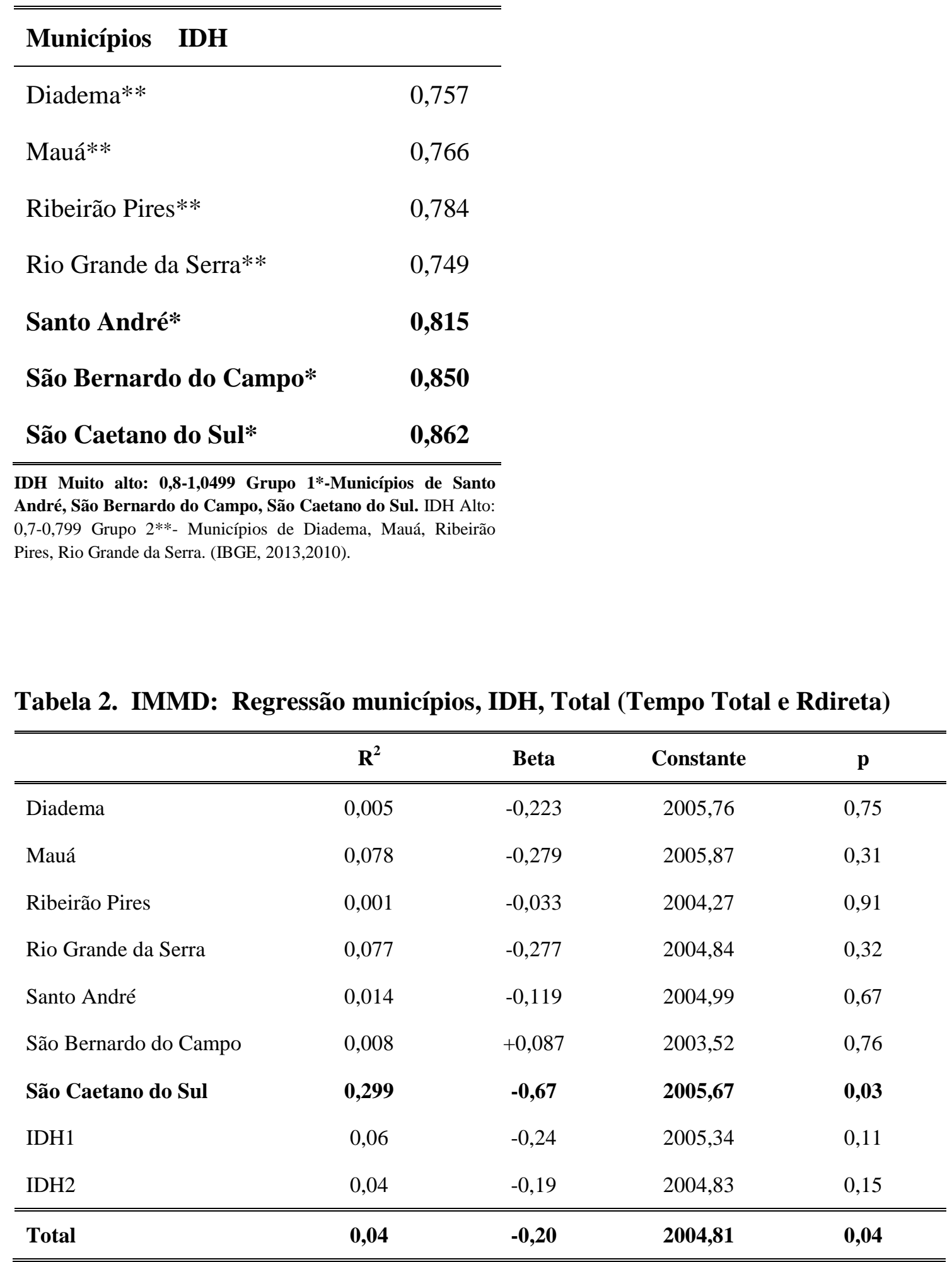


Tabela 3. IMMD: Regressão Milênio municípios, IDH, Total (Tempo Milênio e Rdireta)

\begin{tabular}{lcccc}
\hline \hline & $\mathbf{R}^{\mathbf{2}}$ & Beta & Constante & $\mathbf{p}$ \\
\hline \hline Diadema & 0,00 & $-0,004$ & 2005,52 & 0,99 \\
Mauá & 0,047 & $-0,215$ & 2006,43 & 0,5 \\
Ribeirão Pires & 0,059 & $+0,244$ & 2004,68 & 0,45 \\
Rio Grande da Serra & 0,006 & $+0,08$ & 2005,34 & 0,81 \\
Santo André & 0,04 & $+0,06$ & 2005,13 & 0,85 \\
São Bernardo do Campo & 0,175 & $+0,419$ & 2002,95 & 0,17 \\
São Caetano do Sul & $\mathbf{0 , 2 8 2}$ & $\mathbf{- 0 , 5 4 7}$ & $\mathbf{2 0 0 6 , 5 6}$ & $\mathbf{0 , 0 7}$ \\
IDH1 & 0,08 & $-0,087$ & 2005,85 & 0,61 \\
IDH2 & 0,003 & $+0,53$ & 2005,33 & 0,72 \\
\hline \hline Total & $\mathbf{0 , 0}$ & $\mathbf{+ 0 , 0 0 4}$ & $\mathbf{2 0 0 5 , 4 8}$ & $\mathbf{0 , 9 7}$ \\
\hline \hline
\end{tabular}

